\author{
UNIVERSIDADE DE SÃO PAULO \\ FACULDADE DE ODONTOLOGIA DE BAURU
}

Raphaella Coelho Michel

Efeitos da fotobiomodulação com laser e LED na proliferação e migração de fibroblastos gengivais de pacientes com e sem Síndrome de Down

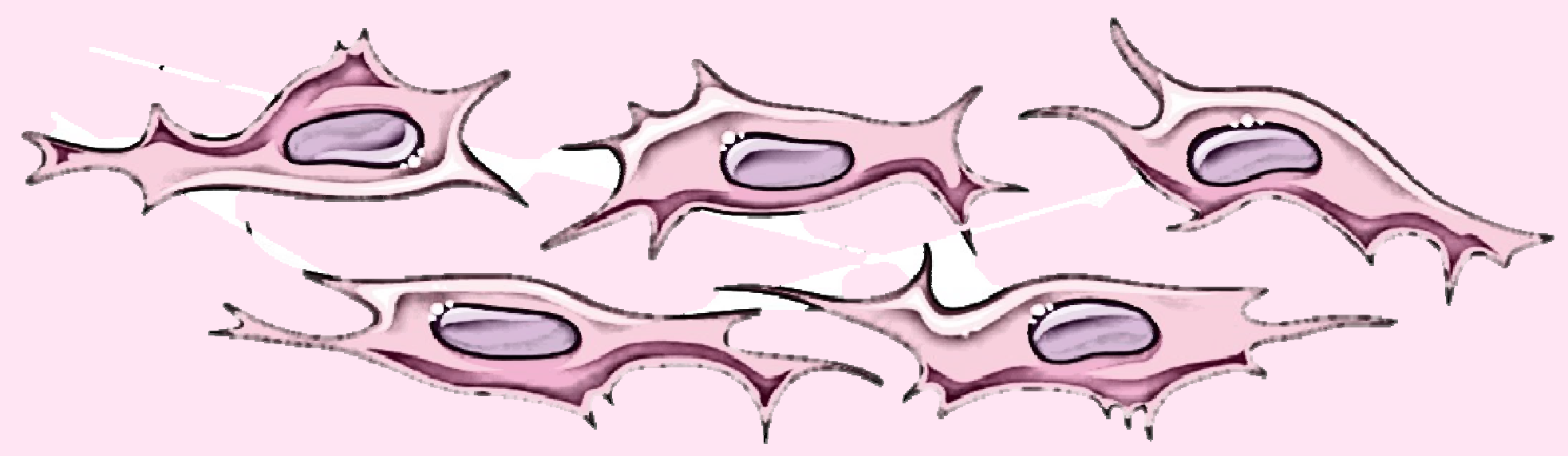



Raphaella Coelho Michel

\section{Efeitos da fotobiomodulação com laser e LED na proliferação e migração de fibroblastos gengivais de pacientes com e sem Síndrome de Down}

Dissertação apresentada a Faculdade de Odontologia de Bauru da Universidade de São Paulo para obtenção do título de Mestre em Ciências no Programa de Ciências Odontológicas Aplicadas, na área de concentração Reabilitação Oral com linha de pesquisa em Periodontia.

Orientadora: Prof. Dr. Carla Andreotti Damante 


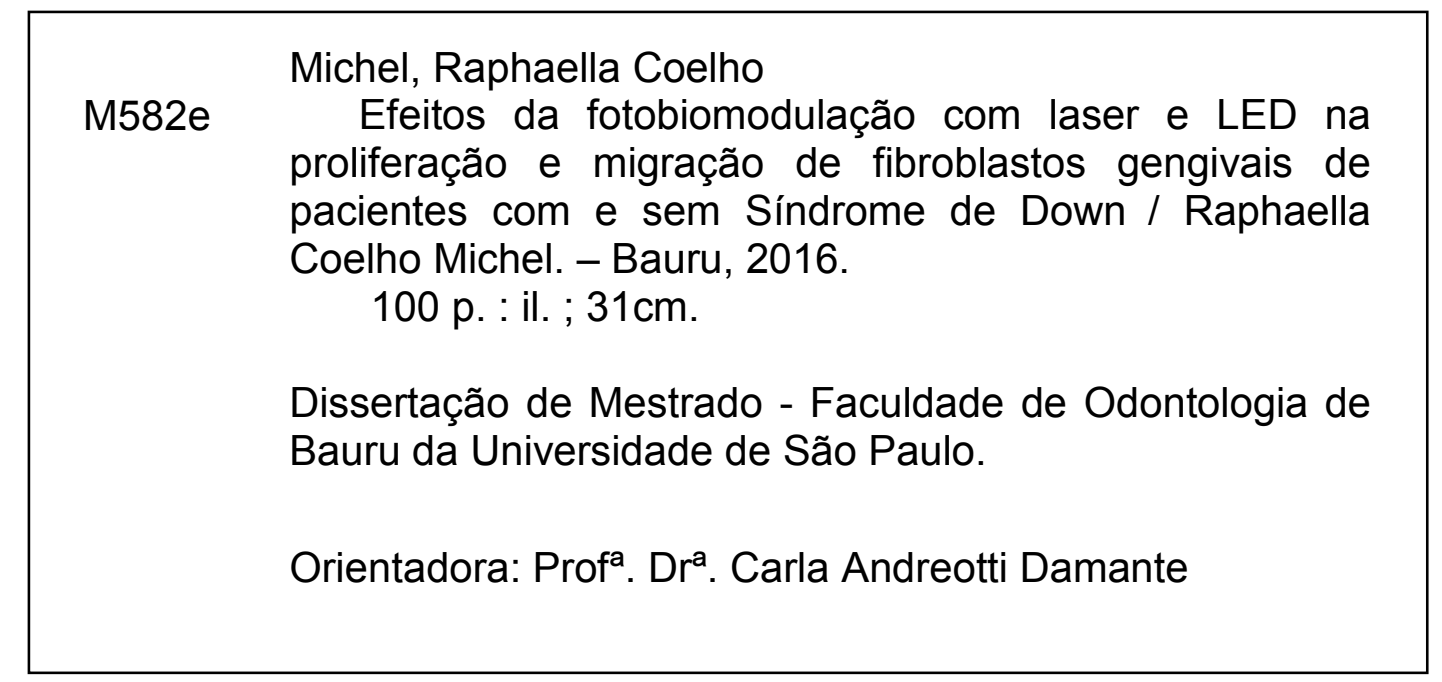

Autorizo, exclusivamente para fins acadêmicos e científicos, a reprodução total ou parcial desta dissertação, por processos fotocopiadores e outros meios eletrônicos.

Assinatura:

Data:

Comitê de Ética da FOB-USP

Protocolo $\mathrm{n}^{\circ}$ : CAAE 49844715.0.0000.5417

Data: 04/12/2015 


\section{DADOS CURRICULARES}

\section{Raphaella Caelha Michel}

$\begin{array}{ll}\text { Nascimento } & \text { O5 de dezembro de } 1987 \\ \text { Naturalidade } & \text { Belo Horizonte - MG } \\ \text { Filiação } & \text { Maria Elisa Coelho Michel } \\ & \text { Marcos Michel } \\ 2007-2011 & \text { Graduação em Odontologia pela } \\ & \text { Pontíficia Universidade Católica (PUC- } \\ & \text { MG) } \\ 2011-2013 & \text { Especialização em Implantodontia pela } \\ & \text { ABO-MG (Associação Brasileira de } \\ & \text { Odontologia de Minas Gerais) } \\ 2012-2014 & \text { Especialização em Periodontia pela } \\ & \text { IPSEM-MG (Instituto da Previdência dos } \\ & \text { Servidores do Estado de Minas Gerais) } \\ 2013-2014 & \text { Estágio laboratorial no departamento de } \\ & \text { Odontologia Restauradora da UFMG } \\ & \text { (Universidade Federal de Minas Gerais) } \\ & \text { Mestrado em Ciências Odontológicas } \\ & \text { Aplicadas, Área de Concentração } \\ & \text { Reabilitação Oral com linha de pesquisa } \\ \text { em Periodontia, pela FOB-USP, como } & \text { bolsista CAPES } \\ \text { Associações } 2016 & \text { SBPqO - Sociedade Brasileira de } \\ & \text { Pesquisa Odontológica }\end{array}$





\section{DEDICATÓRIA}

Dedico esta dissertação à toda a minha família. Em especial aos meus pais e meus irmãos por toda ajuda, confiança e carinho de sempre. Sem vocês nada disso seria possível! 



\section{AGRADECIMENTOS}

Em primeiro lugar agradeço a Deus por ter me dado a oportunidade de evolução espiritual através desse mundo material.

Aos mais amados pais. Vocês são minha alegria, minha vontade de acertar na vida! Não posso descrever aqui minha gratidão, é impossível. O que posso é discorrer a vocês que sempre estarei por perto, (mesmo que as vezes esteja geograficamente longe) para ama-los, para continuarmos a ser sempre essa família unida e linda. A finalização desta etapa em minha vida é quase que única e exclusivamente conquistada devido ao suporte amoroso, firme, financeiro e de muita paciência de vocês dois. Quero sempre poder corresponder às expectativas e investimentos que recebo de vocês meus queridos Papi e Mami! E quem sabe um dia poderei ser tão boa assim com meus filhos, Amo vocês demais!

Aos meus queridos irmãos, Dadá, Gugu e Fravis. Tenho certeza de que sem a parceria de todos vocês ao longo de minha vida, a mesma seria bem diferente e com menos alegria. Sou muito grata a todos vocês por me socorrerem naquelas horas difíceis. Eu os amo muito!

Ao meu querido cunhado Rodrigo e cunhada Mariana, que são meus irmãos na verdade. Não posso também descrever aqui minha gratidão, vocês foram essenciais para que eu estivesse aqui hoje, podendo realizar um sonho! Obrigada por todo apoio!! Amo vocês!

Minha querida Lala, você representa muita alegria, alto astral e sabedoria em minha vida, obrigada pela amizade sincera de quase 30 anos. Somos e seremos sempre parceiras!! Amo muito você!

Aos meus amores, a família mais linda: Pipi querida, Claudim, Lili e Manu. Quando a saudade bate me lembro dos inúmeros momentos felizes e amorosos que tivemos. Muito obrigada por fazerem parte de minha vida, amo todos vocês.

À minha grande amiga lolanda, por todo o carinho, conselhos e momentos vividos. Você é uma grande amiga que com certeza levarei pro resto de minha vida. Muito obrigada por ser essa mulher incrível e amorosa!!! Conte comigo sempre amiga! 

Agradeço também a amizade e carinho de sempre dos primos Lulu, Dafne e Saulim, pessoas que eu sempre vou querer por perto! Muito obrigado!

Em especial à minha querida Simone que eternamente levarei em meu coração.

Xandão, Dani, Tikid e Tia Vera muito obrigada pela amizade de sempre. Faço muita questão de vocês em minha vida!

Á minha amada tia Marcinha, muito obrigada por todo apoio e carinho, sei que torce de verdade para o meu sucesso e eu faço questão de tê-la sempre por perto!

Aos meus tios Márcio e Maria Helena, muito obrigada pelo carinho e incentivo que sempre me deram!!!

À minha família Bauruense, especialmente a Periodontia que me acolheu e cuidou de mim, principalmente quando estive doente, agradeço a toda família Perio pelo carinho e consideração. Sem vocês nada seria possível!

Agradeço a convivência e aos momentos compartilhados com todos meus colegas de departamento, em especial aos da minha turma: Luísa Valle, Vitor Stuani, Gustavo Manfredi e Andréia Sousa. Muito obrigado por todos os momentos e os conselhos. Sem vocês, tudo seria mais difícil Meu MUITO OBRIGADO por tudo! Luisa, Valle tudo, Ana frozen, equilibrada, vizinha, amiga, irmã, parceira de tudo..Não consigo imaginar Bauru sem você, obrigada por ser uma amiga verdadeira, que sempre posso contar! Você foi essencial para esta conquista lulu!! Muito obrigada mesmo!

Gustavo, mene, irmão, amigo e nosso querido entretenimento, você sempre será um grande amigo, muito especial. Torço muito por você! Obrigada pelas longas conversas e grandes análises!! Tenho muita sorte de ser sua amiga! Conte comigo sempre!

Vitor, misterioso, gentleman, cavalheiro, amigo de verdade, você foi muito importante para mim nesses dois anos, te desejo sempre muito sucesso!! Obrigada por tudo, pelos conselhos, pela amizade! Você é o cara vitão!!! 

Deia, determinada, salvadora da pátria e dos oprimidos, você realmente é capaz de acabar com a fome da África e ao mesmo tempo ser linda, educada e amorosa com todos!! Não tenho palavras para lhe agradecer, quero sua amizade para sempre!

Agradeço aos egressos e em especial a turma de mestrado novo (Giovana, Ísis, Matheus e Érika), por todos os momentos compartilhados. Em especial ao Matheus Cardoso pelos momentos memoráveis na execução desta pesquisa, muito obrigada mesmo!

À Paula Karam (Paulinha) e ao Matheus Cardoso por toda ajuda, principalmente nas fases iniciais da pesquisa e pelos momentos incríveis que passamos no CIP.

Paula Karam torço muito para o seu sucesso, te desejo também muito amor e saúde! Obrigada por sempre me ajudar, foi muito importante para mim!! Sucesso sempre!! Você merece!

Ao meu querido companheiro Anderson Silva por toda ajuda, conselho, carinho, paciência e dedicação em todos os momentos. Não acredito em coincidências e ter o seu apoio foi fundamental para a realização deste sonho! Você me fez acreditar que ainda existem pessoas que valem a pena nesse mundo! Obrigada do fundo do meu coração!

À minha grande amiga Bruna Fidêncio, professora e colega de pós-graduação, mas acima de tudo, uma ótima pessoa que foi se desenhando nesses anos. Obrigada por tudo e por todos momentos felizes que passei em sua companhia!!

À minha grande amiga Paula Cunha, muito obrigado por todo o carinho e pelas palavras ditas nos momentos que eu mais precisava ouvir. Exemplo de força e dedicação, você é uma mulher incrível e torço muito para seu sucesso! Obrigada por tudo!

Ao grande amigo Rafael Ferreira (Pomarola) responsável por muita alegria nessa minha estadia em Bauru, sem você nada teria graça! Espero algum dia poder retribuir tanta amizade sincera! É até injusto ter que descrever tanto carinho em tão poucas palavras. Obrigada pela consideração e amizade desenvolvidos durante minha pós-graduação, bem como os conselhos, diversos momentos de alegria e de 

crescimento profissional. Conte sempre comigo, pois sei que sempre poderei contar com você. SEMPRE!

Agradeço a todos os professores da Disciplina de Periodontia, meus verdadeiros mestres que me mostraram a grande beleza da Periodontia. Sou extremamente grata a todos.

Professor Sebastião, obrigada pela consideração e por todos trabalhos, parcerias, artigos que fizemos juntos!

Professora Malu, muito obrigada por todos os conselhos e aprendizados! Obrigada pela experiência clínica compartilhada!!!

Porfessora Adriana, agradeço pelo carinho e atenção, por todos os conselhos e por sempre acreditar em mim!!!

A vida acadêmica nos apresenta algumas surpresas. Posso dizer que sou abençoada por toda ajuda e atenção que tenho recebido nesse período. Quero agradecer imensamente todo carinho e atenção de algumas pessoas que se preocuparam comigo, sendo essas pessoas a Profa. Dra. Carla Andreotti Damante e Profa. Dra. Mariana Zangrando. Muito obrigado por tudo. Levarei vocês sempre em meu coração. Contem sempre comigo para tudo.

Profa. Dra. Mariana Zangrando, a senhora me mostrou um mundo acadêmico de muitas conquistas e realizações, acreditou em mim desde o começo e por isso conseguimos muitas conquistas juntas! Só posso dizer que a senhora será sempre meu grande exemplo!! Obrigada pela paciência e dedicação!

Profa. Dra. Carla Andreotti Damante, sempre com tanto carinho e determinação, a senhora me mostrou que problemas podem ficar leves e que essa selva acadêmica pode se tornar um lugar mais agradável e de muito trabalho a ser feito. Não tenho palavras para descrever o apoio da senhora! Muito obrigada por tudo!

Agradeço a todos os funcionários da "Família Perio": Asascleide Vital (Cleidinha), Edilaine Lúcio Rodrigues Torrecilha, Ivânia Komatsu da Costa Arruda, Marcela Maria Pereira e Marco Antonio de Godoy. Muito obrigado por tudo! 

Agradeço em especial à Ivânia Komatsu da Costa Arruda que dispôs de seu tempo para sempre me ajudar na clínica, como também em momentos delicados da minha vida, como quando fiquei doente. Muito obrigado por todos os conselhos e por tudo que tem me proporcionado dentro e fora da Faculdade. Sou muito grata a tudo, pela ajuda e carinho fornecido nesses anos, sendo essenciais para essa minha caminhada. Conte sempre comigo, pois levarei você sempre comigo.

A todos os meus colegas do CIP (Centro Integrado de Pesquisa), que sempre me proporcionaram diversos momentos de alegria e de descontração, regados a muito conhecimento. Em especial, Cínthia e Rafa, muito obrigada por toda ajuda.

Agradeço a confiança e carinho do Prof. Dr. Rodrigo Oliveira, pela oportunidade de trabalho no laboratório e as inúmeras ajudas com a metodologia da pesquisa. 



\section{Agradecimentas Institucianais}

À esta Faculdade, em nome da diretora Profa. Dra. Maria Aparecida de Andrade Moreira Machado e ao vice-diretor Prof. Dr. Carlos Ferreira dos Santos, por nos oferecer a melhor infra-estrutura possível.

Ao Prof. Dr. Guilherme Janson, presidente da Comissão de Pós-Graduação por todo o auxílio e atenção dissipada.

Ao Prof. Dr. José Rubo, chefe do departamento de Prótese por toda ajuda dissipada.

À CAPES (Coordenação de Aperfeiçoamento Pessoal de Nível Superior) pela disponibilidade inicial da bolsa de estudo. 

"A diferença entre um remédio e um veneno está só na dosagem". (Paracelso - Médico e físico do séc. XVI) 



\section{RESUMO}

A terapia de fotobiomodulação tem sido vastamente utilizada em cultura de fibroblastos com o objetivo de se verificar seu real efeito na cicatrização de feridas e de se estabelecer os melhores parâmetros de luz. Pacientes com síndrome de Down (SD) possuem alta prevalência da doença periodontal (DP) e importantes alterações imunológicas, as quais podem interferir no processo de cicatrização. O objetivo do presente estudo foi de avaliar os efeitos da utilização de Laser e LED em fibroblastos gengivais de pacientes com e sem SD (FSD e FGH, respectivamente), verificando a viabilidade celular e o processo In vitro de cicatrização de feridas. As células foram cultivadas em placas de 96 poços (1×103 célula/poço) e colocadas em estado de aquiescência (meio DMEM com $1 \%$ de soro fetal bovino) $24 \mathrm{~h}$ antes da irradiação e retomando sua condição inicial de 10\% de soro fetal bovino (SFB) instantes antes da aplicação de Laser (AIGaAs - 660nm e AIGalnP - 810nm) e LED ( $637 \pm 15 \mathrm{~nm}$ ) com exceção do controle negativo (C-) que continuou com $1 \%$ de SFB. Os grupos foram divididos em: C+ (sem irradiação, 10\% SFB), C- (sem irradiação, $1 \%$ SFB), LIV5 (5 J/cm2 por 3s), LIV8 (8 J/cm2 por $5 \mathrm{~s})$, LV5 (5 J/cm2, por 3s), LV8 $(8 \mathrm{~J} / \mathrm{cm} 2$ por $5 \mathrm{~s})$, LED3 $(0,03 \mathrm{~J} / \mathrm{cm} 2$ por $3 \mathrm{~s})$ e LED5 $(0,05 \mathrm{~J} / \mathrm{cm} 2$ por $5 \mathrm{~s})$. A potência utilizada foi a mesma tanto para o Laser como para o LED $(40 \mathrm{~mW})$. A viabilidade celular foi avaliada através dos testes colorimétricos MTT e Cristal Violeta, nos períodos de $24,48,72$ e $96 \mathrm{~h}$. O teste de cicatrização de feridas In vitro (placas de 24 poços) para avaliação da migração dos fibroblastos, foi nos períodos de 12, 24, $36 \mathrm{e}$ 48h. A análise estatística foi realizada através do teste ANOVA de medidas repetidas complementado pelo teste de Tukey $(p<0,05)$. Os grupos experimentais, em grande parte dos períodos, obtiveram melhor viabilidade celular em relação ao C+, com exceção do grupo LIV8 que apresentou crescimento celular próximo de zero, em todos os períodos. Para FSD os melhores resultados foram com LIV5, LED3 e LED5 $(p<0,05)$, enquanto que para FGH, foi o LV5 $(p>0,05)$. No ensaio de cicatrização de feridas os melhores resultados foram LIV5 para FGH $(p<0,05)$ e todos os tratamentos com exceção do LIV8 para FSD $(p<0,05)$. Os FSD apresentaram maior fechamento da ferida em relação ao $\mathrm{FGH}$ nos períodos de $24 \mathrm{e}$ $36 \mathrm{~h}(p<0,05)$. Como conclusão, a fotobiomodulação por Laser e LED mostrou ser efetiva para viabilidade celular, tanto para o FGH como para o FSD, com exceção do Laser infravermelho de maior densidade de energia e maior tempo de exposição 

(LIV8). Na migração celular, a fotobiomodulação foi efetiva no maior fechamento da ferida para os FSD. Logo, a terapia de fotobiomodulação por Laser e LED, com os parâmetros adequados, parecer ser um tratamento adjuvante promissor para pacientes com SD.

Palavras chave: Síndrome de Down, Laser, Cultura celular, Fibroblasto 



\section{ABSTRACT \\ Effects of photobiomodulation with laser and LED on the proliferation and migration of gingival fibroblasts from patients with and without Down syndrome}

The photobiomodulation therapy has been widely used in fibroblast culture in order to verify its effects on wound healing and to establish the best parameters of light. Down's syndrome patients (DS) present high prevalence of periodontal disease (PD) and important immunological changes, which could interfere on the wound healing process. The aim of this study was to evaluate the Laser and LED effects on gingival fibroblasts cultures from patients with or without DS (FSD and FGH, respectively), through cell viability tests and in vitro wound healing test. Cells were grown in 96-well plates $\left(1 \times 10^{3}\right.$ cells / well) and then, put in a quiescence environment, (DMEM medium with $1 \%$ fetal bovine serum) for 24 hours before irradiation. After that an initial condition of $10 \%$ fetal bovine serum (FBS) was set before Laser (Red -AIGaAs - 660nm and Infrared - AIGalnP - 810nm) and LED (637 $\pm 15 \mathrm{~nm})$ application, with the exception of the negative control (C-) which still remained with $1 \%$ FBS. The groups were divided in: $\mathrm{C}+$ (no irradiation, 10\% FBS), $\mathrm{C}$ (no irradiation 1\% FBS), LIV5 $\left(5 \mathrm{~J} / \mathrm{cm}^{2}\right.$ for $\left.3 \mathrm{~s}\right)$, LIV8 (8 J / $\mathrm{cm}^{2}$ for $\left.5 \mathrm{~s}\right), \operatorname{LV} 5\left(5 \mathrm{~J} / \mathrm{cm}^{2}\right.$ for $\left.3 \mathrm{~s}\right)$, LV8 $\left(8 \mathrm{~J} / \mathrm{cm}^{2}\right.$ for $\left.5 \mathrm{~s}\right)$, LED3 $\left(0.03 \mathrm{~J} / \mathrm{cm}^{2}\right.$ for 3 seconds) and LED5 $\left(0,05 \mathrm{~J} / \mathrm{cm}^{2}\right.$ for $\left.5 \mathrm{~s}\right)$. The power output was the same for both Laser and LED $(40 \mathrm{~mW})$. Cell viability was evaluated through MTT and Crystal Violet colorimetric tests, in periods of 24,48,72 and $96 \mathrm{~h}$. The in vitro wound healing assay (24 well plates), measured the fibroblasts migration, during 12 , 24, 36 and 48 hours. Statistical analysis was performed using repeated measures ANOVA complemented by Tukey's test $(p<0.05)$. The experimental groups, in most periods, presented higher cell viability compared to $\mathrm{C}+$, except for the LIV8 group that exhibited cell growth near to zero, in all periods. In relation to FSD, the best results were with LIV5, LED 3 and LED 5 ( $p<0.05)$, while to $\mathrm{FGH}$, the LV5 presented higher viability $(p<0.05)$. The best results for the wound healing test were LIV5 for FGH $(p<0,05)$ and all groups but LIV8 for FSD $(p<0,05)$. FSD cells presented higher wound closure in relation to $\mathrm{FGH}$ at 24 and $36 \mathrm{~h}(p<0,05)$. In conclusion, the Laser and LED photobiomodulation was effective for cell growth, for both FGH and FSD cells, except for the infrared laser with higher energy density and longer exposure 

time (LIV8). Photobiomodulation was more effective for wound closure by FSD cells. Therefore, laser and LED photobiomodulation therapy, with appropriate parameters, seems to be a promising adjunctive treatment for patients with DS.

Key-words: Down syndrome, Laser, Cellular culture, Fibroblast 



\section{LISTA DE ILUSTRAÇÕES}

Figura 1 - Laser de baixa intensidade Theralase (DMC - São Carlos-SP) 53

Figura 2 - Protótipo de LED. Óptica do Instituto de Física de São Carlos....... 53

Figura 3 - Fotografia dos cristais de Formazan (Teste MTT) 53

Figura 4 - Gráfico de viabilidade celular por Cristal Violeta do FGH. 58

Figura 5 - Gráfico de viabilidade celular por MTT do FGH 59

Fugura 6 - Gráfico de viabilidade celular por Cristal violeta do FSD. 60

Figura 7 - Gráfico de viabilidade celular por MTT do FSD 61

Figura 8 - Fotografias do ensaio de cicatrização de feridas 63

Figura 9 - Gráfico avaliando grupos experimentais vs. Célula 64

Figura 10 - Gráfico mostrando o preenchimento da ferida vs. Tempo. 64 



\section{LISTA DE QUADROS}

QUADRO 1 Descrição dos parâmetros utilizados para o laser vermelho, infravermelho e LED. 



\section{LISTA DE ABREVIATURA E SIGLAS}

$\begin{array}{ll}\% & \text { Porcentagem } \\ { }^{\circ} \mathrm{C} & \text { Graus Celsius } \\ < & \text { Menor } \\ > & \text { Maior } \\ \leq & \text { Menor ou igual } \\ \geq & \text { Maior ou igual } \\ \pm & \text { Desvio padrão } \\ \circledR & \text { Marca registrada } \\ \text { APAE } & \text { Associação de pais e amigos dos excepcionais } \\ \text { ANOVA } & \text { Teste de análise de variância } \\ \text { CAPES } & \text { Coordenação de aperfeiçoamento pessoal do ensino superior } \\ \text { CEP } & \text { Comitê de ética em pesquisa } \\ \text { Cm } & \text { Centímetro(s) } \\ \text { cm }{ }^{2} & \text { Centímetro quadrado } \\ \text { DB } & \text { Distancias biológicas } \\ \text { DNA } & \text { Ácido desoxirribonucleico } \\ \text { Dp } & \text { Densidade de Potência (W/cm²) } \\ \text { DP } & \text { Doença Periodontal } \\ \text { d.p. } & \text { Desvio padrão } \\ \text { Dr(a). } & \text { Doutor(a) } \\ \text { ELISA } & \text { Ensaio imunoenzimático (Enzime Linked Immunosorbent Assay) } \\ \text { et al. } & \text { E outros; Colaboradores } \\ \text { FOB } & \text { Faculdade de Odontologia de Bauru } \\ \text { IFSC } & \text { Instituto de Física de São Carlos } \\ \text { InGaAIP } & \text { Índio, gálio, alumínio e fósforo } \\ \mathrm{J} & \text { Joule } \\ \text { Arseneto de } & \text { Arsenato de Gáio-aluminio } \\ \text { Gálio-Alumínio } & \\ \text { J/cm }{ }^{2} & \text { Joule por centímetro quadrado (medida de densidade de energia) } \\ \text { JCE } & \text { Junção cemento-esmalte } \\ & \end{array}$



LASER

LED

LILT

LP

$\mathrm{NCl}$

Min

$\mathrm{Mm}$

$\mathrm{mW}$

$\mathrm{Nm}$

PCD

PCR

PCR-real time

$P g$

$\mathrm{pH}$

PNE

Prof(a).

PS

RG

RACR

ROS

Rpm

$S$

SP

SS

vS

TBO

Tf

TNFa

USP

W
Amplificação da luz por emissão estimulada de radiação (Light Amplification by Stimulated Emission of Radiation)

Diodo emissor de luz (Light Emitting Diode)

Terapia com laser em baixa intensidade (Low intensity laser) therapy)

Ligamento periodontal

Nível clínico de inserção

Minuto(s)

Milímetro(s)

Miliwatt(s)

Nanômetro(s)

Pessoas com deficiência

Reação em cadeia da polimerase (Polymerase chain reaction)

Reação em cadeia da polimerase em tempo real

Porphyromonas gingivalis

Potência hidrogeniônico

Pacientes com necessidades especiais

Professor(a)

Profundidade de sondagem

Recessão gengival

Raspagem e alisamento corono-radicular

Espécies reativas de oxigênio (Reactive oxygen Species)

Rotações por minuto

Segundo(s)

São Paulo

Sangramento à sondagem

Versus

Corante azul de toluidina $\mathrm{O}$ (Toluidine blue Orto)

Tannerella forshitia

Fator de necrose tumoral alfa

Universidade de São Paulo

Watt (medida de potência) 



\section{SUMÁRIO}

1 INTRODUÇÃO

2 REVISÃo DE LITERATURA

$2.1 \quad$ PACIENTES COM SÍNDROME DE DOWN ……................................27

2.2 DOENÇA PERIODONTAL EM PACIENTES COM SD ……..................29

2.3 TERAPIA DE FOTOBIOMODULAÇÃO ……..........................................

2.3.1 Fotobiomodulação em ensaios com fibroblastos .........................................35

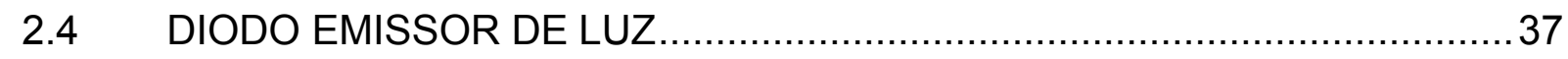

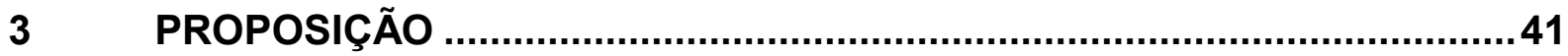

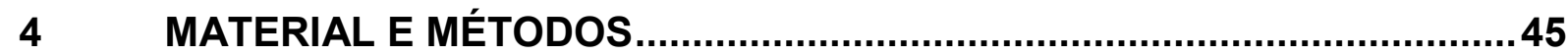

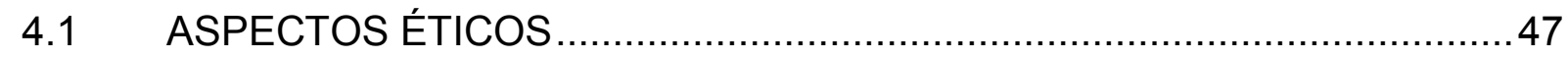

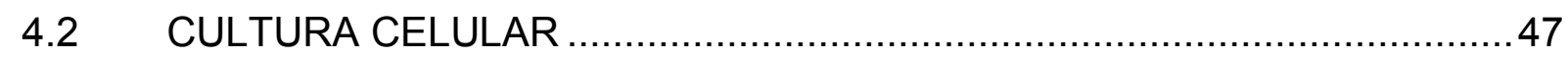

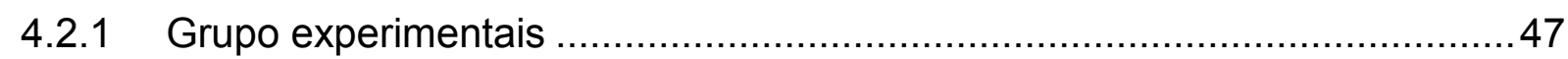

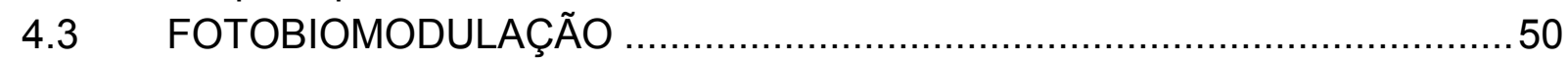

4.4 EXPERIMENTO DE VIABILIDADE CELULAR ….................................51

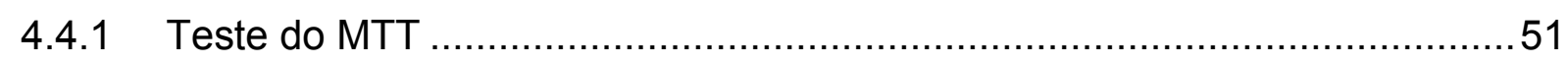

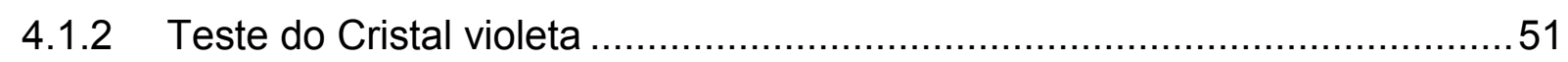

4.5 Ensaio de cicatrização de feridas In vitro .............................................52

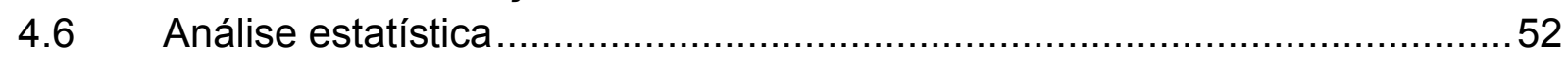

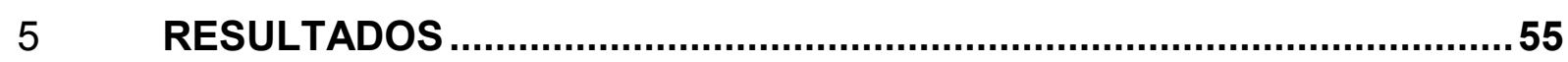

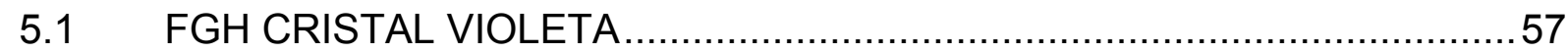

5.1.1 Comparação dos grupos em relação aos controles e entre si (96) …..........57

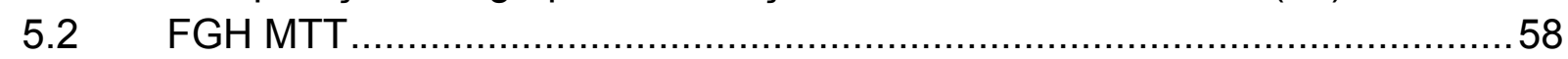

5.2.1 Comparação dos grupos em relação aos controles e entre si (96) ..............58

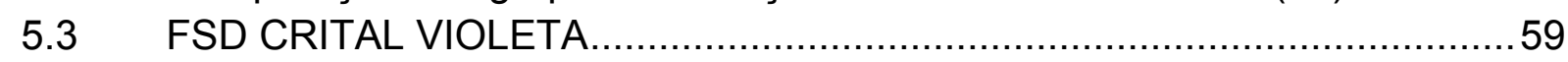

5.3.1 Comparação dos grupos em relação aos controles e entre si (96) ..............59

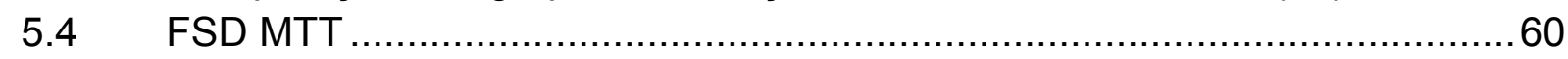

5.4.1 Comparação dos grupos em relação aos controles e entre si (96) ..............60

5.5 ENSAIO DE CICATRIZAÇÃO IN VITRO .................................................

6 DISCUSSÃO

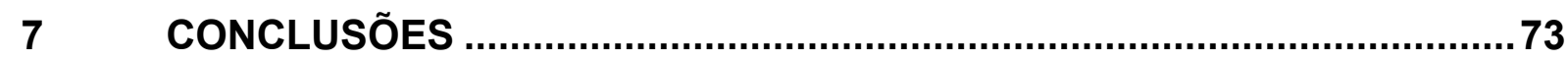

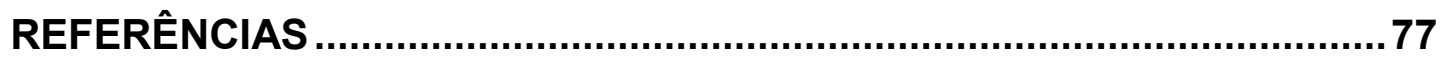

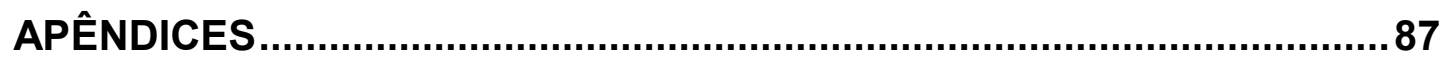

ANEXOS 


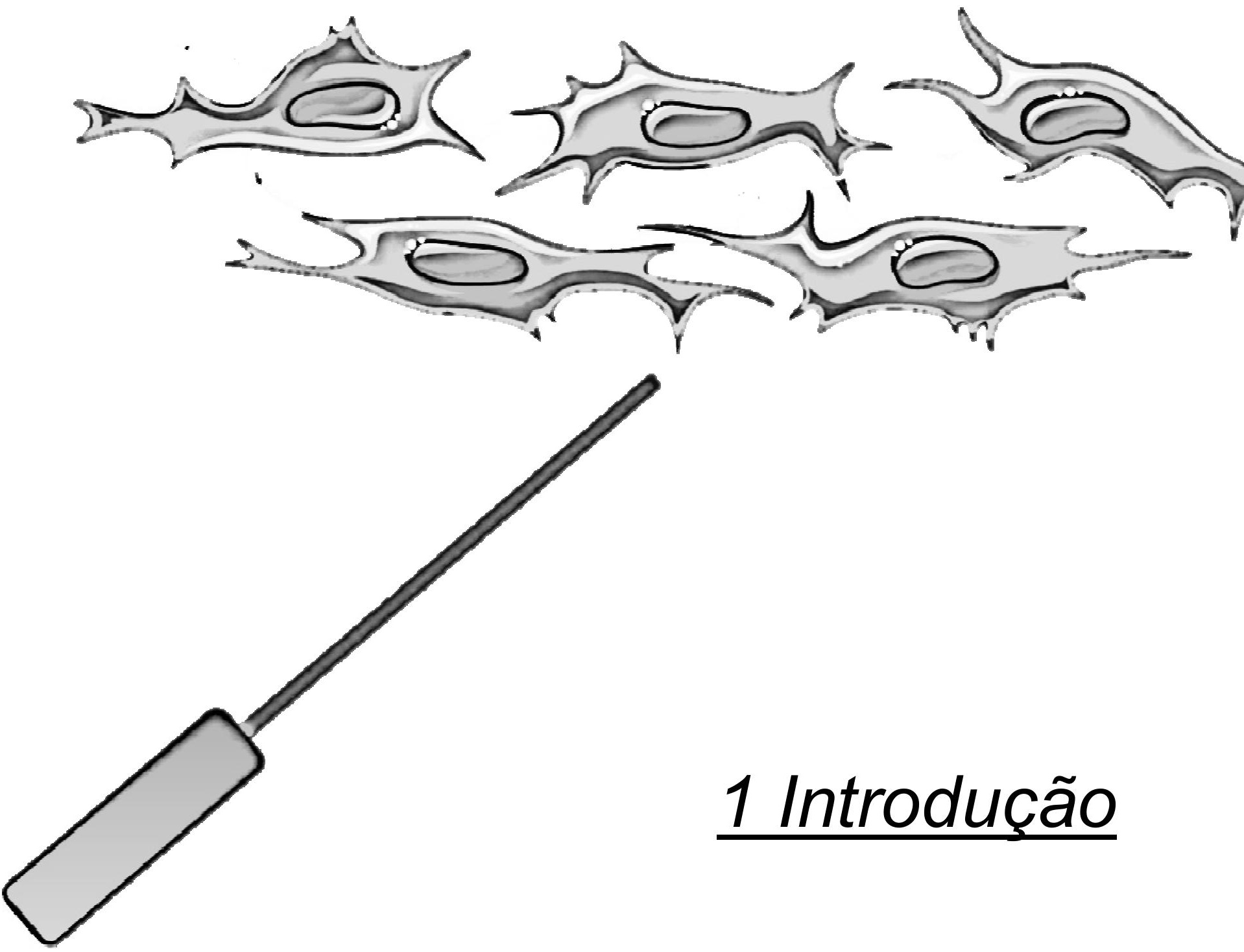



\section{INTRODUÇÃO}

A Síndrome de Down (SD) é uma condição genética, reconhecida há mais de um século por John Langdon Down (1886) e constitui uma das causas mais frequentes de deficiência mental, compreendendo cerca de $18 \%$ do total dos deficientes cognitivos em instituições especializadas. É uma das anomalias cromossômicas mais frequentes, com uma incidência populacional de aproximadamente um em cada 600 nascidos vivos (NETTINA, 1999). Estima-se que $3 \%$ da população mundial possuem a trissomia no cromossomo 21 , com maior prevalência em indivíduos brancos, sendo rara em negros (SCHWARTZMAN, 1999).

A prevalência de doença periodontal em adolescentes com SD é de $30 \%$ a 40\% maior que na população em geral, sendo que em indivíduos na vida adulta, a porcentagem é de cerca de $100 \%$. A doença periodontal é induzida por bactérias do biofilme, sendo caracterizada inicialmente por uma inflamação gengival, formação de bolsas periodontais, perda de inserção, destruição óssea e sua progressão leva à perda dentária. O comprometimento periodontal nestes pacientes atinge tanto a dentição decídua quanto a permanente de forma generalizada e os estudos sugerem que sua severidade aumenta com a idade (CAVALCANTE, 2009). A severidade da doença periodontal na SD possui características semelhantes com o padrão de periodontite agressiva (antigamente chamada de periodontite juvenil) (SOUZA, 2011).

A alta prevalência da doença periodontal nestes indivíduos é decorrente de características deficientes da resposta imunológica do hospedeiro e não somente, de fatores locais relacionados à pobre higiene bucal. Há alta frequência de infecções subgengivais pelo Aggregatibacter actinomycetemcomitans (A.a.) (BARR-AGHOLME et al., 1992), maiores níveis de prostaglandina E2 no fluido gengival (BARRAGHOLME et al., 1997) e de metaloproteinases da matriz, sugeridas como tendo importante papel na destruição do tecido periodontal (HALINEN et al., 1996), quando comparados aos grupos controles saudáveis. Foram relatados também outros fatores relacionados a anormalidades na resposta imunológica (CAVALCANTE et al., 2009; CARRANZA, 2012) como: quimiotaxia de neutrófilos deficiente (IZUME et 
al., 1989; SREEDEVI et al., 1998); fagocitose parcial de leucócitos contra estafilococos (GREGORY et al., 1972); redução numérica dos linfócitos; desenvolvimento anormal de linfócitos (BARRENA et al., 1992) e diminuição da adesividade de linfócitos (MURPHY \& EPSTEIN, 1992). Além desses fatores, pacientes com SD apresentam estresse oxidativo progressivo, o que pode contribuir para as suas características clínicas, particularmente, a periodontite progressiva relacionada ao envelhecimento precoce (KOMATSU et al, 2013).

Desta forma, o uso concomitante de tratamentos que melhorem a resposta cicatricial dos pacientes com SD frente ao tratamento periodontal convencional, devem ser avaliados. Os lasers em baixa intensidade são agentes terapêuticos com propriedades antiinflamatórias, analgésicas e de aceleração da cicatrização de feridas (TUNÉR \& HODE., 1996). Semelhantemente, a irradiação com LED apresenta efeitos favoráveis em nível celular, com maior proliferação de fibroblastos, presumindo benefício em potencial para os resultados clínicos (VINCK et al., 2003). Além de aumentar a proliferação de fibroblastos, o uso de LED promove a cicatrização da ferida in vivo (TADA et al., 2009).

Os efeitos do laser na cicatrização de feridas têm sido atribuídos, em estudos in vitro, ao estímulo de vários sistemas biológicos como aumento da proliferação e atividade celular (ALMEIDA-LOPES et al., 2001; PREIRA et al., 2002; MARQUES et al., 2004; AZEVEDO et al., 2006; EDUARDO et al., 2007), aumento da produção de colágeno (MARQUES et al., 2004, PEREIRA et al., 2002), aumento da síntese de DNA (LOEVSCHALLI \& ARENHOLT-BINDSLEV., 1994; SKINNER et al., 1996), modulação da produção dos fatores de crescimento (YU et al., 1994; DAMANTE 2009), redução na produção de prostaglandinas (SAKURAI et al., 2000). Apenas um trabalho comparou o efeito do LED e Laser na proliferação de fibroblastos, encontrando resultados semelhantes (VINCK et al., 2003).

Pacientes sem alterações sistêmicas importantes raramente necessitam de tratamento para cicatrização da ferida, porém a fotobiomodulação tem um possível efeito positivo em condições de cicatrização comprometida (REDDY et al., 2001; REDDY et al., 1998). Sendo assim, o uso do laser em baixa intensidade e do LED pode ser uma alternativa viável para melhorar a resposta dos pacientes com SD, reduzindo inflamação e melhorando o potencial de reparação frente ao tratamento 
periodontal.

Neste contexto, diante das atuais evidências dos benefícios adicionais do laser e do LED, como também pela ausência de estudos em pacientes com SD, o presente trabalho possui caráter inovador com possibilidade de grande relevância clínica futura, desenvolvendo-se tratamentos clínicos mais individualizados e eficientes, que possam proporcionar melhor qualidade de vida para esses pacientes. 



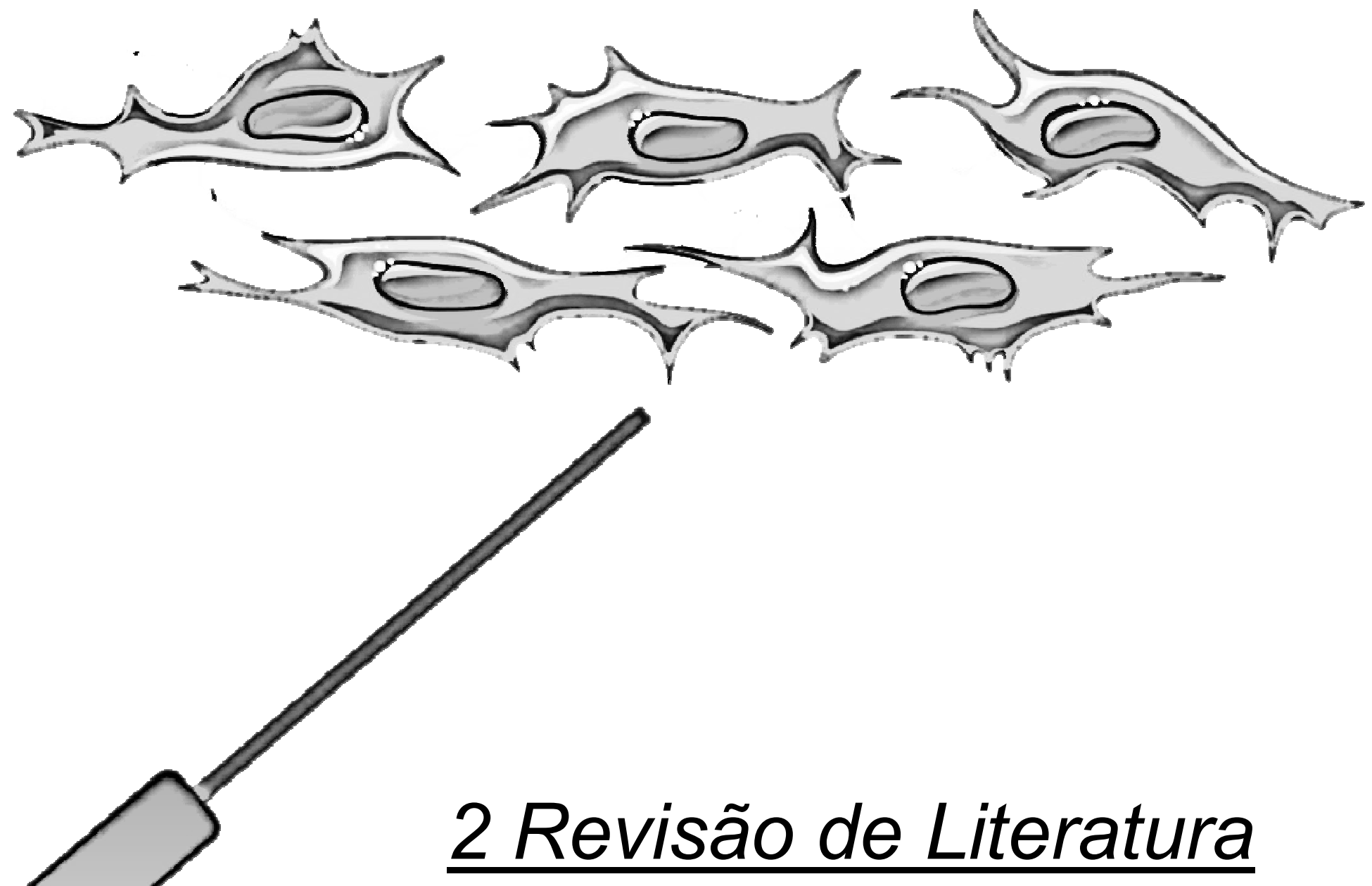





\section{REVISÃO DE LITERATURA}

Para fins didáticos, esta revisão de literatura será dividida em tópicos abordando os aspectos referentes à etiologia, prevalência e tratamento da DP em pacientes com SD. E também, aspectos concernentes à fotobiomodulação por LED e Laser na proliferação de fibroblastos, visando melhora na cicatrização.

\subsection{Pacientes com SD}

Medicina Periodontal é um termo relativamente recente, porém bastante consolidado na grande área de ciências da saúde. Consiste no estudo da relação bidirecional das patologias bucais periodontais com reações e condições sistêmicas do indivíduo (WILLIAMS, OFFENBACHER, 2000).

O equilíbrio entre a saúde periodontal e sistêmica deve ser mantido principalmente nos pacientes que possuem alguma deficiência sistêmica, como pacientes sindrômicos. Este grupo é chamado de pacientes com necessidades especiais, os quais requerem atenção e abordagem específicas por um período ou pelo resto de suas vidas (MUGAYAR, 2000). A grande demanda desses pacientes em consultórios odontológicos direcionou o surgimento de uma nova especialidade na Odontologia, denominada Odontologia para Pacientes com Necessidades Especiais (ABOPE, 2010).

O indivíduo de SD é o paciente com necessidade especial de maior prevalência da população mundial, com aproximadamente $3 \%$ na população mundial (SCHWARTZMAN, 1999).

Descrita inicialmente por John Langdon Down (1986), a SD se apresenta como uma condição genética, mais comumente encontrada em pacientes caucasianos e raramente prevalente em indivíduos negros (SCHWARTZMAN, 1999). O primeiro pesquisador a estabelecer a relação da SD com alterações genéticas uma relação entre alguma deficiência na capacidade mental com alterações genéticas foi o geneticista Jérôme Lejeune em 1958, sendo o 
responsável pelo descobrimento da trissomia do 21. Dois anos após o descobrimento, o termo "Mongolismo" foi descartado e substituído por Anomalia da Trissomia do cromossomo 21. Além da trissomia do 21, a SD pode se originar através da triplicação do braço longo do cromossomo 21, 14 ou 15 (MUSTACCHI, ROZONE, 1990) ou pelo mosaicismo, caracterizado quando parte das células se apresenta com 46 cromossomos e a outra com a Trissomia do 21 (HASSOLD, SHERMAN, 2000).

Devido ao mecanismo de não disjunção meiótica, em cerca de $80 \%$ dos casos de Trissomia do 21, o cromossomo extra é de origem materna, sendo a idade materna avançada um dos principais motivos para essa incidência (MUSTACCHI Z., 1990). Dessa forma, o envelhecimento do gameta feminino pode estar diretamente relacionado com a gestação de uma criança com SD (BORGES-OSORIO, ROBINSON., 2002).

Embora grande parte dos abortos espontâneos estarem associados as alterações cromossômicas, a SD é a mais compatível com a vida. Todavia, devido a complicações cardíacas e respiratórias, a taxa de sobrevivência dos neonatais com SD é consideravelmente diminuída, com taxa de mortalidade infantil de aproximadamente um quarto das crianças recém-nascidas com SD (NETTINA., 1999).

As características fenotípicas de um paciente com SD são consideravelmente distintas, totalizando cerca de 30 características clínicas que estão relacionadas com a alta expressão de genes específicos que se encontram no cromossomo 21 (CARTER.,1960). Entre as características de maiores complexidades, destacam-se as cardiopatias congênitas, deficiências no sistema imune, hipotonia generalizada, microcefalia, e alterações gastrointestinais congênitas, instabilidade atlanto-axial, maior incidência de ataques convulsivos e de leucemia, perda auditiva, hipotireoidismo, alterações oculares e senilidade precoce (MUSTACCHI., ROZONE, 1990; NIZETIC., 2001; LAI, WILLIAMS, 1989; JOHANNSEN, CHRISTENSEN, MAI, 1996). Entre as demais características, a baixa estatura, mãos curtas e largas com uma única prega palmar transversa (linha simiesca - 40\%), quinto dedo encurvado (clinodactilia), estão fortemente ligadas ao diagnóstico da SD (MUSTACCHI, ROZONE, 1990). 
No que diz respeito às características clínicas intrabucais, os pacientes com SD também podem apresentar: palato ogival, pseudo-macroglossia ou boca entreaberta (devido à pseudomacroglossia e/ou hipotonia), língua fissurada, menor prevalência de cáries em relação à DP e aumento da severidade da DP, dentes conóides, oligodontia e retardo e alteração na sequência da erupção dentária (REY SC, 1990).

\subsection{Doença periodontal em pacientes com SD}

A DP é causada por um processo infeccioso originado de patógenos presentes no biofilme dentário e que por consequência inicia uma exacerbada resposta imune do hospedeiro, causando maior destruição tecidual (SALVI, LANG, 2005).

Por volta de 30 a $40 \%$ dos pacientes com SD apresentam DP na adolescência. Todavia, na fase adulta, estima-se que esse número alcance $100 \%$ dos pacientes com SD (REULAND-BOSMA W,1986). Apesar de um adequado controle de placa e higiene bucal ser fundamental no tratamento da DP, no estudo de Swallow (1964) foi demonstrado que mesmo com o controle de placa, os pacientes com SD apresentavam maior severidade da DP. Logo, as características sistêmicas do paciente sindrômico devem ser levadas em consideração.

Estudos mostraram que uma diminuída quimiotaxia por neutrófilos, aumento da atividade da matriz metaloproteinase (MMPs) por neutrófilos e fibroblastos gengivais, defeito na ativação e adesão pela molécula de adesão intercelular (ICAmi) por linfócitos, como também aumento na expressão do receptor molecular CD8 nos linfócitos e um aumento da atividade das metaloproteinases da matriz (MMPs) por neutrófilos e fibroblastos gengivais são responsáveis pela severidade e alta incidência da DP em pacientes com SD (YAVUZYLMAZ et al., 1993; SREEDEVI, MUSHI, 1998; BARR-AGHOME et al., 1997; HALINEN et al., 1996; KOMATSU et al., 2001; COSSARIZZA et al., 1990; LIN et al., 2001). 
Um estudo in vitro comparou a adesão e proliferação de fibroblastos gengivais e de pacientes com e sem SD frente a ação por Porphyromonas gingivalis (P.g.). Os resultados demonstraram que P.g. prontamente invadiu os fibroblastos de SD comparados aos fibroblastos gengivais normais, o que prejudicou a mobilidade celular. Os autores sugeriram que esta característica também pode estar envolvida na etiologia da periodontite na SD (Murakami et al, 2008).

Um estudo (ZIGMOND et al., 2006) com acompanhamento de 10 anos comparou as condições periodontais e o tratamento de pacientes com e sem SD. O programa de prevenção foi aplicado periodicamente em ambos os grupos e consistiu em instruções de higiene bucal e raspagem supra e subgengival. No entanto, apesar dos parâmetros gengivais e de higiene bucal similares, os pacientes com SD apresentaram maior prevalência, extensão e severidade da doença periodontal que o grupo controle.

O tratamento do paciente com SD requer um manejo especial, pois podem apresentar demência, problemas comportamentais, mudanças de personalidade, diminuição da sociabilidade, apatia, frequência aumentada de convulsões e perda da habilidade cognitivas (ROIZEN, PATTERSON, 2003), sendo um tratamento de grande complexidade.

Em um estudo clínico randomizado com pacientes com SD realizado por Ferreira (2015), observou-se que inicialmente esses pacientes apresentavam alta prevalência (100\%) e severidade (96\%) da DP da amostra. Observou-se também que o grupo que associou a terapia fotodinâmica antimicrobiana (aPDT) ao tratamento convencional não obteve maior efetividade perante $\mathrm{o}$ tratamento periodontal convencional (RACR).

Dessa forma, a busca por tratamentos adjuvantes na terapia periodontal em pacientes com SD é de grande importância para o adequado manejo e tratamento desses pacientes sindrômicos. Dentre os diversos tratamentos, podemos destacar a utilização de Laser de baixa intensidade, já bastante sedimentada na literatura, e o Diodo Emissor de Luz (LED), que recentemente tem se tornou alvo de pesquisas. 


\subsection{Terapia de fotobiomodulação}

A terapia com laser em baixa intensidade ou fotobiomodulação (Anders, Lanzafame e Arany, 2015) é utilizada na odontologia principalmente para aceleração de cicatrização de feridas. Foi inicialmente utilizada para acelerar a cicatrização de feridas em ratos, através do laser de rubi (MESTER,1971). Sobre o mecanismo que sustenta a atividade benéfica do laser em baixa intensidade nos tecidos bucais, duas teorias são aceitas. A primeira refere-se à capacidade da luz, que, sob um determinado comprimento de onda, ativa a cadeia respiratória mitocondrial celular. A segunda teoria pressupõe-se que a luz atue na abertura dos canais de cálcio na membrana celular. Em ambas as teorias, ocorre um aumento no metabolismo celular, com uma produção elevada de trifosfato de adenosina- ATP (KARU T,1989; SMITH K,1991).

Estudos mostram que a fotobiomodulação consegue aumentar a atividade metabólica celular, aumentando seu potencial regenerativo, neoformação vascular e regeneração tecidual (ABERGEL RP, GLASSBERG E, UITTO J, 1988; BIHARI J, MESTER AR; TERRIBLE WMV, 1988).

A densidade de energia do laser pode produzir um efeito benéfico as células, bem como causar inibição do crescimento celular. Estudos com fibroblastos mostraram que os melhores resultados foram obtidos com densidade de energia ao redor de $2 \mathrm{~J} / \mathrm{cm}^{2}$ (BOLTON P, YOUNG S, DYSON M, 1991; WEI YU, NAIM JO, 1994; ALMEIDA-LOPES L, 1991).

É de conhecimento na literatura que o melhor efeito da fotobiomodulação in vitro acontece quando as células passaram por um processo de estresse previamente sua aplicação (RYHANEN L, RANTALA-RYHANEN S, TAN EML, 1982; ALMEIDA-LOPES, RIGAU J, JAEGER MMM, BRUGNERA Jr, 1998). Os estudos também comparam a utilização de laser vermelho visível com laser infravermelho. Apesar de grande parte dos estudos apontarem um melhor efeito para o vermelho visível, existem estudos que sustentam a utilização do infravermelho como melhor opção (LUBART R, FRIEDMANN H, PELED I, GROSSMAN N,1993; LAM TS; RYHANEN L, RANTALA-RYHANEN S, TAN EML, 1982, DAMANTE et al., 2009). 
Em um estudo clínico randomizado duplo-cego, foi avaliado o efeito da fotobiomodulação na cicatrização da área doadora (palato) após a remoção de enxerto conjuntivo subepitelial para cirurgia de recobrimento radicular. O grupo teste ( $n=16$ ) recebeu a aplicação do laser de GaAlAs, $660 \mathrm{mn}, 30 \mathrm{~mW}$ e com densidade de energia total de $15 \mathrm{~J} / \mathrm{cm}^{2}$, por 20 segundos. O grupo controle $(\mathrm{N}=16)$ recebeu a imposição do laser, todavia com uma ponta de borracha preta sem que houvesse penetração da luz. Os pacientes foram acompanhados nos períodos de 7, 14, 45, 60 e 90 dias. Como resultado, a avaliação colorimétrica da área doadora, a espessura do tecido cicatrizado, a dor e o desconforto e a quantidade de remédios ingeridos, não mostraram diferença estatística entre os grupos. Apenas no período de 45 dias, a mensuração da área não cicatrizada foi maior estatisticamente para o grupo controle, evidenciando uma cicatrização mais rápida para o grupo que recebeu o laser, no período em questão (DIAS et al., 2015-A).

Em estudo similar, avaliando a fotobiomodulação na cicatrização da área operada, 40 pacientes foram distribuídos aleatoriamente em dois grupos, sendo que o grupo teste recebeu aplicação do laser de GaAlAs, $660 \mathrm{mn}, 30 \mathrm{~mW}$ e com densidade de energia total de $15 \mathrm{~J} / \mathrm{cm}^{2}$, por 20 segundos, na área receptora do enxerto conjuntivo subepiletial. Aplicação foi realizada imediatamente após a suturas e em todos dias subsequentes, por 7 dias. O grupo controle recebeu a imposição do laser sem penetração da luz. No acompanhamento de 6 meses, não houve diferença estatística entre os grupos em relação a profundidade de sondagem, ganho de mucosa ceratinizada e nível de inserção clínica. Todavia, o grupo teste obteve resultados estatisticamente maiores para o recobrimento radicular completo (DIAS SB AT EL, 2015-B)

A avaliação do laser de baixa intensidade no tratamento de periodontite moderada foi realizada em um estudo randomizado de boca dividida duplo-cego. Dos 17 pacientes incluídos na pesquisa, um lado da maxila (grupo teste) recebeu a aplicação de laser em dois comprimentos de onda, separadamente: 635mn (InGaAIP) $10 \mathrm{~mW}, 4.5 \mathrm{~J} / \mathrm{cm}^{2}$, por 90 segundos e $835 \mathrm{mn}$ (GaAlAs) $70 \mathrm{~mW}, 8.75 \mathrm{~J} / \mathrm{cm}^{2}$, por 25 segundos, uma vez por semana, durante 6 semanas. O outro lado (grupo controle) recebeu uma aplicação placebo, com o uso de LED em baixo comprimento de onda. Todos pacientes foram submetidos a raspagem e alisamento radicular previamente a aplicação do laser. $\mathrm{Na}$ avaliação da profundidade de sondagem, 
índice de placa e sangramento gengival, houve uma redução esteticamente maior para o grupo teste. Nos ensaios laboratoriais, não houve diferença entre grupos, nos testes de elasticidade, MMP-8 e IL-1 $\beta$ e também em relação microbiota analisada com 12 tipos de bactérias. Entretanto, houve decréscimo estatisticamente significante do volume de fluído crevicular gengival para o grupo teste. Os autores concluíram que a aplicação do laser de baixa intensidade foi efetiva na redução da inflamação do tecido gengival (QUADRI T, MIRANDA L, TUNER'R J, GUSTAFSSON A, 2005)

A utilização do laser de baixa intensidade também foi avaliada no tratamento de defeitos infra-ósseos. O estudo randomizado de boca dividida foi conduzido com 13 pacientes que receberam regeneração óssea guiada com a utilização de laser Nd:YAG (grupo teste) em um lado da mandíbula e RGO sem aplicação de laser (grupo controle) no lado contralateral. O laser foi aplicado em comprimento de onda de $889 \mathrm{mn}, 100 \mathrm{~mW}, 4 \mathrm{~J} / \mathrm{cm}^{2}$, por 5 minutos, logo após a cirurgia e nos dias 1, 2, 3, 5 e 7 subsequentes à cirurgia. Como resultado, o grupo teste obteve uma diferença estatisticamente significante na redução da PS, RG e sangramento a sondagem, bem como o aumento do $\mathrm{NCl}$. Os autores concluíram que a fotobiomodulação como tratamento adjuvante na terapia de RGO foi eficaz, trazendo benefícios para o tratamento periodontal em questão (DOGAN GE, DEMIR T, ORBAK R, 2014).

No estudo de Oztuna et al. (2011), os autores pesquisaram o efeito da fotobiomodulação em um estudo clínico randomizado, no qual 74 recessões classe I e II de Miller foram divididas em 2 grupos. O grupo teste recebeu cirurgia de retalho coronalmente avançado (RCA) mais aplicação de diodo de laser, 588nm, 140mW, $4 \mathrm{~J} / \mathrm{cm}^{2}$, por 5 minutos, antes e após a sutura do retalho, e no pós-operatório de 7 dias. No grupo controle não houve irradiação com laser, apenas RCA. Como resultado, observaram que houve diferença estatisticamente relevante para o grupo teste na redução de profundidade de sondagem (RPS) $(p=0.014)$, redução da largura da recessão $(\operatorname{RLR})(p=0.015)$, aumento de tecido queratinizado $(T K)(p=$ 0.009) e nível de inserção clínica $(\mathrm{NIC})(p=0.018)$, após 1 ano de acompanhamento. Apesar de não haver diferença estatística para o recobrimento radicular completo $(\mathrm{RRC})$, o grupo teste obteve melhores resultados. Os autores concluíram que a fotobiomodulação pode ser considerada como um tratamento adjuvante eficaz, com melhor estabilidade dos resultados. 
A aplicação de laser de baixa intensidade foi testada em um estudo de boca dividida, no qual os pacientes passaram por cirurgias de gengivectomia ou gengivoplastia, em pelo menos 6 dentes. Todos os pacientes receberam guias personalizados para que a aplicação do laser não atingisse áreas adjacentes. $O$ grupo teste recebeu a aplicação de diodo de laser a $588 \mathrm{~nm}, 120 \mathrm{~mW}, 4 \mathrm{~J} / \mathrm{cm}^{2}$, por 5 minutos, após a cirurgia e estabilização do sangramento, e no pós operatório de 7 dias. O grupo controle recebeu aplicação de laser placebo (sem ativação do laser), sendo que todos os pacientes foram avaliados nos períodos pré operatório, pós operatório, 3, 7 e 15 dias. O parâmetro avaliado foi a área de epitelização ou quantidade de tecido queratinizado através do uso de uma solução evidenciadora (identificação de área com ausência de epitélio) e fotografias, calculando a área através de um software. Os resultados mostraram que houve diferença estatística entre os grupos, em todos os períodos, com epitelização mais rápida para o grupo teste $(p<0.001)$. A completa cicatrização foi confirmada entre os dias 18 e 21 para o grupo teste e 19 e 24 dias para o grupo controle. Como conclusão, a fotobiomodulação pode diminuir o tempo de cicatrização de cirurgias de gengivectomia e gengivoplastia (OZCELIK et al., 2008).

Com o objetivo de avaliar o efeito da fotobiomodulação na cicatrização de feridas na mucosa oral, Damante et al, 2004 realizaram um estudo clínico com aplicação de Laser (GaAlAs, $630 \mathrm{~nm}, 15 \mathrm{~mW}, 4 \mathrm{~J} / \mathrm{cm}^{2}$ ) após cirurgias de gengivoplastia. Foram divididos em 2 grupos: 1) Controle, sem aplicação de Laser; 2) Teste, com aplicação de Laser após a cirurgia e mais 3 aplicações com intervalo de 48 horas. Para a análise histomorfométrica, foram realizadas biópsias de papilas entre os laterais e incisivos centrais, nos períodos de 7, 14, 21 e 60 dias de pósoperatório. Para a realização dessas biópsias os pacientes foram aleatoriamente distribuídos e cada paciente participou apenas de um período. As análises morfométricas e morfológicas não apresentaram diferença estatística entre os grupos, obtendo semelhante maturação celular e da lâmina própria, aumento de vasos sanguíneos e espessura epitelial. Os autores sugerem que por se tratar de pacientes sistemicamente saudáveis em ambos os grupos, o efeito da fotobiomodulação, não apresentou diferenças estatísticas, bem como não prejudicou a cicatrização. 


\subsubsection{Fotobiomodulação em ensaios com fibroblastos}

Para avaliação do crescimento celular e síntese de procolágeno, fibroblastos NIH 3T3 foram irradiados pelo laser de baixa intensidade Ga-As (904nm, $120 \mathrm{~mW}$ ). O estudo foi conduzido com 4 grupos, sendo: 1) Grupo controle- sem aplicação de laser; 2) Duas aplicações de laser com densidade de energia de $2 \mathrm{~J} / \mathrm{cm}^{2}, 6 \mathrm{em} 6 \mathrm{~h}$, $16 \mathrm{~s}, 4 \mathrm{~J} / \mathrm{cm}^{2}$; 3) Duas aplicações, $6 \mathrm{em} 6 \mathrm{~h}$, sendo a primeira com $1 \mathrm{~J} / \mathrm{cm}^{2}$, e a segunda com $2 \mathrm{~J} / \mathrm{cm}^{2}, 16 \mathrm{~s}$ totalizando $3 \mathrm{~J} / \mathrm{cm}^{2}$; 4) Duas aplicações, com intervalo de 6 horas, sendo a primeira aplicação com $2 \mathrm{~J} / \mathrm{cm}^{2}$ (8 segundos) e na segunda com $3 \mathrm{~J} / \mathrm{cm}^{2}$ (24 segundos), totalizando $5 \mathrm{~J} / \mathrm{cm}^{2}$. Os grupos 2 e 3 obtiveram um aumento no crescimento celular estatisticamente significante em relação ao grupo 1(controle).

O grupo 4 obteve resultados semelhantes ao grupo controle. Não houve diferença estatística em relação a síntese de procolágeno. Em suma, a resposta celular é dependente dos parâmetros de laser a serem utilizados, podendo ou não trazer efeitos benéficos à célula (PEREIRA et al., 2002).

Outro estudo avaliou o efeito da fotobiomodulação do laser infravermelho e vermelho visível, na cicatrização de feridas em ratos. Todas as aplicações de laser foram feitas em uma mesma potência de $35 \mathrm{~mW}$. Os grupos foram distribuídos em: 1) Controle, sem aplicação de laser; 2) Laser vermelho (685nm e 20J/cm²); 3) Laser infravermelho (830nm e $\left.20 \mathrm{~J} / \mathrm{cm}^{2}\right)$; 4) Associação do laser vermelho e infravermelho $\left(685 \mathrm{~nm} / 830 \mathrm{~nm}\right.$ ambos em $\left.10 \mathrm{~J} / \mathrm{cm}^{2}\right)$; 5) Vermelho $\left(685 \mathrm{~nm}\right.$ e $\left.50 \mathrm{~J} / \mathrm{cm}^{2}\right)$; 6) Infravermelho (830nm e 50J/cm²); 7) Associação de vermelho e infravermelho (685 / $830 \mathrm{~nm}$ ambos em $25 \mathrm{~J} / \mathrm{cm}^{2}$ ). Os ratos foram sacrificados nos períodos de 3,5 e 7 dias após a aplicação e analisados histologicamente. Todos os grupos com aplicação de laser obtiveram menor inflamação e maior proliferação de fibroblastos em relação ao grupo controle. Todavia, os melhores resultados foram observados com o grupo 4. Os autores concluíram que apesar de todos os grupos irradiados terem apresentado resultados positivos, o grupo com menor densidade de energia e associação dos dois comprimentos de onda (685nm e $830 \mathrm{~nm})$ obteve os melhores resultados (MENDEZ et al., 2004)

A terapia de fotobiomodulação foi testada em diferentes comprimentos de onda, na cultura de células endoteliais e fibroblastos de rato $(\mathrm{C} 3 \mathrm{H})$ em um estudo in vitro. Os comprimentos de onda estabelecidos foram: 635, 645, 655, 665 e 675nm 
(laser vermelho) e $810 \mathrm{~nm}$ (laser infravermelho), $5 \mathrm{~mW} / \mathrm{cm}^{2}, 10 \mathrm{~J} / \mathrm{cm}^{2}$, com uma única aplicação. Para avaliação da viabilidade celular foi utilizado um teste colorimétrico semelhante ao teste de MTT, com adição do composto de tetrazólio. Os resultados mostraram que os fibroblastos tiveram maior crescimento com o comprimento de onda de $665 \mathrm{~nm}$ e $675 \mathrm{~nm}$. Todavia, quando expostos ao comprimento de onda de $810 \mathrm{~nm}$, houve uma inibição do crescimento dos fibroblastos. Em relação as células endoteliais, o pico de maior crescimento celular foi com o comprimento de onda de $655 \mathrm{~nm}$, sendo que quando submetido ao comprimento de onda de $810 \mathrm{~nm}$, apesar de apresentar crescimento, foi a menor proliferação celular, em relação aos outros grupos. Concluiu-se que o tipo celular influencia na fotobiomodulação, bem como o comprimento de onda (MOORE et al., 2005).

Em estudo semelhante, foi avaliado o crescimento celular de fibroblastos gengivais humanos (linhagem celular LMF) por meio da fotobiomodulação com diferentes densidades de potência, através do laser GaAlAs, em um comprimento de onda de $660 \mathrm{~nm}$. $O$ experimento foi dividido em 3 grupos, sendo que o primeiro grupo (controle) não recebeu irradiação. $O$ segundo recebeu a irradiação com densidade de potência de $142.85 \mathrm{~mW} / \mathrm{cm}^{2}$ e o terceiro com $428.57 \mathrm{~mW} / \mathrm{cm}^{2}$. Foi realizada a contagem de células nos períodos de 2, 6 e 9 dias, após a irradiação. $O$ grupo controle obteve a menor contagem de células, comparando com os grupos experimentais. O segundo grupo apresentou, no dia 2, um valor três vezes maior e no dia 9 , um valor 10 vezes maior que o grupo controle respectivamente. No período do dia 9, o segundo grupo obteve maiores resultados quando comparado ao grupo. O grupo 3 apresentou resultados estatisticamente maiores que o grupo controle, todavia após o período do dia 6 , houve um decréscimo significante dos resultados $(p<0.001)$. Os autores concluíram que a densidade de potência é um importante parâmetro e que deve ser cautelosamente estabelecida pelos profissionais na aplicação de seus pacientes (AZEVEDO et al., 2006).

Em um estudo in vitro foi avaliado a viabilidade celular através da utilização do laser InGaAIP em dois tipos de células: 1) $3 T 3$ Linhagem imortalizada de fibroblastos murinos; 2) Fibroblastos removidos cirurgicamente de queloides humanas. Foram aplicadas duas dosagens do laser, de $3 \mathrm{~J}$ e $21 \mathrm{~J}$, nos períodos de 24, 48 e 72 horas, sendo testado em ambas as células. As células foram cultivadas em meio DMEM, com $10 \%$ de SFB, 2 Mm de Glutamina, $100 \mathrm{U} / \mathrm{mL}$ de Penicilina e 
$100 \mu \mathrm{g} / \mathrm{mL}$ de sulfato de estreptomicina. Através do teste colorimétrico MTT observou-se que nas duas células testadas a melhor proliferação dos fibroblastos aconteceu na da dosagem de $3 \mathrm{~J}$. No teste de análise do ciclo celular, para as duas células, a dosagem de $21 \mathrm{~J}$ aumentou a percentagem de hipodiploidia devido a apoptose celular ou pela diminuição da divisão celular. Na análise de morte celular, para as células $3 T 3$, a dosagem de $21 \mathrm{~J}$ demonstrou maior porcentagem no período de 72h. Já para os fibroblastos de queloides, a maior porcentagem apareceu com a irradiação de $21 \mathrm{~J}$ no período de $24 \mathrm{~h}$. Os autores concluíram que as células 3T3 são menos sensíveis ao efeito de fotobiomodulação do laser e que nas duas células, a dosagem de $3 \mathrm{~J}$ apresentou melhor viabilidade celular e menor resultado de morte celular (FRIGO et al., 2010).

\subsection{Diodo Emissor de Luz (LED)}

A literatura referente a utilização de LED como fonte para a terapia de fotobiomodulação é significantemente menor em relação as pesquisas com Laser. Um dos motivos para tal questão, deve-se ao fato de que incialmente se acreditava que a coerência da luz emitida poderia influenciar nos resultados da fotobiomodulação, sendo que o LED, ao contrário do laser, emite uma luz incoerente. Entretanto, estudos mais recentes mostraram que a coerência da luz não é responsável pelos efeitos da fotobiomodulação, descartando assim a hipótese de que o LED não produz efeitos benéficos na fototerapia (VINCK et al., 2003).

Com o propósito de se averiguar se realmente a fotobiomodulação com LED produziria efeitos similares ao laser de baixa intensidade, Vinck et al. (2003) compararam a utilização do laser e do LED em fibroblastos de embriões de galinha. Inicialmente foi realizada a cultura primária dos fibroblastos e com subsequentes subcultivos até a terceira passagem. Foram utilizados três comprimentos de onda na fototerapia com LED: 1) $570 \mathrm{~nm}$ (luz verde),160mW, por 1 minuto; 2) 660nm (vermelho visível), $80 \mathrm{~mW}$, por 2 minutos; e 950nm (infravermelho), 10mW, por 3 minutos. O comprimento de onda do laser de baixa potência GaAIAs utilizado foi de $830 \mathrm{~nm}$, com densidade de potência de $40 \mathrm{~mW}$, por 5 segundos. As irradiações foram realizadas uma vez ao dia, durante 3 dias, sendo que o grupo controle recebeu 
irradiação placebo. As placas com os fibroblastos cultivados foram alocadas aleatoriamente para cada parâmetro estabelecido. Os resultados do teste colorimétrico MTT mostraram que em todos os grupos houve um aumento estatisticamente significativo para a proliferação de fibroblastos, quando comprados ao grupo controle. Os grupos LED verde e vermelho visível apresentaram um significante aumento do crescimento celular $(p<0.001)$ quando comparado ao grupo LED infravermelho. Não houve diferença estatística entre o grupo LED infravermelho e grupo Laser GaAIAs. Os autores concluíram que o LED pode ser um eficaz fotobiomodulador, com efeitos benéficos aos fibroblastos.

O estudo de Sousa et al, 2010, avaliou o efeito da fotobiomodulação por LED, em 3 diferentes comprimentos de onda, em fibroblastos de ratos. Os grupos experimentais foram: 1) Controle (sem irradiação); 2) LED vermelho $(700 \mathrm{~nm}, 15 \mathrm{~mW}$, por 8s); 3) LED verde (530nm, $8 \mathrm{~mW}$, por 50s); 4) LED azul (460nm, 22mW, por 36s). A média de densidade de energia foi de $10 \mathrm{~J} / \mathrm{cm}^{2}$. Os resultados histológicos mostraram que os grupos LED vermelho e LED verde obtiveram maior quantidade de fibroblastos, estatisticamente maior que o grupo controle. O grupo LED azul não apresentou diferença estatística em relação ao grupo controle. Os autores concluíram que o LED possui efeito positivo da terapia de fotobiomodulação, em fibroblasto.

Volpato et al.(2011) avaliaram o efeito da fotobiomodulação através do uso de laser e LED, em fibroblastos Balb /c 3T3, sob condições de déficit nutricional. Foram estabelecidos 8 grupos: 1) Laser vermelho (660nm, $\left.40 \mathrm{~mW}, 4 \mathrm{~J} / \mathrm{cm}^{2}\right)$ por $\left.4 \mathrm{~s} ; 2\right)$ Laser vermelho $\left(660 \mathrm{~nm}, 40 \mathrm{~mW}, 8 \mathrm{~J} / \mathrm{cm}^{2}\right)$ por $\left.8 \mathrm{~s} ; 3\right)$ Laser infravermelho $(780 \mathrm{~nm}, 50 \mathrm{~mW}$, $\left.5 \mathrm{~J} / \mathrm{cm}^{2}\right)$ por $\left.4 \mathrm{~s} ; 4\right)$ Laser infravermelho $\left(780 \mathrm{~nm}, 50 \mathrm{~mW}, 10 \mathrm{~J} / \mathrm{cm}^{2}\right)$ por $\left.8 \mathrm{~s} ; 5\right)$ LED $\left(637 \mathrm{~nm}, 40 \mathrm{~mW}, 4 \mathrm{~J} / \mathrm{cm}^{2}\right)$ por $\left.4 \mathrm{~s} ; 6\right)$ LED $\left(637 \mathrm{~nm}, 40 \mathrm{~mW}\right.$ e $\left.8 J / \mathrm{cm}^{2}\right)$ por $\left.8 \mathrm{~s} ; 7\right) \mathrm{C}+$ (Sem aplicação de Laser ou LED, condições ideais de cultivo); 8) C- (Sem aplicação de Laser ou LED, déficit nutricional- $5 \%$ SFB). Tanto no teste de viabilidade celular por MTT, como no de análise de atividade lissosomal, mostraram que todos os grupos experimentais foram melhores que o $\mathrm{C}^{+}$, e que o grupo que obteve maior resultado estatisticamente significante foi 0 Laser infravermelho. Os autores concluíram que a terapia de fotobiomodulação foi capaz de estimular a proliferação de fibroblastos, sob uma condição de déficit nutricional. 
Em um estudo in vitro foi avaliado o efeito anti-inflamatório da fotobiomodulação por LED, em fibroblastos gengivais humanos tratados com lipopolissacarídeos (LPS) do $P$. gingivalis. Foram divididos em 4 grupos: 1) Controle (sem irradiação e sem LPS); 2) Fibroblastos sem LPS com irradiação; 3) Fibroblastos com LPS sem irradiação; 4) fibroblastos com LPS + irradiação. Os parâmetros utilizados para o LED foram de $635 \mathrm{~nm}$ e densidade de potência de $5 \mathrm{~mW} / \mathrm{cm}^{2}$, durante 1 hora. Foram utilizadas análise de Western-blot e imunoensaio de enzima ligada, para verificar a expressão génica da proteína ciclooxigenase-2 (COX2) e níveis de prostaglandinas $E_{2}\left(P E_{2}\right)$ respectivamente. Os resultados mostraram que a irradiação por LED aliviou o estresse celular e diminuiu a experessão de COX2 e liberação de $\mathrm{PGE}_{2}$, nos fibroblastos com LPS, o que resultou em uma diminuição da liberação de citosinas pró-inflamatórias. Os autores concluíram que a fotobiomodulação por LED reduz a inflamação e pode ser utilizada clinicamente como um tratamento anti-inflamatório (Choi et al, 2012).

No estudo de Oliveira et al. (2012) foi realizada uma comparação entre a utilização de laser e LED, em ratos anêmicos e não anêmicos. Os ratos foram aleatoriamente distribuídos em 7 grupos: 1) rato anêmico, sem ferida e tratamento; 2) rato anêmico sem tratamento; 3) rato anêmico com aplicação de Laser; 4) rato anêmico com aplicação de LED; 5) rato saudável sem tratamento; 6) rato saudável com aplicação de Laser; 7) rato saudável com aplicação de LED. Os parâmetros utilizados para o laser foram de $660 \mathrm{~nm}, 40 \mathrm{~mW}$ e $10 \mathrm{~J} / \mathrm{cm}^{2}$, e para o LED de $700 \pm 20$ $\mathrm{nm}, 15 \mathrm{~mW}$ e $10 \mathrm{~J} / \mathrm{cm}^{2}$. A aplicação de Laser e LED foi realizada nos períodos após a cirurgia, em um intervalo de 48 horas, 7, 14 e 21 dias. O resultado histológico mostrou que houve diferença estatística entre os ratos saudáveis e anêmicos $(p<0.008$ e $p<0.001$, respectivamente). A contagem de fibroblastos dos ratos saudáveis foi estatisticamente maior para a utilização de Laser $(p<0.008)$. Por outro lado, a utilização de LED obteve resultado significantemente maior para os ratos anêmicos $(p<0.001)$. Os autores concluíram que nos parâmetros utilizados, o Laser foi mais efetivo para fibroblastos de ratos saudáveis e o LED para fibroblastos de ratos anêmicos. 
Em um recente estudo de Wang et al. (2015), os autores avaliaram o efeito da fotobiomodulação com LED, em áreas doadoras de cirurgias de enxerto gengival livre em ratos. Para a avaliação da viabilidade e citotoxicidade celular, a irradiação com LED foi realizada em fibroblastos retirados do palato, nos parâmetros de 660$25 \mathrm{~nm}, 3 \mathrm{~mW}$ e com densidades de energia de $5,10,20 \mathrm{~J} / \mathrm{cm}^{2}$, com respectivo tempo de irradiação: 6, 12 e 24 minutos. Para análise histológica e imuno-histoquímica, os 72 ratos foram avaliados nos seguintes grupos: 1) Controle (sem aplicação de LED); 2) Alta dosagem $\left(20 \mathrm{~J} / \mathrm{cm}^{2}\right)$ e 3) Baixa dosagem $\left(0,10 \mathrm{~J} / \mathrm{cm}^{2}\right)$. O resultado da viabilidade celular mostrou que houve diferença estatística superior, no período de 72 horas após a irradiação, para as densidades de energia de 5 e $20 \mathrm{~J} / \mathrm{cm}^{2}$ em relação a não aplicação do LED. A citotoxicidade mostrou redução estatisticamente maior na aplicação de LED 5 e $20 \mathrm{~J} / \mathrm{cm}^{2}$, em ambos os períodos de 24 e $72 \mathrm{~h}$. $O$ fechamento da ferida foi obtido mais rapidamente com o LED a $5 \mathrm{~J} / \mathrm{cm}^{2}$, no período de 12 horas. 

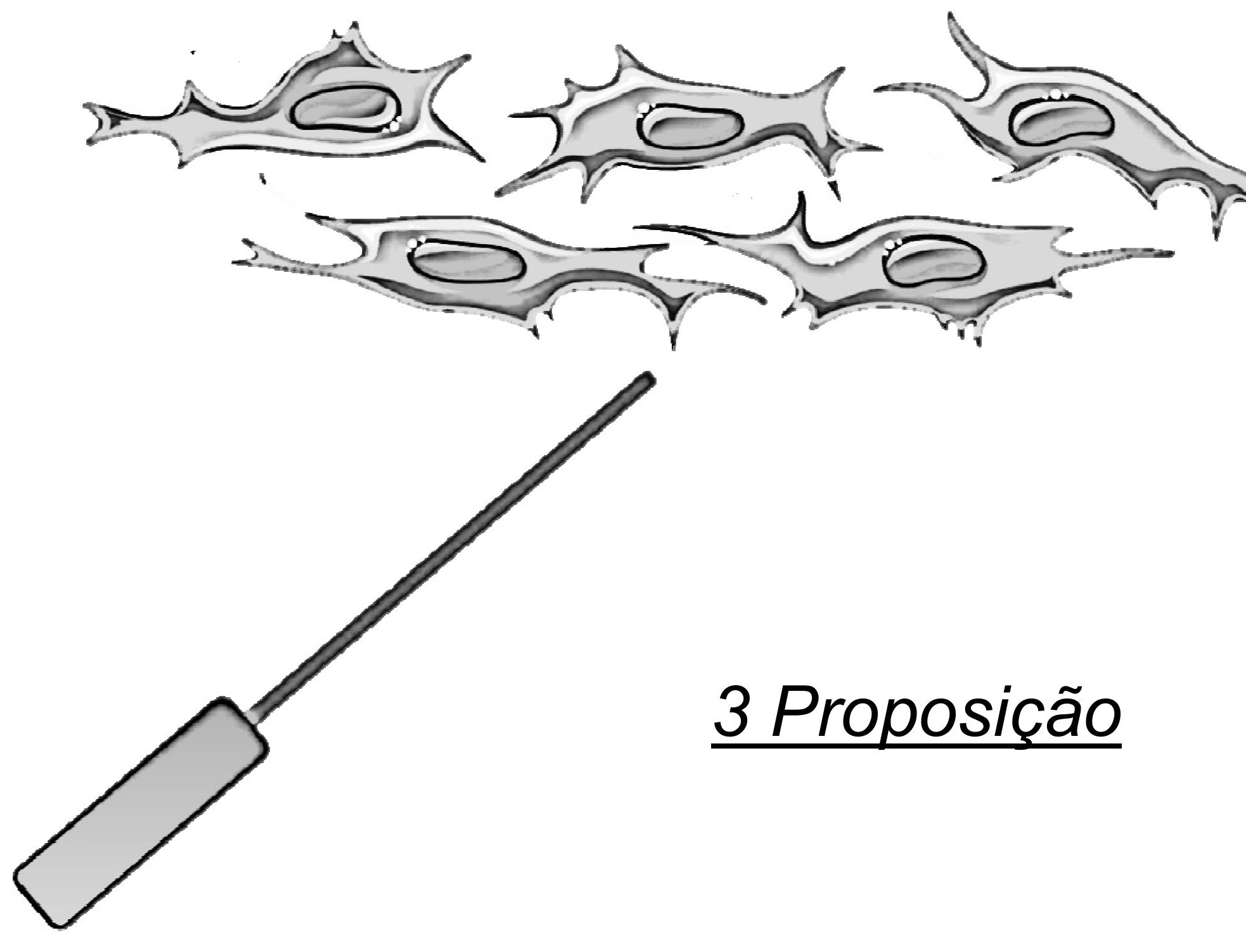



\section{PROPOSIÇÃO}

Comparar os efeitos da fotobiomodulação com laser em baixa intensidade e diodo emissor de luz, com diferentes parâmetros, na proliferação e migração de fibroblastos gengivais humanos oriundos de pacientes com e sem síndrome de Down. 



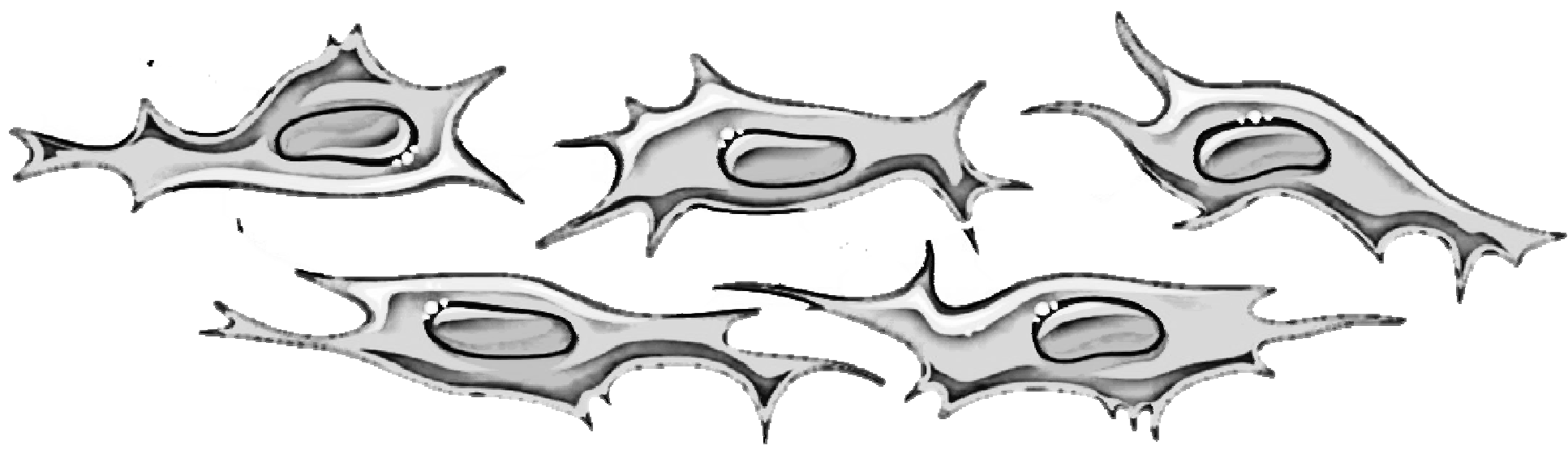

\section{Material e Métodos}





\section{MATERIAL E MÉTODOS}

\subsection{Aspectos éticos}

Anteriormente à execução deste estudo, o mesmo foi submetido à apreciação e aprovação pelo Comitê de Ética em Pesquisa com Seres Humanos (CEP) da Faculdade de Odontologia de Bauru - USP - CAAE: 49844715.0.0000.5417 (Anexo A).

\subsection{Cultura celular}

As células utilizadas na presente pesquisa, foram células congeladas em nitrogênio líquido, obtidas por cultura primária em um estudo prévio (dados ainda não publicados), aprovado pelo comitê de ética, número do protocolo CAAE: 26051214.0.0000.5417. Essas células foram provenientes de 2 pacientes tratados na clínica de Periodontia da FOB-USP que necessitavam de cirurgias periodontais ressectivas, sendo um paciente com Síndrome de Down e o outro sem a síndrome. A coleta foi realizada em áreas que necessitaram de procedimentos de cunha distal ou gengivectomia interna.

Após o descongelamento, as células, na $8^{a}$ passagem, foram cultivadas em meio Dulbeco`s Modified Eagle Medium (DMEM, Cultilab, Campinas, Brasil), com $10 \%$ de soro fetal bovino (SFB, Cultilab) e 1\% de solução antibiótica antimicótica (Sigma Chemical Company, St. Louis, USA) em um ambiente úmido, a $36,5^{\circ} \mathrm{C}$ e $5 \%$ de dióxido de carbono $\left(\mathrm{CO}_{2}\right)$.

\subsubsection{Grupos experimentais}

O plaqueamento, cultivo e tempos de irradiação serão descritos separadamente para cada experimento. Os grupos experimentais, com 5 réplicas cada, foram divididos em: 
C+ - controle positivo - DMEM 10\% SFB

C- - Controle negativo - DMEM 1\% SFB

LV5 - laser vermelho $-5 \mathrm{~J} / \mathrm{cm}^{2}$

LV8 - laser vermelho $-8 \mathrm{~J} / \mathrm{cm}^{2}$

LIV5 - laser infravermelho - $5 \mathrm{~J} / \mathrm{cm}^{2}$

LIV8 - laser infravermelho - $8 \mathrm{~J} / \mathrm{cm}^{2}$

LED3 - LED 3s

LED5 - LED 5s

A distribuição dos grupos nas placas foi baseada em um teste simples com fotografias da placa no momento da irradiação para verificar o tamanho do halo de luz formado. Foi então padronizada a distância de 2 poços vazios para o laser e 3 para o LED a fim de não haver sobreposição dos halos de luz.

. Placa C+ e C-

$24 \mathrm{~h}$

$48 \mathrm{~h}$

$72 \mathrm{~h}$

96h

$24 \mathrm{~h}$

$48 \mathrm{~h}$

$72 \mathrm{~h}$

96h

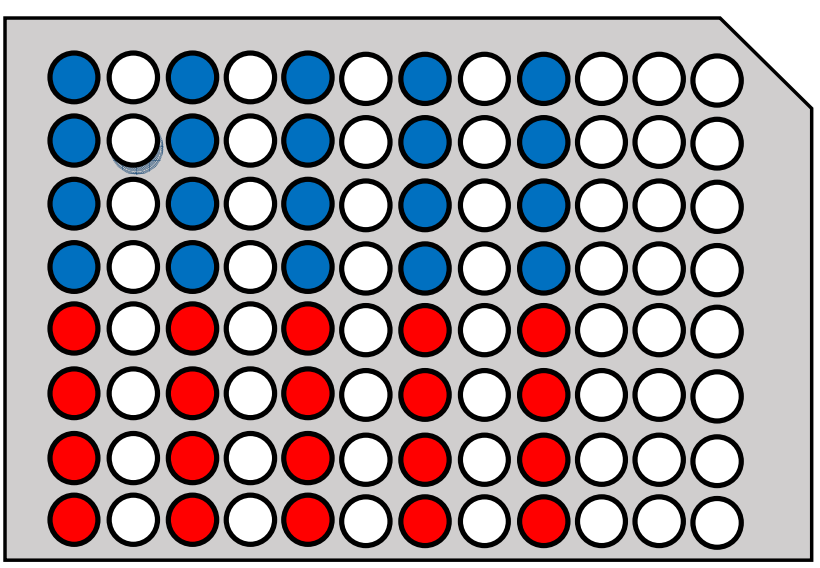

$C+10 \%$ SFB

C- $1 \%$ SFB 
. Placa LV5 e LV8

$5 \mathrm{~J} / \mathrm{cm}^{2}$

$8 \mathrm{~J} / \mathrm{cm}^{2}$
000000000000 000000000000 000000000000 000000000000 000000000000 000000000000 000000000000 000000000000

. Placa LIV5 e LIV8

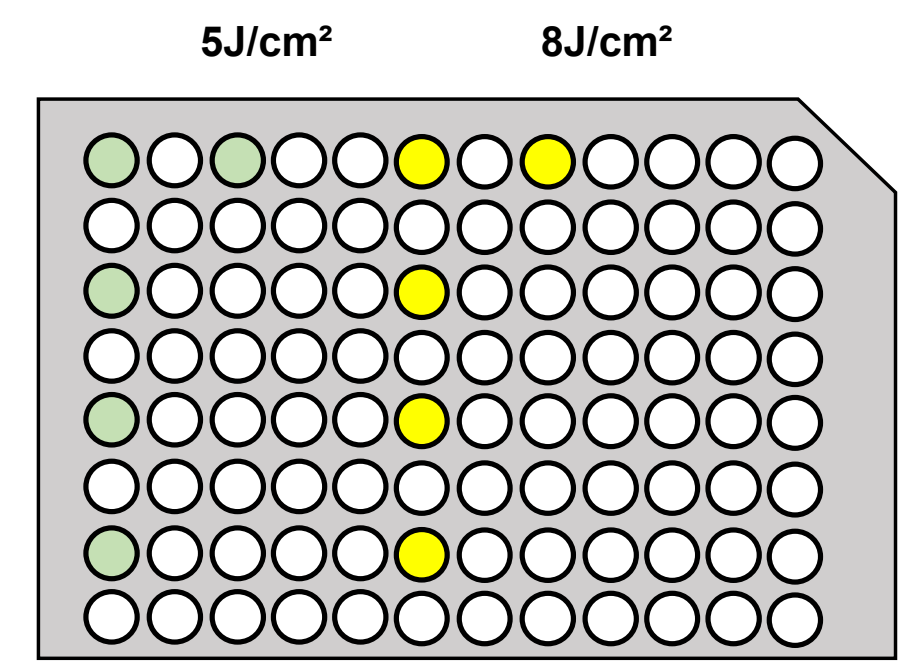

. Placa LED3 e LED5

$3 s$ $5 s$

000000000000 000000000000 000000000000 000000000000 000000000000 000000000000 ○00000000000 000000000000 


\subsection{Fotobiomodulação}

O laser utilizado nesse estudo foi o diodo em baixa intensidade Theralase (DMC - São Carlos-SP) (Fig 1) com comprimento de onda de 810nm (infravermelho próximo) e 660nm (vermelho). O LED foi um protótipo fabricado pelo grupo de Óptica do Instituto de Física de São Carlos (OIFSC) (Fig 2), com comprimento de onda de $637 \pm 15 \mathrm{~nm}$. Os parâmetros de irradiação estão descritos no Quadro 1

A irradiação foi realizada com a ponta em contato com a base da placa e direcionada para o centro do poço. Como há perda de $12 \%$ potência do laser ao atravessar a placa de poliestireno (Damante \& Marques 2014) a potência foi aumentada no aparelho para compensar a perda $(45 \mathrm{~mW})$.

Quadro 1: Descrição dos parâmetros utilizados para o laser vermelho, infravermelho e LED.

\begin{tabular}{|c|c|c|c|c|c|c|c|c|}
\hline & $\begin{array}{c}\text { Potência } \\
\text { real }\end{array}$ & $\Lambda$ & $\begin{array}{l}\text { Meio } \\
\text { ativo }\end{array}$ & $\begin{array}{l}\text { Densidade } \\
\text { de energia }\end{array}$ & Tempo & $\begin{array}{l}\text { Densidade de } \\
\text { potência }\end{array}$ & $\begin{array}{l}\text { Área ponta } \\
\text { Área poço }\end{array}$ & $\begin{array}{c}\text { Energia } \\
\text { total }\end{array}$ \\
\hline Vermelho & $\begin{array}{c}40 \\
\mathrm{~mW}\end{array}$ & $\begin{array}{l}660 \\
\mathrm{~nm}\end{array}$ & $\begin{array}{l}\text { AlGa } \\
\ln P\end{array}$ & $\begin{array}{l}5 \mathrm{~J} / \mathrm{cm}^{2} \\
8 \mathrm{~J} / \mathrm{cm}^{2}\end{array}$ & $\begin{array}{l}3 s \\
5 s\end{array}$ & $\begin{array}{c}1666 \mathrm{~mW} / \mathrm{cm}^{2} \\
126 \mathrm{~mW} / \mathrm{cm}^{2} \\
20 \\
\mathrm{~mW} / \mathrm{cm}^{2}\end{array}$ & $\begin{array}{c}0,024 \mathrm{~cm}^{2}- \\
\text { ponta } \\
0,316 \mathrm{~cm}^{2} \text { - } \\
\text { poço } 96 \\
1,91 \mathrm{~cm}^{2} \text { - } \\
\text { poço } 24\end{array}$ & $\begin{array}{l}0,12 \mathrm{~J} \\
0,2 \mathrm{~J}\end{array}$ \\
\hline $\begin{array}{c}\text { Infra } \\
\text { vermelho }\end{array}$ & $40 \mathrm{~mW}$ & $\begin{array}{l}810 \\
\mathrm{~nm}\end{array}$ & GaAIAs & $\begin{array}{l}5 \mathrm{~J} / \mathrm{cm}^{2} \\
8 \mathrm{~J} / \mathrm{cm}^{2}\end{array}$ & $\begin{array}{l}3 s \\
5 s\end{array}$ & $\begin{array}{c}1666 \mathrm{~mW} / \mathrm{cm}^{2} \\
126 \mathrm{~mW} / \mathrm{cm}^{2} \\
20 \\
\mathrm{~mW} / \mathrm{cm}^{2}\end{array}$ & $\begin{array}{c}0,024 \mathrm{~cm}^{2}- \\
\text { ponta } \\
0,316 \mathrm{~cm}^{2}- \\
\text { poço } 96 \\
1,91 \mathrm{~cm}^{2}- \\
\text { poço } 24\end{array}$ & $\begin{array}{c}0,12 \mathrm{~J} \\
0,2 \mathrm{~J}\end{array}$ \\
\hline LED & $\begin{array}{c}40 \\
\mathrm{~mW}\end{array}$ & $\begin{array}{c}637 \\
\pm 15 \mathrm{~nm}\end{array}$ & & $\begin{array}{l}0,05 \mathrm{~J} / \mathrm{cm}^{2} \\
0,03 \mathrm{~J} / \mathrm{cm}^{2}\end{array}$ & $\begin{array}{l}3 s \\
5 s\end{array}$ & $150 \mathrm{~mW} / \mathrm{cm}^{2}$ & $\begin{array}{c}0,316 \mathrm{~cm}^{2}- \\
\text { poço } 96 \\
1,91 \mathrm{~cm}^{2}- \\
\text { poço } 24\end{array}$ & $\begin{array}{l}0,01 \mathrm{~J} \\
0,009 \mathrm{~J}\end{array}$ \\
\hline
\end{tabular}

* Obs: Para os lasers vermelho e infravermelho apenas o diâmetro da ponta foi levado em consideração para execução dos cálculos, e para o LED apenas o diâmetro do poço. 


\subsection{Experimentos de viabilidade celular}

Para esses experimentos foram plaqueadas $10^{3}$ células em poços determinados nas placas 96 poços conforme o esquema ilustrativo descrito acima. Após $24 \mathrm{~h}$ o meio de cultivo foi trocado por meio DMEM complementado por $1 \% \mathrm{SFB}$ para induzir um estado de quiescência nas células (ALMEIDA-LOPES ET AL, 2001/ DAMANTE ET AL, 2009). Após $24 \mathrm{~h}$ esse meio foi trocado por meio convencional com exceção do grupo controle negativo e imediatamente as diferentes irradiações foram aplicadas. Os grupos controle positivo e negativo não foram irradiados e receberam meio com $10 \%$ e $1 \%$ de SFB, respectivamente. A avaliação da viabilidade celular foi realizada nos períodos de 24,48 e 72 e 96h após as irradiações, sendo utilizadas três placas para cada período experimental. Os grupos controle ficaram em placas separadas, porém, foram levados à capela durante todo o tempo necessário para irradiação das outras placas a fim de que sofressem a mesma variação de temperatura, umidade e luz.

\subsubsection{Teste do MTT}

Os dados do crescimento celular foram obtidos através da análise da viabilidade celular pela atividade mitocondrial das células pelo método da redução do MTT (brometo de 3-(4,5-dimetiltiazol-2-yl)-2,5- difeniltetrazólio) (Mossman, 1983). Esse teste quantifica a conversão do MTT, que é solúvel em água, em cristais de formazan insolúveis (Fig 3). O formazan, de cor azul purpúrea, é solubilizado e, então, sua concentração é determinada pela densidade óptica em espectrofotômetro com filtro de 562nm (Flud flow Optimal囚).

\subsubsection{Teste do cristal violeta}

O corante cristal violeta também foi utilizado para determinar a viabilidade celular devido a sua habilidade de ligação ao DNA. Inicialmente o meio de cultura foi desprezado e cada poço foi lavado com PBS 1\% (solução tampão). Logo após, 100 $\mu l$ da solução de coloração de cristal violeta $(5 \%$ cristal violeta, $1,7 \% \mathrm{NaCl}, 3,3 \%$ paraformaldeído em 33,3\% etanol) foram adicionados aos poços e mantidos por três minutos a temperatura ambiente. Em seguida, os poços foram lavados por duas 
vezes com PBS $1 \%$ e foram acrescentados $200 \mu \mathrm{l}$ de Metanol, por 10 minutos. As placas foram mensuradas no espectrofotômetro, no comprimento de onda de $540 \mathrm{~nm}$ (Flud flow Optimal®).

\subsection{Ensaio de cicatrização de feridas in vitro}

A capacidade de migração dos fibroblastos gengivais de pacientes com e sem SD, submetidas ou não ao tratamento de LED e Laser, foi realizada através de um protocolo in vitro de cicatrização de feridas (HOANG; OATES; COCHRAN, 2000). Após 72h do cultivo celular (tempo necessário para preenchimento de cada poço da placa de 24 poços), indução do estado de quiescência e troca dos meios, uma ferida in vitro foi criada, utilizando-se uma ponteira de $5 \mathrm{ml}$. Em seguida as células foram irradiadas com os mesmos protocolos de irradiação descritos anteriormente. Como nesse ensaio foi utilizada uma placa de 24 poços, a irradiação foi pontual no centro da placa no local da "ferida" criada com a pipeta. A migração celular foi avaliada nos períodos de 12, 24, 36 e $48 \mathrm{~h}$.

A análise de migração dos fibroblastos para a área central da ferida foi realizada por fotografias obtidas através de uma câmera acoplada ao microscópio invertido (OLYMPUS CKX41TR obtido através do processo FAPESP 2014/ 052342). As áreas das feridas foram analisadas em microscópico óptico (Olympus BX51, Miami, FL, EUA) equipado com câmera com câmera fotográfica (OLYMPUS c 5060) e submetidas à análise por software Image J (Wayne Rasband, National Institute of Mental Health, EUA) através da mensuração da área da "ferida" (BASSO et al.,2012).

\subsection{Análises estatística}

Os dados de viabilidade celular medidos em densidade óptica (DO) foram analisados e submetidos ao teste ANOVA de medidas repetidas complementado pelo teste de Tukey. Não foi necessário a utilização do teste de normalidade, pois o 
teste ANOVA de medidas repetidas representa o teste não paramétrico mais sensível.

As medidas de área de cobertura das células foram transformadas em porcentagem para permitir comparação entre os grupos. Após isso, foram avaliadas pelo teste ANOVA de medidas repetidas complementado pelo teste de Tukey.

Todos os testes foram realizados adotando-se um nível de significância de $5 \%(p<0,05)$

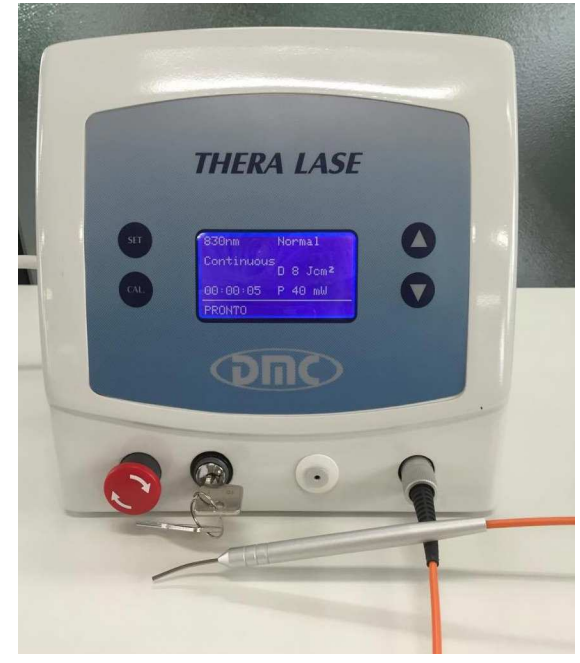

Figura 1: Laser de baixa intensidade

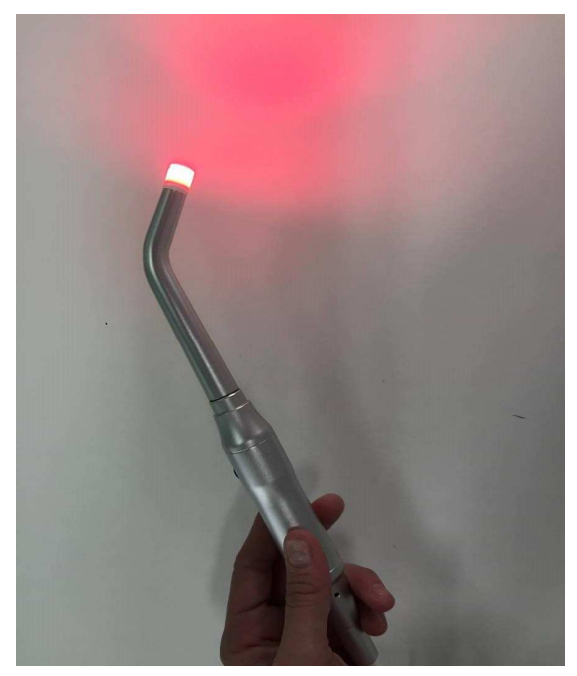

Figura 2: LED vermelho (protótipo OIFSC)

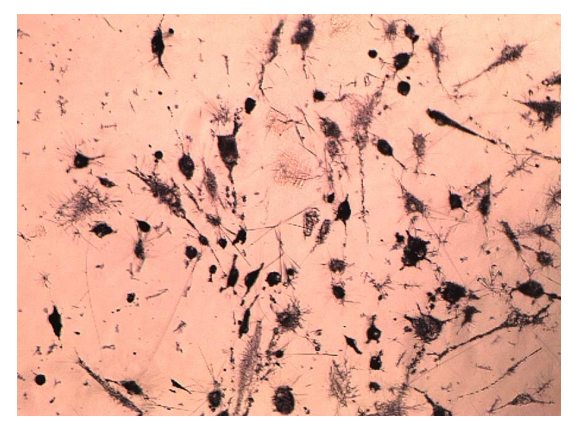

Figura 3: Cristais de Formazam do teste MTT (LED5 72h) 



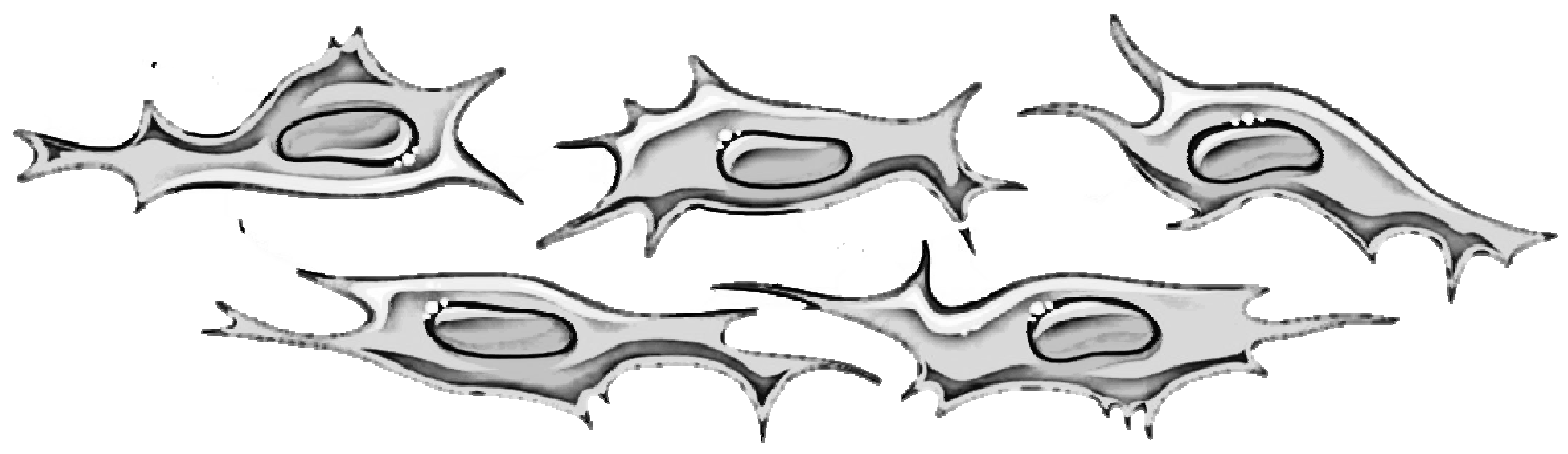

$\underline{5 \text { Resultados }}$ 



\section{RESULTADOS}

Os resultados do experimento comparando os tipos celulares, períodos e grupos experimentais, estão em tabelas no Apêndice A e B. Com o propósito de facilitar a descrição dos resultados mais relevantes neste capítulo, os mesmos serão divididos e descritos conforme o tipo celular, o ensaio colorimétrico e ensaio de cicatrização in vitro. Inicialmente os grupos experimentais foram comparados aos grupos controles, e em seguida foram comparados entre si no período final de $96 \mathrm{~h}$. Esta última comparação foi ilustrada através de esquemas para interpretação mais dinâmica dos resultados.

\subsection{FGH Cristal violeta}

\subsubsection{Comparação dos grupos em relação aos grupos controle e entre si} (96h)

A figura 4 mostra os resultados da análise de viabilidade celular por cristal violeta das células FGH. Com exceção dos grupos LIV8 e LV8, todos os grupos quando comparados ao $\mathrm{C}+$ mostraram um aumento, em algum período, da viabilidade celular estatisticamente significante para os grupos experimentais $(p<0,05)$. O grupo LV8 não apresentou diferença estatística em relação ao $\mathrm{C}+$. Entretanto, nos períodos de 48h e 96h, o grupo LIV8 apresentou menor viabilidade celular $(p<0,05)$, em relação ao grupo $\mathrm{C}+$, com valores bem próximos de zero.

Quando comparados com o C-, os grupos experimentais apresentaram maiores valores $(p<0,05)$, em algum período, com exceção do grupo LIV8. Ao comparar o LIV8 verificou-se que três dos quatro períodos (24,48 e 96h) obtiveram resultados menores que o $\mathrm{C}$ - $(p<0,05)$, sendo que o período de $72 \mathrm{~h}$ não apresentou diferença estatística. Em relação ao período final de $96 \mathrm{~h}$, apenas o grupo LV5 apresentou resultados maiores que o $\mathrm{C}+(p>0,05)$. Os grupos LIV5, LV8, LED3 e LED5 não apresentaram diferença estatística em relação ao C+. 


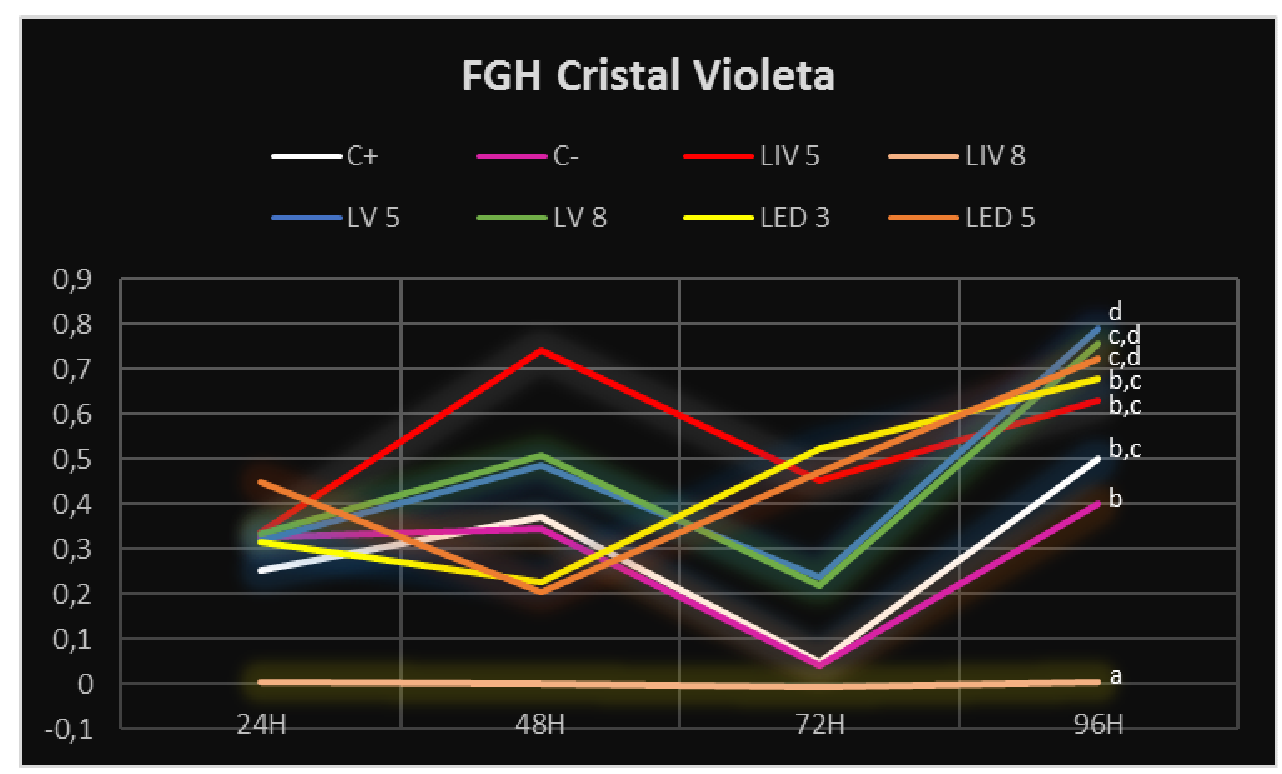

Figura 4: Gráfico de viabilidade celular por Cristal Violeta do FGH. Letras diferentes $=(p<0,05)$, descrito apenas para o período de $96 \mathrm{~h}$.

Um resumo dos resultados no período de $96 \mathrm{~h}$, o qual seria o mais significante, está descrito abaixo em forma de esquema:

$$
\begin{aligned}
& . \text { LV5 }=\text { LV8 = LED5 = LED3 = LIV5 = C+ = C- > LIV8 } \\
& . \text { LV5 }>\text { C+ }
\end{aligned}
$$

\subsection{FGH MTT}

\subsubsection{Comparação dos grupos em relação aos grupos controle e entre si} (96h)

A figura 5 mostra que em todos os grupos experimentais, na maioria dos períodos analisados, não houve diferença estatística entre os grupos e o $\mathrm{C}+$. $\mathrm{O}$ grupo LIV8 apresentou, em todos os períodos, valores menores que o $C+(p<0,05)$.

Em relação ao C-, os grupos LED3, LV8 e LV5 apresentaram maiores valores de viabilidade celular $(p<0,05)$. Todavia, o grupo LIV8, nos períodos de $48 \mathrm{~h}$ e $96 \mathrm{~h}$, apresentou menores valores quando comparado ao C- $(p<0,05)$, e nos períodos de $24 \mathrm{~h}$ e $72 \mathrm{~h}$ não houve diferença estatística. No período final de $96 \mathrm{~h}$ os grupos $\mathrm{C}$, LIV5 e LIV8 apresentaram valores significantemente menores que o $C+(p<0,05)$. 


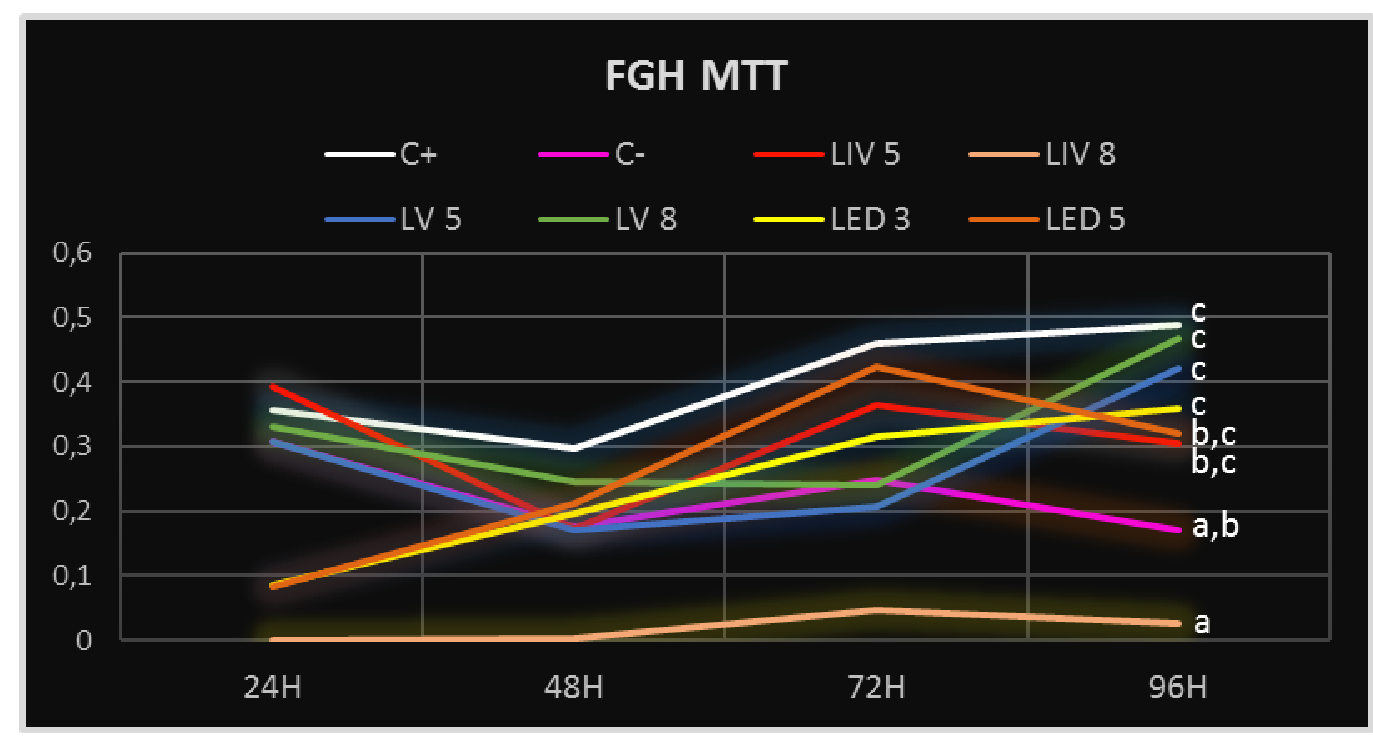

Figura 5: Gráfico de viabilidade celular por MTT do FGH. Letras diferentes $=p<0,05$, descrito apenas para o período de $96 \mathrm{~h}$.

- Um resumo dos resultados no período de $96 \mathrm{~h}$, o qual seria o mais significante, está descrito abaixo em forma de esquema:

$$
\text { LV8 = LV5 = LED3 = LED5 = LIV5 = C+ > C }-=\text { LIV8 }
$$

\subsection{FSD Cristal violeta}

\subsubsection{Comparação dos grupos em relação aos grupos controle e entre si} (96h)

$\mathrm{Na}$ figura 6, os grupos experimentais quando comprados ao grupo $\mathrm{C}+$ observa-se que, com exceção do grupo LIV8, todos os outros mostraram valores maiores que o $\mathrm{C}+(p<0,05)$ em pelo menos um período. O grupo LIV8 apresentou um valor estatisticamente menor, em relação ao $C+$, no período de $24 h(p<0,05)$. Nos demais períodos não houve diferença significante $(p>0,05)$.

Em relação ao C-, todos os grupos mostraram valores estatisticamente maiores, com exceção do grupo LIV8, que nos períodos de 48, 72 e 96h não apresentou diferença estatística. No período de 24h, LIV8 apresentou menor valor 
$(p<0,05)$ que o C-. No período final de 96h os grupos LV5, LV8, LIV5, LED3 e LED5 apresentaram resultados maiores que o $C+(p<0,05)$.

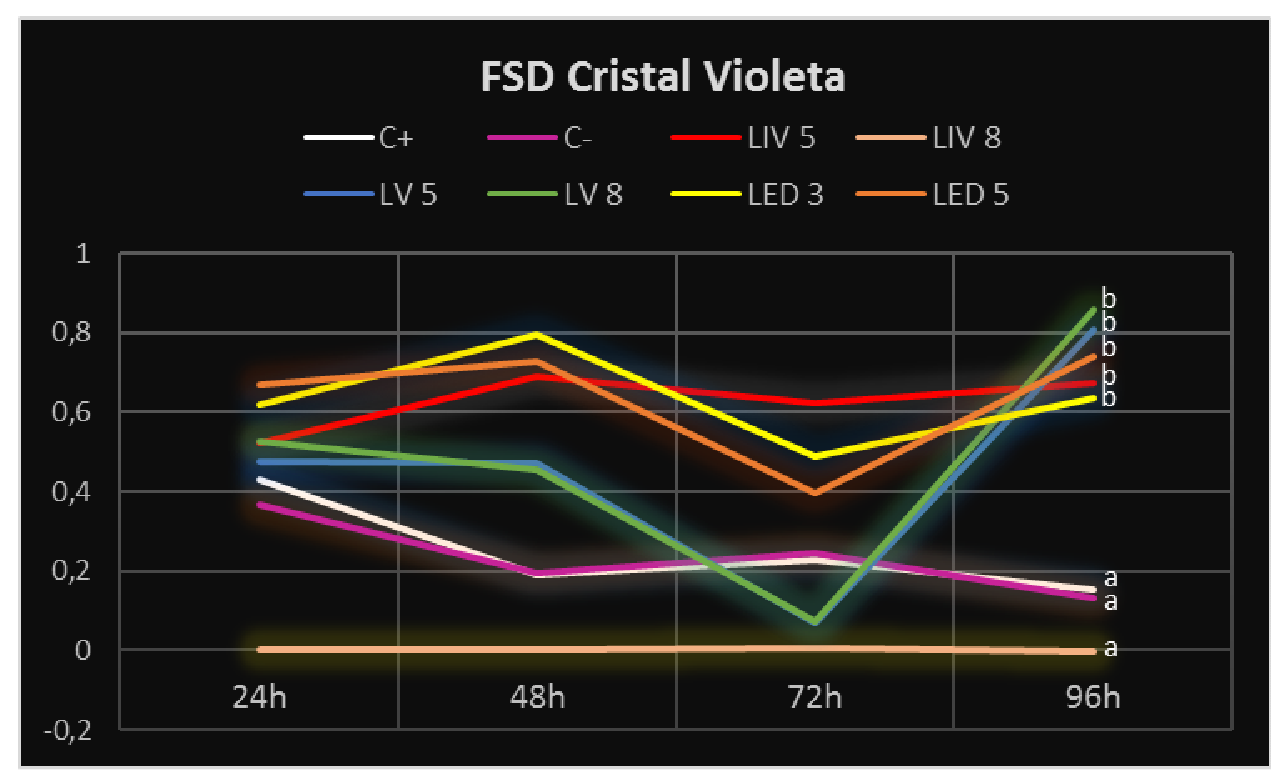

Figura 6: Gráfico de viabilidade celular por Cristal Violeta do FSD. Letras diferentes $=p<0,05$, descrito apenas para o período de $96 \mathrm{~h}$.

- Um resumo dos resultados no período de 96h, o qual seria o mais significante, está descrito abaixo em forma de esquema:

$$
\text { LV8 = LV5 = LED5 = LIV5 = LED3 > C }+=\text { C }-=\text { LIV8 }
$$

\subsection{FSD MTT}

\subsubsection{Comparação dos grupos em relação aos grupos controle}

Na figura 7 observou-se que os grupos experimentais, quando comparados com o C+, os grupos LED3, LED5 e LIV5 obtiveram diferença estatística superior $(p>0,05)$. Entretanto, os grupos LIV8, LV5 e LV8, em algum período, apresentaram resultados sem diferença estatística em relação ao $\mathrm{C}+(p<0,05)$. Em relação ao $\mathrm{C}-$, o grupo LIV8 apresentou, em todos os períodos, resultados significantemente menores 
$(p<0,05)$. Todos os grupos experimentais foram maiores, em algum período, em relação ao C- $(p>0,05)$.

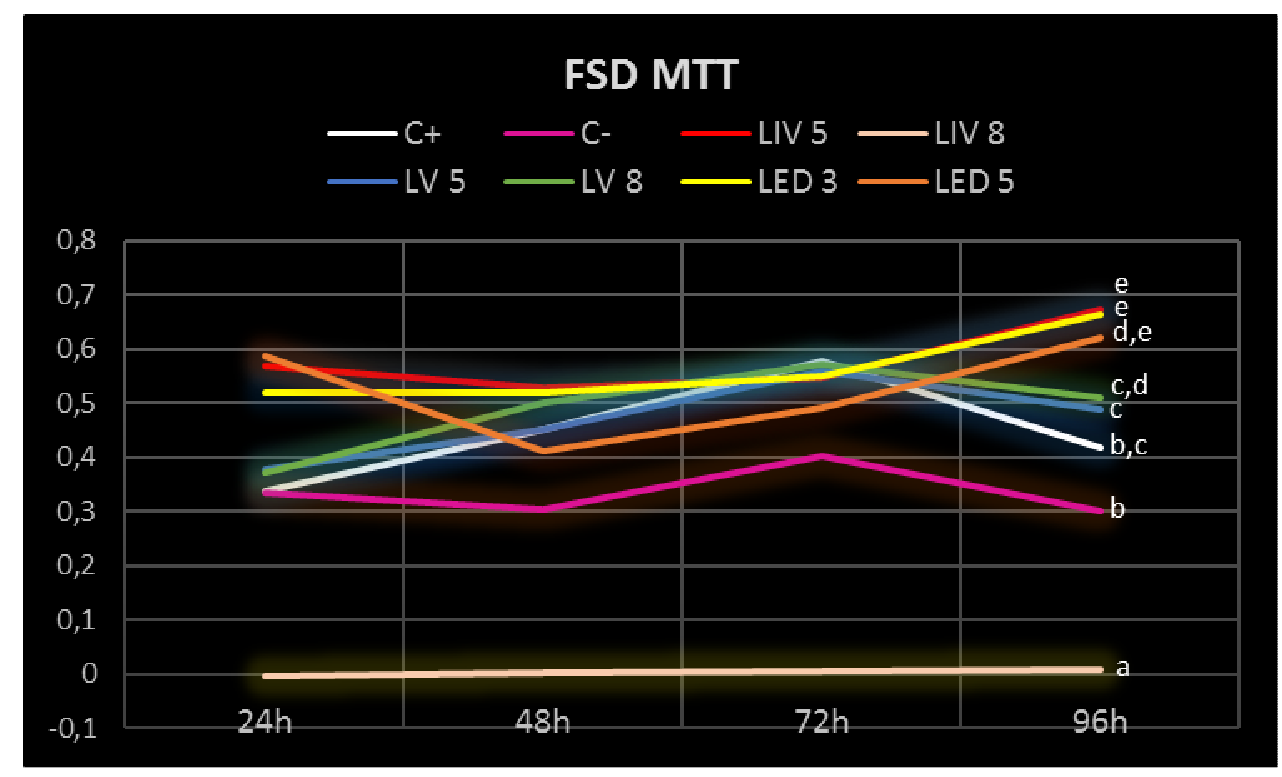

Figura 7: Gráfico de viabilidade celular por MTT do FSD. Letras diferentes $=p<0,05$, descrito apenas para o período de $96 \mathrm{~h}$.

- Um resumo dos resultados no período de 96h, o qual seria o mais significante, está descrito abaixo em forma de esquema:

$$
\text { LIV5 = LED3 = LED5 > C+ = LV8 = LV5 = C- > LIV8 }
$$

\subsection{Ensaio de cicatrização de feridas in vitro}

A figura 8 mostra a migração celular de 3 grupos experimentais (C+ FSD, LIV5 FSD e LIV5 FGH), nos 5 períodos (0h, 12h, 24h, 36h e 48h). Nesta figura foi possível observar que nos grupos LIV5 FSD e LIV5 FGH, houve preenchimento da ferida no período de $36 \mathrm{~h}$. No grupo C+ FSD, o preenchimento ocorreu em $48 \mathrm{~h}$.

Em relação aos dados estatísticos, o pós teste de Tukey mostrou interações significantes apenas para: Tratamento vs. tipo de Célula e Período vs. tipo de célula. Portanto, os resultados serão apresentados em gráficos diferentes. 
A figura 9 mostra os efeitos de cada grupo experimental para cada tipo celular. Pode se observar que para as células FGH, apenas o grupo LIV 5 foi melhor que o controle positivo $(p<0,05)$, sendo que todos os outros grupos foram semelhantes ao $C+(p>0,05)$. Para as células FSD os grupos LV5, LV8, LED3, LED5 e LIV5 mostraram preenchimento maior da ferida em relação ao controle positivo $(p<0,05)$. O controle negativo e o LIV8 foram iguais ao controle positivo $(p>0,05)$.

A figura 10 mostra o preenchimento da ferida ao longo do tempo para as diferentes células. Nota-se que a fotobiomodulação foi mais efetiva no preenchimento pelos FSD, nos períodos de 24 e 36h, com diferenças estatisticamente significantes para os $\mathrm{FGH}(\mathrm{p}<0,05)$. Ao final das $48 \mathrm{~h}$ ambas as células mostraram preenchimento semelhante estatisticamente $(p>0,05)$, porém nota-se que FSD atingiu $100 \%$ de preenchimento enquanto que $\mathrm{FGH}$ atingiu apenas $95,4 \%$. 


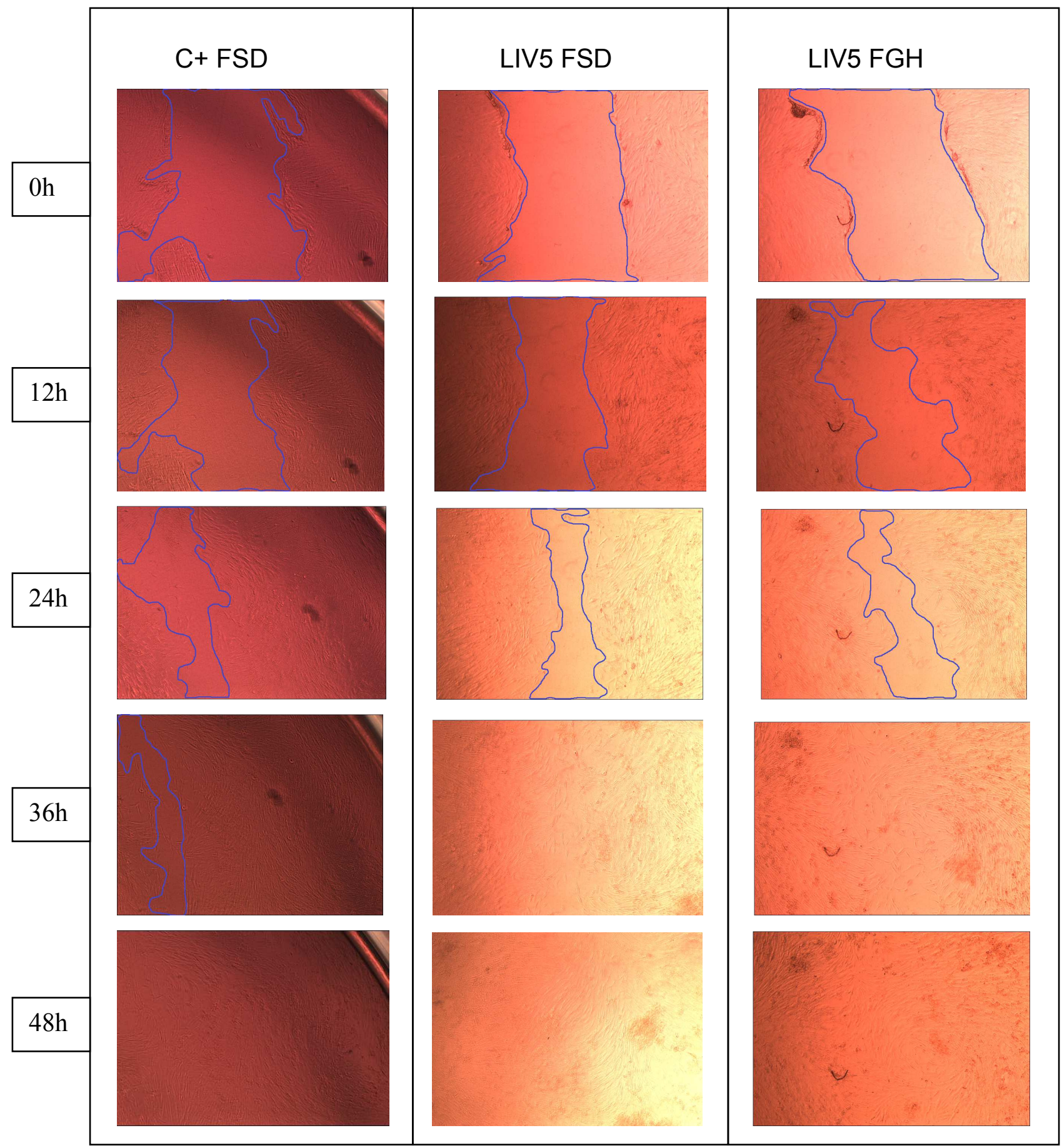

Figura 8 - Fotografias tiradas no ensaio de cicatrização de feridas in vitro. Os grupos LIV5 FSD e LIV5 FGH apresentaram mais rápido preenchimento celular quando comparados ao C+ FSD. 


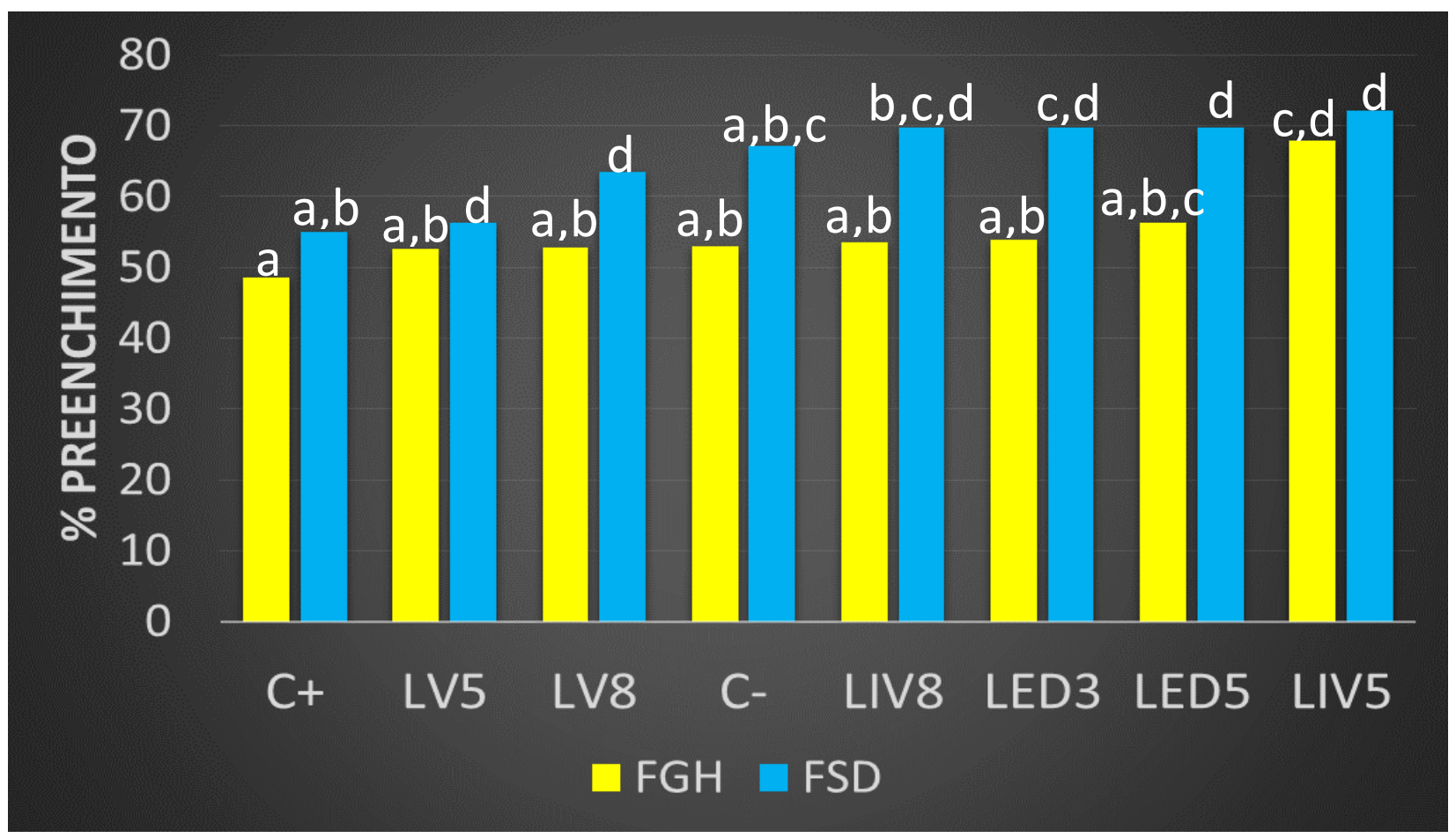

Figura 9 - Gráfico mostrando preenchimento da ferida in vitro (em \%) pelos dois tipos celulares ao longo do tempo. Letras diferentes $=p<0,05$. Abaixo segue a representação em forma de esquema.

FGH: LIV5 > C+ = C- = LIV8 = LIV5 = LV5 = LV8 = LED3 = LED5

FSD: $\quad$ LV5 = LV8 = LED3 = LED5 = LIV5 > C+ = C $-=$ LIV8

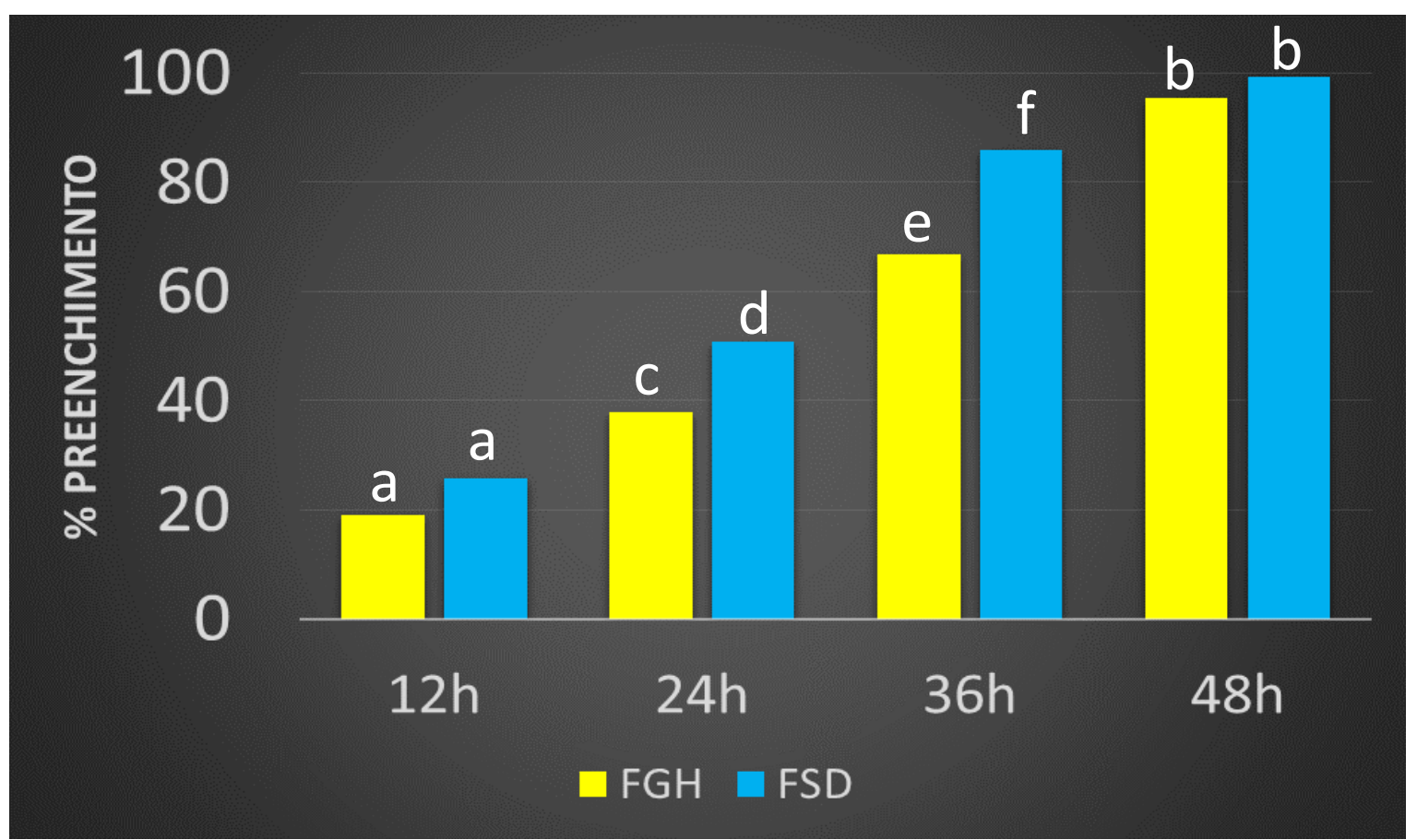

Figura 10 - Gráfico mostrando preenchimento da ferida in vitro (em \%) pelos dois tipos celulares após os diversos tratamentos. Letras diferentes $=p<0,05$. 


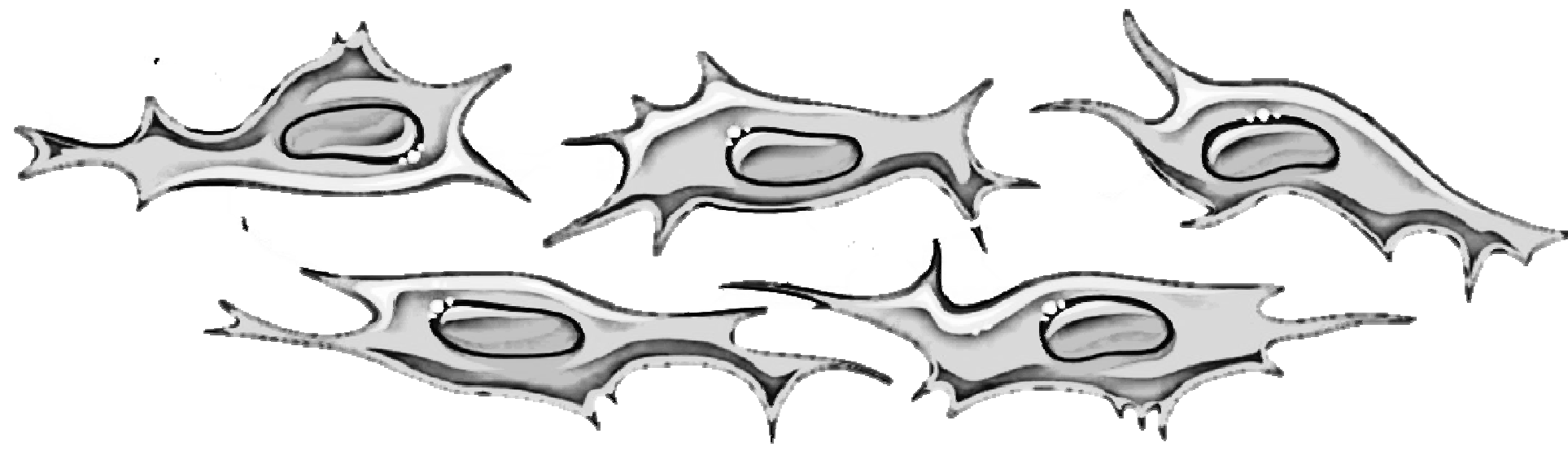

6 Discussão 



\section{DISCUSSÃO}

No presente estudo observou-se que o efeito da fotobiomodulação em culturas de fibroblastos gengivais humanos, com e sem SD, foi positivo tanto para a utilização de Laser como para o LED. Entretanto, um importante achado desta pesquisa foi de que possivelmente uma alta dosagem de energia $\left(8 \mathrm{~J} / \mathrm{cm}^{2}\right)$ e/ou tempo de exposição (5s), no grupo de Laser infravermelho, inviabilizou a proliferação de fibroblastos, com valores de crescimento celular bem próximos de zero.

Os parâmetros do Laser utilizados no presente estudo foram baseados na metodologia empregada por Damante et al, 2009, utilizando-se energia total de 0,12 e 0,2 J tanto para o laser vermelho quanto para o infravermelho. Os parâmetros do LED foram calculados de acordo com as especificações do próprio fabricante, considerando-se o diâmetro do poço como área irradiada, com aplicação pontual, (Quadro 1).

$\mathrm{Na}$ literatura existe uma divergência de resultados, sendo que em alguns estudos a fotobiomodulação por Laser vermelho visível apresentou melhores resultados (LOEVSCHALL et al.,1994; LUBART et al.,1992; YOUNG, BOTTON, 1992), e outros estudos apontam o Laser infravermelho como melhor fotobiomodulador (DAMANTE et al., 2009; ALMEIDA-LOPES et al., 2001). Na presente pesquisa, de maneira geral, não houve diferença estatística dos grupos experimentais entre si, com exceção do grupo infravermelho $\left(8 \mathrm{~J} / \mathrm{cm}^{2}\right)$, no qual apresentou os piores resultados de viabilidade celular.

No estudo de Almeida-Lopes et al.2001, os autores verificaram que o tempo de exposição poderia ser um fator importante no crescimento celular. De acordo com o estudo, em uma mesma densidade de energia e potência, não houve diferença estatística entre laser infravermelho e vermelho. Todavia, quando utilizaram a mesma densidade de energia $\left(2 \mathrm{~J} / \mathrm{cm}^{2}\right)$ e diferentes potências $(10 \mathrm{~mW}$ e $50 \mathrm{~mW})$, modificando assim os tempos de exposição (menor tempo para maior potência), o Laser infravermelho $(50 \mathrm{~mW})$ obteve melhores resultados. 
As energias totais utilizadas no presente estudo $(0,12$ e $0,2 \mathrm{~J})$ foram fixadas em uma mesma potência $(40 \mathrm{~mW})$ obtendo-se, portanto, diferentes tempos de exposição (3s e 5s). O grupo LIV5 (3s) apresentou viabilidade celular. Todavia, para o grupo LIV8 (5s), o resultado obtido foi de muito pouco ou nenhum crescimento celular. Esses achados corroboram, em partes, com o estudo de Almeida-Lopes et al (2001), no qual o tempo de exposição parece influenciar na viabilidade celular. Entretanto, os autores mostraram que sob potências iguais, o Laser infravermelho obteve os melhores resultados. Não obstante, em nosso estudo, não houve predileção pelo tipo de Laser (vermelho ou infravermelho), em uma mesma potência.

O estudo de Azevedo et al,2006, mostrou que uma elevada densidade de potência pode acarretar em menor viabilidade celular. De acordo com o nosso estudo, elevadas densidades de potência não parecem influenciar nos resultados, pois apresentaram crescimento celular. Todavia, em cultura de células, as doses totais de energia devem ser baixas, uma vez que não há interferência de tecidos, sangue, substância fundamental amorfa, entre outros (Hamblin MR, Huang Y. Handbook of Photomedicine). Dessa forma, comparando as doses de energia total do presente estudo $(0,12 \mathrm{~J}$ e $0,2 \mathrm{~J})$ com as doses do estudo de Azevedo et al,2006 $(0,13 \mathrm{~J}$ e $0,14 \mathrm{~J})$, podemos observar que possivelmente a energia total também possa ser um fator crucial para a viabilidade celular.

É importante ressaltar que a área da ponta do Laser ou LED influencia na determinação de seus parâmetros. Os lasers mais recentes possuem pontas menores, o que resulta em uma maior densidade de potência por serem fatores inversos. Logo, o sucesso da fotobiomodulação é dependente da combinação de todos os parâmetros, como comprimento de onda, densidades de energia e potência, bem como a área e número de aplicações de Laser ou LED. Conforme o parágrafo anterior, talvez a medida da energia total em Joules seja um parâmetro mais fiel uma vez que seu valor pode ser obtido multiplicando-se o tempo pela potência e não dependente dos vários diâmetros das pontas ativas de cada fabricante.

Possivelmente, devido ao grande número de variáveis dos parâmetros e aos diferentes tipos de agentes fotobiomoduladores, não há na literatura um consenso sobre quais os melhores parâmetros a serem utilizados na terapia de 
fotobiomodulação. Em uma recente revisão sistemática, os autores concluíram que não existe estabelecido, ainda, um protocolo para a terapia de fotobiomodulação. Entretanto, os autores verificaram melhores resultados na associação de Laser vermelho com infravermelho (LIMA et al., 2015).

Os nossos resultados também mostram que não houve diferença entre os grupos LED e Laser. A utilização de LED no presente estudo não inviabilizou o crescimento celular de fibroblastos com e sem SD. Todavia, para as células de pacientes com SD, tanto o grupo LED3 como o grupo LED5 mostraram melhor viabilidade celular. Relacionando a comparação da fotobiomodulação em células de pacientes saudáveis com células de pacientes com algum problema sistêmico, podemos dizer que o nosso resultado se assemelha ao resultado de Susana et al, 2012, nos quais o LED $\left(700 \mathrm{~nm}, 15 \mathrm{~mW}, 10 \mathrm{~J} / \mathrm{cm}^{2}\right)$, apresentou maior crescimento celular no grupo de fibroblastos anêmicos, em relação aos fibroblastos de ratos não anêmicos.

Via de regra, as pesquisas mostram que o LED possui semelhante ação ao Laser na terapia de fotobiomodulação, sendo que alguns estudos justificam a utilização do LED devido ao seu menor custo financeiro, portabilidade e segurança (FUSHIMI et al., 2012; TADA et al., 2009). Todavia, essas informações não condizem com o atual mercado Brasileiro, no qual o LED não é facilmente encontrado, sendo que provavelmente o único LED comercializado no Brasil seja o LED azul, o qual possui igual ou maior custo financeiro quando comparado ao Laser. É por este motivo, que provavelmente muitas pesquisas são realizadas com protótipos de LED, iguais ao protótipo utilizado na presente pesquisa. Em relação a portabilidade, cada vez mais os equipamentos de Laser estão ficando menores e mais potentes, tendo também fácil manuseio.

Os testes de viabilidade celular empregados nesta pesquisa foram testes colorimétricos, que possuem diferentes mecanismos de ação em nível celular. $O$ teste MTT atua nos mecanismos de respiração celular, através da redução do sal tetrazolato pela enzima hidrogenase succínica presente na mitocôndria das células, adquirindo uma coloração arroxeada que é mensurada por espectrofotometria (BERRIDGE \& TAN, 1993). O corante cristal violeta também é mensurado no espectrofotômetro, utilizado para determinar a viabilidade celular devido a sua 
habilidade de ligação ao DNA, obtendo uma informação quantitativa sobre a densidade relativa de células vivas aderidas na placa de cultura (HENRIKSSON et al., 2006). No presente estudo, optamos por avaliar a viabilidade celular através desses dois tipos de testes, justamente por apresentarem diferentes mecanismos de ação, sugerindo talvez uma possível diferenciada ação do Laser vermelho, infravermelho ou LED. Também aventamos a possibilidade de o teste do MTT que mede atividade mitocondrial, ser influenciado pela fotobiomodulação que ocorre também em nível mitocondrial. Todavia, não foi possível estabelecer nenhuma correlação, sendo que os 3 tipos de agentes fotobiomoduladores apresentaram resultados variáveis tanto para o MTT quanto para o Cristal violeta.

O ensaio de cicatrização de feridas in vitro mostrou que a fotobiomodulação foi eficaz no fechamento da ferida, com maior efeito nas células de pacientes com Síndrome de Down. Uma hipótese para tal achado, seria de que pacientes com síndrome de Down possuem significativas alterações imunológicas, que por sua vez dificultam o processo de cicatrização dos tecidos gengivais, o que acarreta em uma alta prevalência da DP (KOMATSU et al., 2001; COSSARIZZA et al., 1990; LIN et al., 2001). Logo, o efeito de uma terapia adjuvante poderia apresentar melhores resultados, justamente por lidar com um indivíduo que geneticamente possui déficit em seu mecanismo de defesa. Para os FSD, os melhores resultados foram obtidos com todas as terapias menos o LIV8 que não apresentou diferenças em relação aos controles, o que seguiu um certo padrão em relação ao ensaio de viabilidade celular. Porém, para as células FGH, o melhor grupo foi o LIV5, não seguindo o padrão do ensaio anterior. Ainda assim, podemos afirmar que a fotobiomodulação em geral auxiliou no fechamento da ferida in vitro. Vale a pena ressaltar, que no ensaio anterior o grupo LIV8 inibiu a viabilidade celular, enquanto que nesse, ele apenas foi semelhante ao controle positivo, não exercendo então, um efeito inibitório. No presente estudo, os dois tipos de LED foram eficazes no ensaio de cicatrização de feridas, apresentando mais rápido preenchimento da ferida. Este resultado corrobora com o estudo de Park \& Hong (2014), o qual mostrou que o LED preencheu a ferida em menos tempo que os controles.

A revisão de literatura do presente estudo foi realizada através de uma metodologia sistemática, no qual foram obtidos 759 artigos de sobre laser e feridas, sendo 115 em ratos, 16 estudos em ratos diabéticos e 3 estudos em ratos anêmicos. 
Em relação ao efeito da fotobiomodulação em pacientes com SD, nenhum artigo foi encontrado, evidenciando assim, uma falta de estudos na literatura com pacientes com SD. Dessa forma, as evidências do presente estudo são inéditas e de grande valor para a comunidade científica.

Não foi possível concluir o melhor parâmetro de aplicação, já que houve variações entre os testes colorimétricos, entre os tipos celulares e na cicatrização de feridas in vitro, porém em linhas gerais, os lasers pareceram melhores para os fibroblastos de pacientes não sindrômicos. Por outro lado, as células de pacientes com síndrome de Down responderam a todos os outros protocolos de aplicação incluindo o LED. O único protocolo com resultados ruins foi o LIV8 para ambas as células.

De acordo com a revisão sistemática de Lima et al (2015), a associações do laser infravermelho com o vermelho mostrou o melhor resultado de viabilidade celular. Como no presente estudo todas as terapias utilizadas apresentaram crescimento celular sugerimos que, em estudos futuros, mais associações sejam feitas, incluindo o LED, a fim de se investigar melhor tais interações.

A terapia de fotobiomodulação apresenta ser um importante tratamento adjuvante. Entretanto, devido as alterações sistêmicas e possíveis dificuldades locomotoras e mentais, os pacientes com SD necessitam de maior atenção e cuidado, sendo assim, de extrema importância à adição de terapias adjuvantes no tratamento desses pacientes. Outro importante fator a ser considerado é de que a expectativa de vida dos pacientes com SD aumentou consideravelmente nas últimas décadas, resultando no aumento populacional desses pacientes. O presente estudo mostrou, in vitro, que em fibroblastos de pacientes com SD, a fotobiomodulação foi efetiva. Dessa forma, o estabelecimento de um protocolo clínico deve ser melhor investigado. 



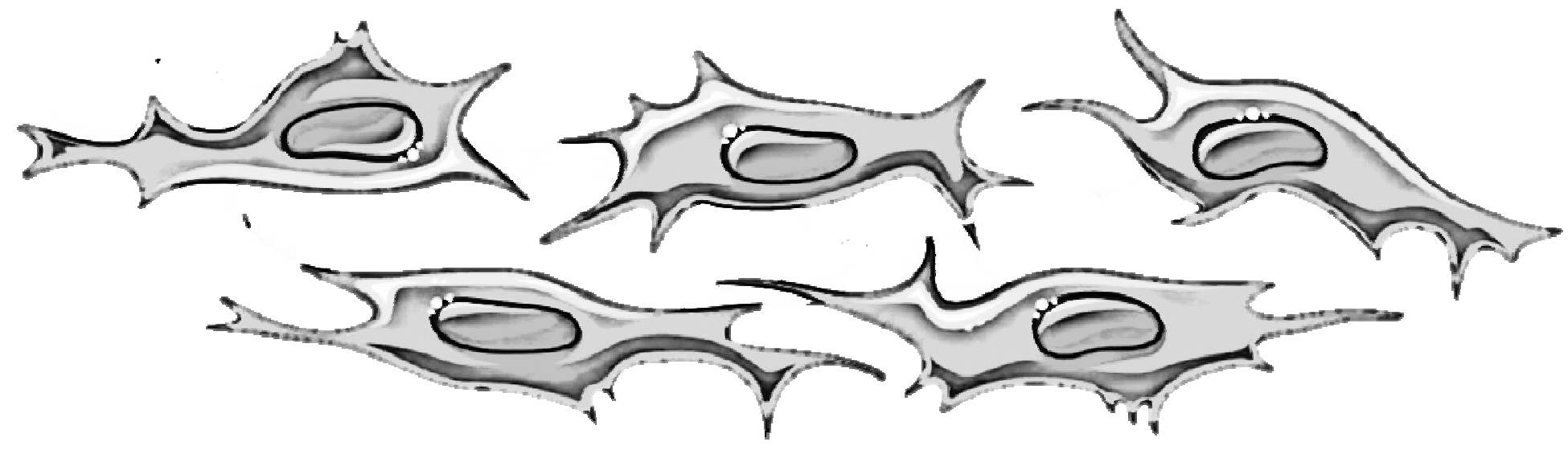

\section{Conclusões}





\section{CONCLUSÕES}

Diante dos resultados pôde-se concluir que a fotobiomodulação tanto com lasers quanto com LED aumenta a viabilidade de fibroblastos gengivais de pacientes com e sem síndrome de Down. Houve variação entre os parâmetros aplicados, sendo que o laser infravermelho numa densidade de energia mais alta, inibiu a viabilidade de ambas as linhagens. Não houve efeito da terapia, nem de estímulo, nem de inibição da migração celular, no ensaio de cicatrização de feridas in vitro. 


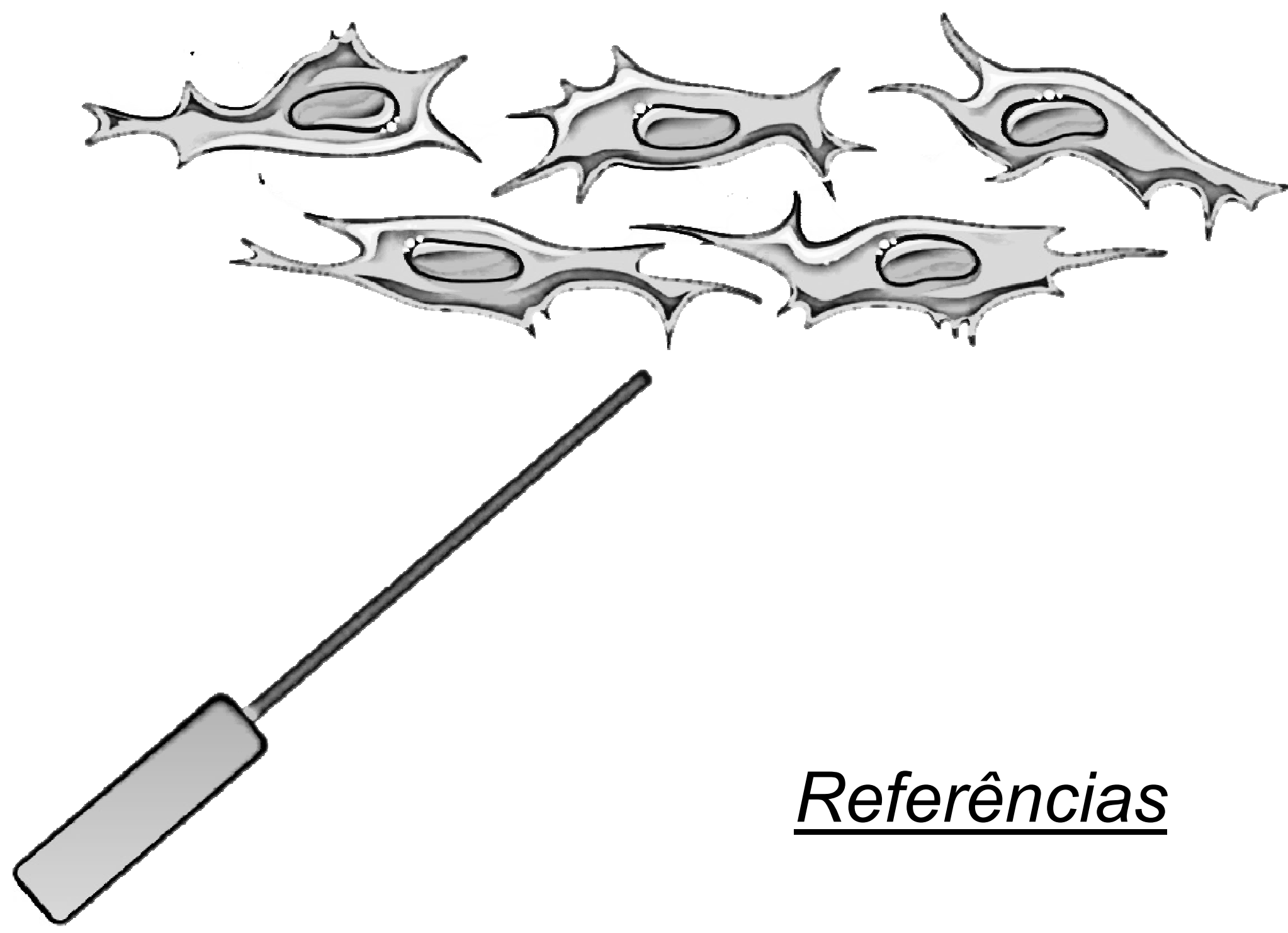



\section{REFERÊNCIAS}

ABERGEL, R.P.; GLASSBERG, E.; UITTO, J. Increased wound-healing rate in pigskin treated by helium-neon laser. Inte Soc Opti Eng Proc. 1988:6-10.

ALMEIDA-LOPES, L.; RIGAU, J.; ZANGARO, R. A.; GUIDUGLI-NETO, J.; JAEGER, M. M. Comparison of the low level laser therapy effects on cultured human gingival fibroblasts proliferation using different irradiance and same fluence. Lasers Surg Med, v. 29, n. 2, p. 179-184, 2001.

ANDERS, J. J.; LANZAFAME, R. J.; ARANY, P. R. Low-level light/laser therapy versus photobiomodulation therapy. Photomed Laser Surg, v. 33, n. 4, p. 183-184, 2015.

AZEVEDO, L. H.; DE PAULA EDUARDO, F.; MOREIRA, M. S.; DE PAULA EDUARDO, C.; MARQUES, M. M. Influence of different power densities of LILT on cultured human fibroblast growth : a pilot study. Lasers Med Sci, v. 21, n. 2, p. 8689, 2006.

BARR-AGHOLME, M.; KREKMANOVA, L.; YUCEL-LINDBERG, T.; SHINODA, K.; MODEER, T. Prostaglandin E2 level in gingival crevicular fluid from patients with Down syndrome. Acta Odontol Scand, v. 55, n. 2, p. 101-105, 1997.

BARRENA, M. J.; ECHANIZ, P.; GARCIA-SERRANO, C.; ZUBILLAGA, P.; CUADRADO, E. Differential expression of lymphocyte function-associated antigen (LFA-1) on peripheral blood leucocytes from individuals with Down's syndrome. Clin Exp Immunol, v. 88, n. 1, p. 41-44, 1992.

BERRIDGE, M. V.; TAN, A. S. Characterization of the cellular reduction of 3-(4,5dimethylthiazol-2-yl)-2,5-diphenyltetrazolium bromide (MTT): subcellular localization, substrate dependence, and involvement of mitochondrial electron transport in MTT reduction. Arch Biochem Biophys, v. 303, n. 2, p. 474-482, 1993.

BIHARI, J; MESTER, A,R. The biostimulative effect of low level laser therapy on longstanding crural ulcers using helium-neon laser, helium-neo laser plus infrared lasers, and noncoherent light: preliminary report of a randomised double blind comparative study. Laser Therapy 1989; 1:97.

BOLTON, P; YOUNG, S; DYSON, M. Macrophage responsiveness to light therapy with varying power and energy densities. Laser Therapy 1991;2:105-111. 
BORGES-OSORIO, M. R.; ROBINSON, W. M. As bases cromossômicas da hereditariedade: alterações cromossômicas. Genética humana. 2.ed. Porto Alegre: Artmed; 2002. p. 68-115.

CARTER, C,O; HAMERTON, J,L; POLANI, P,E; GUNALP, E; WELLER, S,D. Chromossome translocation as a cause of familial mongolism. Lancet 2. 1960:27880 .

CAVALCANTE, L,B; Pires, J,R; SCAREL-CAMINAGA, R,M. Doença periodontal em indivíduos com Síndrome de Down: enfoque genético. RGO Porto Alegre 2009; 57(4): 449-453.

CHOI, H.; LIM, W.; KIM, I.; KIM, J.; KO, Y.; KWON, H.; KIM, S.; KABIR, K. M.; LI, X.; KIM, O.; LEE, Y.; KIM, S.; KIM, O. Inflammatory cytokines are suppressed by lightemitting diode irradiation of $P$. gingivalis LPS-treated human gingival fibroblasts: inflammatory cytokine changes by LED irradiation. Lasers Med Sci, v. 27, n. 2, p. 459-467, 2012.

COSSARIZZA, A.; MONTI, D.; MONTAGNANI, G.; ORTOLANI, C.; MASI, M.; ZANNOTTI, M.; FRANCESCHI, C. Precocious aging of the immune system in Down syndrome: alteration of B lymphocytes, T-lymphocyte subsets, and cells with natural killer markers. Am J Med Genet Suppl, v. 7, n., p. 213-218, 1990.

DAMANTE, C. A.; DE MICHELI, G.; MIYAGI, S. P.; FEIST, I. S.; MARQUES, M. M. Effect of laser phototherapy on the release of fibroblast growth factors by human gingival fibroblasts. Lasers Med Sci, v. 24, n. 6, p. 885-891, 2009.

DAMANTE, C. A.; GREGHI, S. L.; SANT'ANA, A. C.; PASSANEZI, E.; TAGA, R. Histomorphometric study of the healing of human oral mucosa after gingivoplasty and low-level laser therapy. Lasers Surg Med, v. 35, n. 5, p. 377-384, 2004.

DAMANTE, C. A.; MARQUES, M. M. Laser power loss through polystyrene plates for cell culture. Lasers Med Sci, v. 29, n. 1, p. 373, 2014.

DE LIMA, F. J.; DE OLIVEIRA NETO, O. B.; BARBOSA, F. T.; DO NASCIMENTO GALVAO, A. M.; RAMOS, F. W.; DE LIMA, C. C.; DE SOUSA RODRIGUES, C. F. Is there a protocol in experimental skin wounds in rats using low-level diode laser therapy (LLDLT) combining or not red and infrared wavelengths? Systematic review. Lasers Med Sci, v., n., p., 2016.

DE SOUSA, A. P.; SANTOS, J. N.; DOS REIS, J. A., JR.; RAMOS, T. A.; DE SOUZA, J.; CANGUSSU, M. C.; PINHEIRO, A. L. Effect of LED phototherapy of three distinct wavelengths on fibroblasts on wound healing: a histological study in a rodent model. Photomed Laser Surg, v. 28, n. 4, p. 547-552, 2010. 
DIAS, S. B.; FONSECA, M. V.; DOS SANTOS, N. C.; MATHIAS, I. F.; MARTINHO, F. C.; JUNIOR, M. S.; JARDINI, M. A.; SANTAMARIA, M. P. Effect of GaAIAs lowlevel laser therapy on the healing of human palate mucosa after connective tissue graft harvesting: randomized clinical trial. Lasers Med Sci, v. 30, n. 6, p. 1695-1702, 2015.

DOGAN, G. E.; DEMIR, T.; ORBAK, R. Effect of low-level laser on guided tissue regeneration performed with equine bone and membrane in the treatment of intrabony defects: a clinical study. Photomed Laser Surg, v. 32, n. 4, p. 226-231, 2014.

FERNANDES-DIAS, S. B.; DE MARCO, A. C.; SANTAMARIA, M., JR.; KERBAUY, W. D.; JARDINI, M. A.; SANTAMARIA, M. P. Connective tissue graft associated or not with low laser therapy to treat gingival recession: randomized clinical trial. $\mathbf{J}$ Clin Periodontol, v. 42, n. 1, p. 54-61, 2015.

FRIGO, L.; FAVERO, G. M.; LIMA, H. J.; MARIA, D. A.; BJORDAL, J. M.; JOENSEN, J.; IVERSEN, V. V.; MARCOS, R. L.; PARIZZOTO, N. A.; LOPES-MARTINS, R. A. Low-level laser irradiation (InGaAIP-660 nm) increases fibroblast cell proliferation and reduces cell death in a dose-dependent manner. Photomed Laser Surg, v. 28 Suppl 1, n., p. S151-156, 2010.

FUSHIMI, T.; INUI, S.; NAKAJIMA, T.; OGASAWARA, M.; HOSOKAWA, K.; ITAMI, $S$. Green light emitting diodes accelerate wound healing: characterization of the effect and its molecular basis in vitro and in vivo. Wound Repair Regen, v. 20, n. 2 , p. 226-235, 2012.

GREGORY, L.; WILLIAMS, R.; THOMPSON, E. Leucocyte function in Down's syndrome and acute leukaemia. Lancet, v. 1, n. 7765, p. 1359-1361, 1972.

HALINEN, S.; SORSA, T.; DING, Y.; INGMAN, T.; SALO, T.; KONTTINEN, Y. T.; SAARI, H. Characterization of matrix metalloproteinase (MMP-8 and -9) activities in the saliva and in gingival crevicular fluid of children with Down's syndrome. $\mathbf{J}$ Periodontol, v. 67, n. 8, p. 748-754, 1996.

HAMBLIN, MICHAEL, R.; HUANG, Ying-Ying (Ed.). Handbook of photomedicine. Taylor \& Francis, 2013.

HENRIKSSON, E.; KJELLEN, E.; WAHLBERG, P.; WENNERBERG, J.; KJELLSTROM, J. H. Differences in estimates of cisplatin-induced cell kill in vitro between colorimetric and cell count/colony assays. In Vitro Cell Dev Biol Anim, v. 42, n. 10, p. 320-323, 2006. 
HOANG, A. M.; OATES, T. W.; COCHRAN, D. L. In vitro wound healing responses to enamel matrix derivative. J Periodontol, v. 71, n. 8, p. 1270-1277, 2000.

IZUMI, Y.; SUGIYAMA, S.; SHINOZUKA, O.; YAMAZAKI, T.; OHYAMA, T.; ISHIKAWA, I. Defective neutrophil chemotaxis in Down's syndrome patients and its relationship to periodontal destruction. J Periodontol, v. 60, n. 5, p. 238-242, 1989.

JOHANNSEN, P.; CHRISTENSEN, J. E.; MAI, J. The prevalence of dementia in Down syndrome. Dementia, v. 7, n. 4, p. 221-225, 1996.

JONG-TAE PARK; KI SEOK HONG. Effect of Light-Emitting-Diode Irradiation on the Proliferation and Migration in Human Gingival Fibroblasts. Tissue Engineering and Regenerative Medicine, Vol. 12, No. 1, pp 37-42 (2015)

Karu TI. Molecular mechanism of the therapeutic effect of low-intensity laser radiation. Laser in the life Sci. 1998; 2(1):53-74.

KOMATSU, T.; DUCKYOUNG, Y.; ITO, A.; KUROSAWA, K.; MAEHATA, Y.; KUBODERA, T.; IKEDA, M.; LEE, M. C. Increased oxidative stress biomarkers in the saliva of Down syndrome patients. Arch Oral Biol, v. 58, n. 9, p. 1246-1250, 2013.

LIN, S. J.; WANG, J. Y.; KLICKSTEIN, L. B.; CHUANG, K. P.; CHEN, J. Y.; LEE, J. F.; SHIEH, C. C. Lack of age-associated LFA-1 up-regulation and impaired ICAM-1 binding in lymphocytes from patients with Down syndrome. Clin Exp Immunol, v. 126 , n. 1, p. 54-63, 2001.

LOEVSCHALL, H.; ARENHOLT-BINDSLEV, D. Effect of low level diode laser irradiation of human oral mucosa fibroblasts in vitro. Lasers Surg Med, v. 14, n. 4, p. 347-354, 1994.

LUBART, R.; WOLLMAN, Y.; FRIEDMANN, H.; ROCHKIND, S.; LAULICHT, I. Effects of visible and near-infrared lasers on cell cultures. $\mathbf{J}$ Photochem Photobiol B, v. 12, n. 3, p. 305-310, 1992.

LUBART, R; FRIEDMANN, H; PELED, I; GROSSMAN, N. Light effect on fibroblast proliferation. Laser Therapy 1993;5:55-57.

MARQUES, M. M.; PEREIRA, A. N.; FUJIHARA, N. A.; NOGUEIRA, F. N.; EDUARDO, C. P. Effect of low-power laser irradiation on protein synthesis and ultrastructure of human gingival fibroblasts. Lasers Surg Med, v. 34, n. 3, p. 260265, 2004. 
MENDEZ, T.M.T.V; PINHEIRO, A.L.B; PACHECO, M.T.T; NASCIMENTO, P.M; RAMALHO, L.M.P (2004) Dose and wavelength of laser light have influence on the repair of cutaneous wounds. J Clin Laser Med Surg 22(1):19-25

MESTER, E.; MESTER, A. F.; MESTER, A. The biomedical effects of laser application. Lasers Surg Med, v. 5, n. 1, p. 31-39, 1985.

MOORE, P.; RIDGWAY, T. D.; HIGBEE, R. G.; HOWARD, E. W.; LUCROY, M. D. Effect of wavelength on low-intensity laser irradiation-stimulated cell proliferation in vitro. Lasers Surg Med, v. 36, n. 1, p. 8-12, 2005.

MUGAYAR, L. L. R. Pacientes Portadores de Necessidades Especiais: Manual de odontologia e Saúde Oral. São Paulo, Pancast, 2000: p.13-46.

MURAKAMI, J.; KATO, T.; KAWAI, S.; AKIYAMA, S.; AMANO, A.; MORISAKI, I. Cellular motility of Down syndrome gingival fibroblasts is susceptible to impairment by Porphyromonas gingivalis invasion. J Periodontol, v. 79, n. 4, p. 721-727, 2008.

MURPHY, M.; EPSTEIN, L. B. Down syndrome (DS) peripheral blood contains phenotypically mature CD3+TCR alpha, beta+ cells but abnormal proportions of TCR alpha, beta+, TCR gamma, delta+, and CD4+ CD45RA+ cells: evidence for an inefficient release of mature $T$ cells by the $D S$ thymus. Clin Immunol Immunopathol, v. 62, n. 2, p. 245-251, 1992.

MUSTACCHI, Z.; ROZONE, G. Síndrome de Down. Aspectos clínicos e odontológicos. São Paulo: CID; 1990.

NETTINA, S.M. Prática de enfermagem. $6^{a}$ ed. Rio de Janeiro (RJ): GuanabaraKoogan; 1999.

NEWMAN, M. G.; TAKEI, H. H.; KLOKKEVOLD, P. R.; CARRANZA, F. A. Periodontia clínica. 11.ed. Rio de Janeiro: Elsevier, 2011. 1328 p.

NIZETIC, D. Functional genomics of the Down syndrome. Croat Med J, v. 42, n. 4, p. 421-427, 2001.

OFFENBACHER, S.; BARROS, S. P.; SINGER, R. E.; MOSS, K.; WILLIAMS, R. C.; BECK, J. D. Periodontal disease at the biofilm-gingival interface. J Periodontol, v. 78, n. 10, p. 1911-1925, 2007.

OLIVEIRA SAMPAIO, S. C.; DE, C. M. J. S.; CANGUSSU, M. C.; PIRES SANTOS, G. M.; DOS SANTOS, M. A.; DOS SANTOS, J. N.; PINHEIRO, A. L. Effect of laser 
and LED phototherapies on the healing of cutaneous wound on healthy and irondeficient Wistar rats and their impact on fibroblastic activity during wound healing. Lasers Med Sci, v. 28, n. 3, p. 799-806, 2013.

OZCELIK, O.; CENK HAYTAC, M.; KUNIN, A.; SEYDAOGLU, G. Improved wound healing by low-level laser irradiation after gingivectomy operations: a controlled clinical pilot study. J Clin Periodontol, v. 35, n. 3, p. 250-254, 2008.

OZTURAN, S.; DURUKAN, S. A.; OZCELIK, O.; SEYDAOGLU, G.; HAYTAC, M. C. Coronally advanced flap adjunct with low intensity laser therapy: a randomized controlled clinical pilot study. J Clin Periodontol, v. 38, n. 11, p. 1055-1062, 2011.

PEREIRA, A. N.; EDUARDO CDE, P.; MATSON, E.; MARQUES, M. M. Effect of lowpower laser irradiation on cell growth and procollagen synthesis of cultured fibroblasts. Lasers Surg Med, v. 31, n. 4, p. 263-267, 2002.

QADRI, T.; MIRANDA, L.; TUNER, J.; GUSTAFSSON, A. The short-term effects of low-level lasers as adjunct therapy in the treatment of periodontal inflammation. $\mathbf{J}$ Clin Periodontol, v. 32, n. 7, p. 714-719, 2005.

REDDY, G. K.; STEHNO-BITTEL, L.; ENWEMEKA, C. S. Laser photostimulation of collagen production in healing rabbit Achilles tendons. Lasers Surg Med, v. 22, n. 5, p. 281-287, 1998.

REDDY, G. K.; STEHNO-BITTEL, L.; ENWEMEKA, C. S. Laser photostimulation accelerates wound healing in diabetic rats. Wound Repair Regen, v. 9, n. 3, p. 248255, 2001.

REULAND-BOSMA, W.; VAN DIJK, J.; VAN DER WEELE, L. Experimental gingivitis around deciduous teeth in children with Down's syndrome. J Clin Periodontol, v. 13, n. 4, p. 294-300, 1986.

REY, S.C.; BIRMAN, E. G. Odontologia e síndrome de Down: aspectos crâniofaciais. In: Mustacchi Z, Rozone G. Síndrome de Down: aspectos clínicos e odontológicos. São Paulo: CID; 1990. p. 198-217.

ROIZEN, N. J.; PATTERSON, D. Down's syndrome. Lancet, v. 361, n. 9365, p. 1281-1289, 2003.

RYHANEN, L.; RANTALA-RYHANEN, S.; TAN, E. M.; UITTO, J. Assay of collagenase activity by a rapid, sensitive, and specific method. Coll Relat Res, v. 2, n. 2, p. 117-130, 1982. 
SAKURAI, Y.; YAMAGUCHI, M.; ABIKO, Y. Inhibitory effect of low-level laser irradiation on LPS-stimulated prostaglandin E2 production and cyclooxygenase-2 in human gingival fibroblasts. Eur J Oral Sci, v. 108, n. 1, p. 29-34, 2000.

SALVI, G. E.; LANG, N. P. Host response modulation in the management of periodontal diseases. J Clin Periodontol, v. 32 Suppl 6, n., p. 108-129, 2005.

SCHWARTZMAN, J. S. Síndrome de Down. São Paulo (SP): Mackenzie Memmon 1999.

SKINNER, S. M.; GAGE, J. P.; WILCE, P. A.; SHAW, R. M. A preliminary study of the effects of laser radiation on collagen metabolism in cell culture. Aust Dent $\mathbf{J}, \mathrm{v}$. 41, n. 3, p. 188-192, 1996.

SOUZA, R,C; LIMA, F,F; FARACO-SCHWED, F,N; Alegretti CE, Scabar LF, Martins $\mathrm{RB}$ et al. Use of photodynamic therapy as an adjuvant to periodontal treatment in patients with Down syndrome - case report. J Health Sci Inst. 2011;29(2):96-9.

SREEDEVI, H.; MUNSHI, A. K. Neutrophil chemotaxis in Down syndrome and normal children to Actinobacillus actinomycetemcomitans. J Clin Pediatr Dent, v. 22, n. 2, p. 141-146, 1998.

SWALLOW, J. N. Dental Disease in Children with Down's Syndrome. J Ment Defic Res, v. 8, n., p. SUPPL:102-118, 1964.

TADA, K.; IKEDA, K.; TOMITA, K. Effect of polarized light emitting diode irradiation on wound healing. J Trauma, v. 67, n. 5, p. 1073-1079, 2009.

TUNÉR, J; HODE, L. Laser therapy in dentistry and medicine. Edsbruk: Prima Books; 1996.

VINCK, E. M.; CAGNIE, B. J.; CORNELISSEN, M. J.; DECLERCQ, H. A.; CAMBIER, D. C. Increased fibroblast proliferation induced by light emitting diode and low power laser irradiation. Lasers Med Sci, v. 18, n. 2, p. 95-99, 2003.

VOLPATO, L. E.; DE OLIVEIRA, R. C.; ESPINOSA, M. M.; BAGNATO, V. S.; MACHADO, M. A. Viability of fibroblasts cultured under nutritional stress irradiated with red laser, infrared laser, and red light-emitting diode. J Biomed Opt, v. 16, n. 7 , p. $075004,2011$. 
WANG, C. Y.; TSAI, S. C.; YU, M. C.; LIN, Y. F.; CHEN, C. C.; CHANG, P. C. Lightemitting diode irradiation promotes donor site wound healing of the free gingival graft. J Periodontol, v. 86, n. 5, p. 674-681, 2015.

WILLIAMS, R. C.; OFFENBACHER, S. Periodontal medicine: the emergence of a new branch of periodontology. Periodontol 2000, v. 23, n., p. 9-12, 2000.

YAVUZYILMAZ, E.; ERSOY, F.; SANAL, O.; TEZCAN, I.; ERCAL, D. Neutrophil chemotaxis and periodontal status in Down's syndrome patients. J Nihon Univ Sch Dent, v. 35, n. 2, p. 91-95, 1993.

YOUNG, S.; BOLTON, P.; DYSON, M.; HARVEY, W.; DIAMANTOPOULOS, C. Macrophage responsiveness to light therapy. Lasers Surg Med, v. 9, n. 5, p. 497505, 1989.

YU, W.; NAIM, J. O.; LANZAFAME, R. J. The effect of laser irradiation on the release of bFGF from 3T3 fibroblasts. Photochem Photobiol, v. 59, n. 2, p. 167-170, 1994.

ZIGMOND, M.; STABHOLZ, A.; SHAPIRA, J.; BACHRACH, G.; CHAUSHU, G.; BECKER, A.; YEFENOF, E.; MERRICK, J.; CHAUSHU, S. The outcome of a preventive dental care programme on the prevalence of localized aggressive periodontitis in Down's syndrome individuals. J Intellect Disabil Res, v. 50, n. Pt 7, p. 492-500, 2006. 

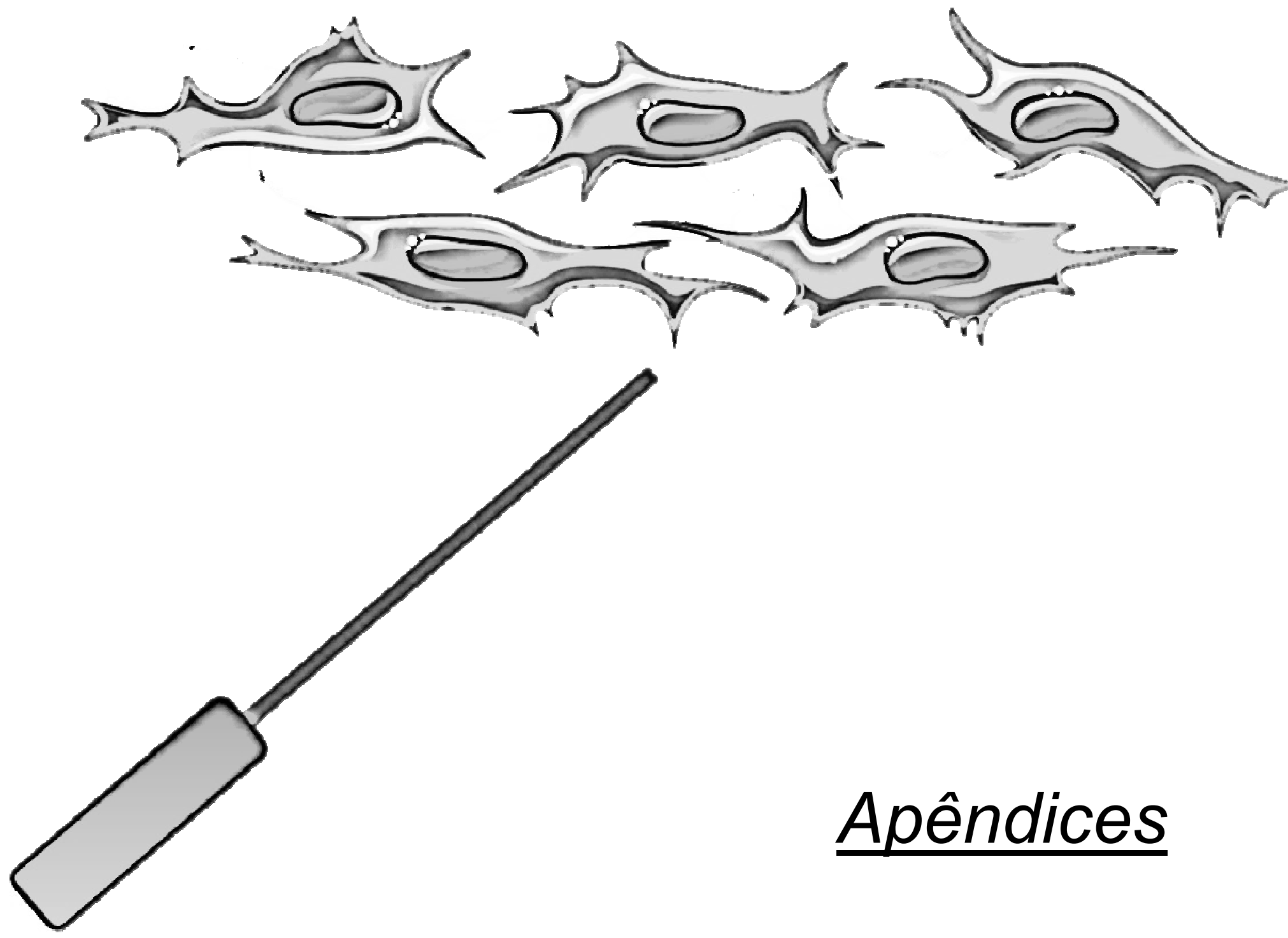



\section{Apêndice A- Tabela dos dados estatísticos para o teste MTT}

\begin{tabular}{|c|c|c|c|c|c|c|c|c|c|c|c|c|c|c|c|c|c|c|c|c|c|c|c|c|c|c|c|c|}
\hline & GRUPOF & ERIOD & célula & MTT & $a$ & $\mathrm{~b}$ & C & d & e & $f$ & $\mathrm{~g}$ & $\mathrm{~h}$ & $\mathrm{i}$ & $j$ & $\mathrm{k}$ & 1 & $\mathrm{~m}$ & $n$ & 0 & $p$ & $q$ & $r$ & $s$ & $t$ & $\mathrm{u}$ & v & $x$ & $\mathrm{z}$ \\
\hline 25 & LIV8 & $24 \mathrm{H}$ & FGH & 0,001800 & $* * * *$ & $* * * *$ & & & & & & & & & & & & & & & & & & & & & & \\
\hline 28 & LIV8 & $48 \mathrm{H}$ & FSD & 0,003000 & $* * * *$ & $* \star * \star *$ & & & & & & & & & & & & & & & & & & & & & & \\
\hline 27 & LIV8 & $48 \mathrm{H}$ & $\mathrm{FGH}$ & 0,003200 & $* \star * * *$ & $* * \star *$ & & & & & & & & & & & & & & & & & & & & & & \\
\hline 30 & LIV8 & $72 \mathrm{H}$ & FSD & 0,004600 & $* * * * *$ & $* * * *$ & & & & & & & & & & & & & & & & & & & & & & \\
\hline 57 & LED5 & $24 \mathrm{H}$ & FGH & 0,080200 & $* * * *$ & $* * * *$ & $* * * *$ & $* * * *$ & & & & & & & & & & & & & & & & & & & & \\
\hline 49 & LED3 & $24 \mathrm{H}$ & FGH & 0,085000 & $* * * *$ & $* * * *$ & $* * * *$ & $* * * *$ & & & & & & & & & & & & & & & & & & & & \\
\hline 35 & LV5 & $48 \mathrm{H}$ & $\mathrm{FGH}$ & 0,169200 & $* * * *$ & $* * * *$ & $* * * *$ & $* * * *$ & $* * * *$ & & & & & & & & & & & & & & & & & & & \\
\hline 15 & C- & $96 \mathrm{H}$ & FGH & 0,171000 & $* * * * *$ & $* * * *$ & $* * * *$ & $* * * *$ & $* * * *$ & & & & & & & & & & & & & & & & & & & \\
\hline 19 & LIV5 & $48 \mathrm{H}$ & $\mathrm{FGH}$ & 0,172600 & $* * * *$ & $* * * *$ & $* * * *$ & $* * * *$ & $* * * *$ & & & & & & & & & & & & & & & & & & & \\
\hline 45 & LV8 & $72 \mathrm{H}$ & $\mathrm{FGH}$ & 0,241800 & & & & $* \star * \star *$ & $* * \star *$ & $* * \star *$ & $* \star \star \star *$ & $* \star * \star *$ & & & & & & & & & & & & & & & & \\
\hline 43 & LV8 & $48 \mathrm{H}$ & $\mathrm{FGH}$ & 0,246200 & & & & $* * \star *$ & $* * \star *$ & $* * * *$ & $* \star * \star *$ & $* * \star *$ & $* * \star * *$ & & & & & & & & & & & & & & & \\
\hline 13 & $\mathrm{C}-$ & $72 \mathrm{H}$ & $\mathrm{FGH}$ & 0,247200 & & & & $* * \star *$ & $* * * *$ & $* * * *$ & $* \star * \star *$ & $* * * *$ & $* * * * *$ & $* * * *$ & & & & & & & & & & & & & & \\
\hline 3 & $\mathrm{C}+$ & $48 \mathrm{H}$ & $\mathrm{FGH}$ & 0,298400 & & & & & $* \star * *$ & $* * * *$ & $* \star * \star *$ & $* * * *$ & $* * \star * *$ & $* * * * *$ & $* * * *$ & & & & & & & & & & & & & \\
\hline 16 & C- & $96 \mathrm{H}$ & $\mathrm{FSD}$ & 0,302400 & & & & & $* \star * *$ & $* * * *$ & $* \star * *$ & $* * \star *$ & $* * * *$ & $* * * *$ & $* \star \star \star *$ & & & & & & & & & & & & & \\
\hline 12 & $\mathrm{C}-$ & $48 \mathrm{H}$ & FSD & 0,305000 & & & & & $* \star * \star$ & $* * * *$ & $* \star * \star *$ & $* * \star *$ & $* * * * *$ & $* * * *$ & $* \star \star \star *$ & & & & & & & & & & & & & \\
\hline 23 & LIV5 & $96 \mathrm{H}$ & $\mathrm{FGH}$ & 0,305400 & & & & & $* \star * *$ & $* * * *$ & $* \star * \star *$ & $* * * * \mid$ & $* * * * *$ & $* * * * *$ & $* * * *$ & & & & & & & & & & & & & \\
\hline
\end{tabular}




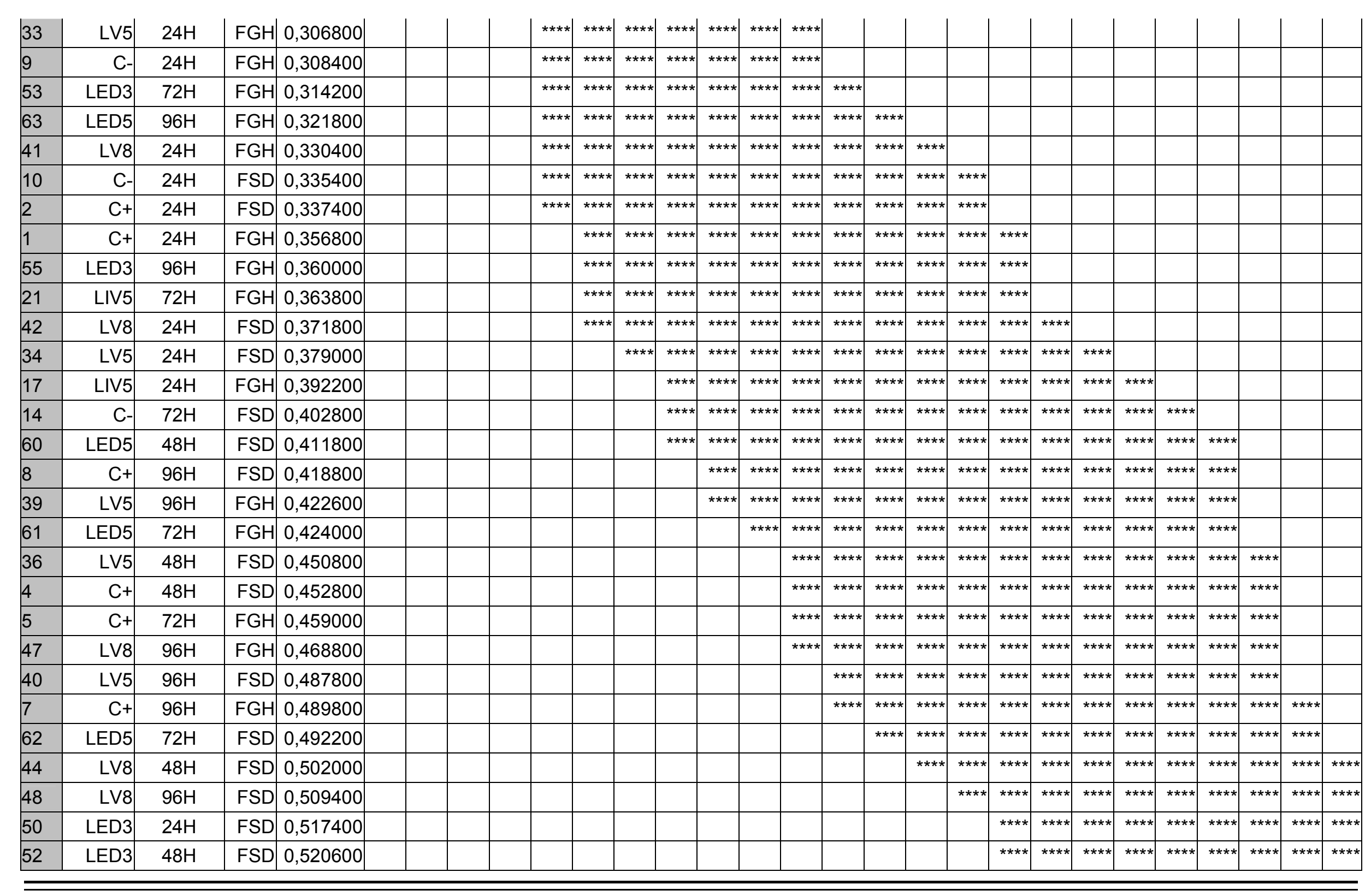


Apêndices 91

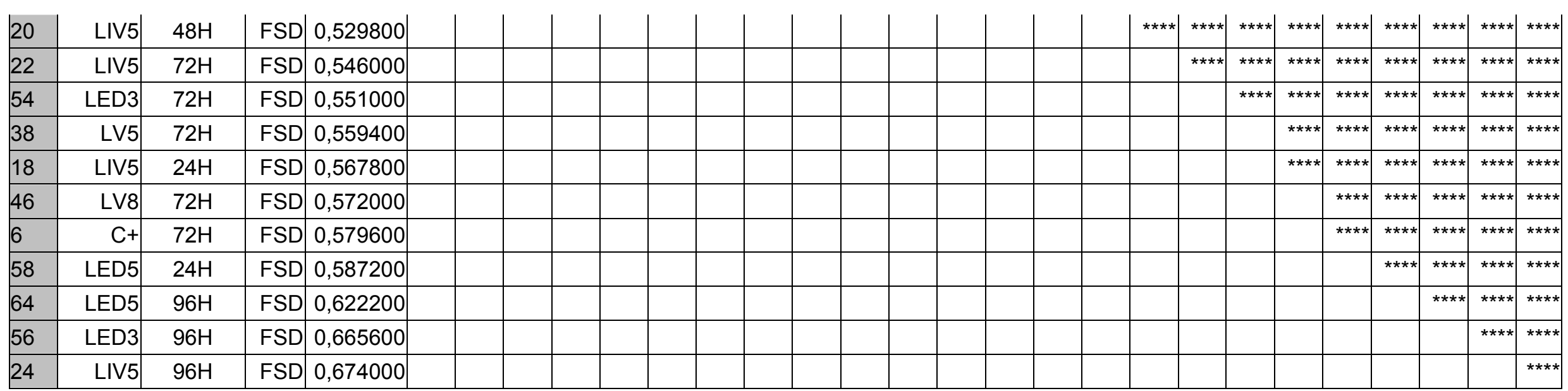


Apêndice B- Tabela dos dados estatísticos para o teste Cristal violeta

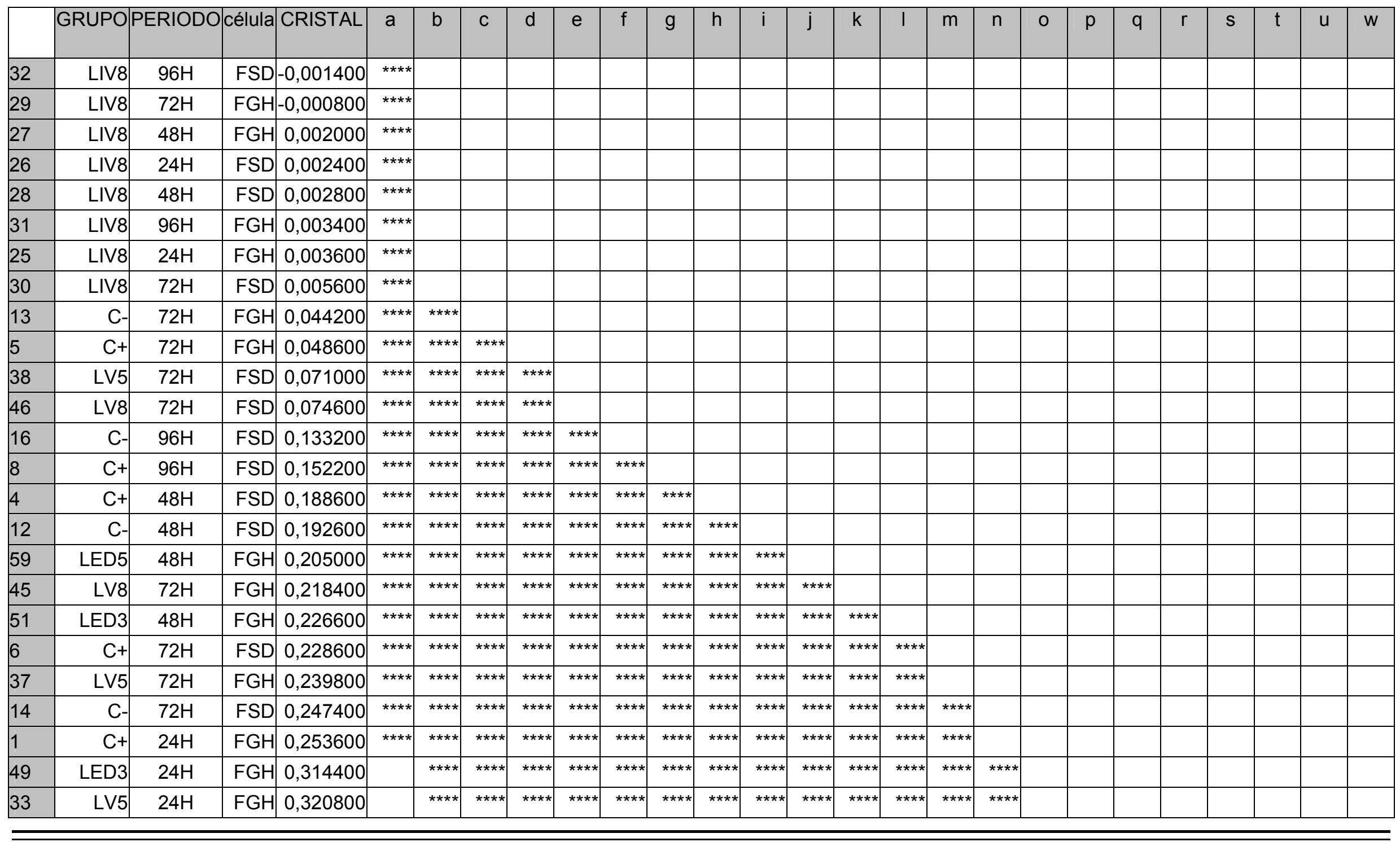




\begin{tabular}{|c|c|c|c|c|c|c|c|c|c|c|c|c|c|c|c|c|c|c|c|c|c|c|c|c|}
\hline 9 & $\mathrm{C}-$ & $24 \mathrm{H}$ & $\mathrm{FGH}$ & 0,325200 & $* * * *$ & $* * * *$ & $* * * *$ & $* * * *$ & $* * * *$ & $* * * *$ & $* * * *$ & $* * * *$ & $* * * *$ & $* * * *$ & $* * * *$ & $* * * *$ & & & & & & & & \\
\hline 41 & LV8 & $24 \mathrm{H}$ & $\mathrm{FGH}$ & 0,333800 & & $* * * *$ & $* * * *$ & $* * * *$ & $* * * *$ & $* * * *$ & $* * * *$ & $* * * *$ & $* * * *$ & $* * * *$ & $* * * *$ & $* * * *$ & & & & & & & & \\
\hline 17 & LIV5 & $24 \mathrm{H}$ & $\mathrm{FGH}$ & 0,337800 & & $* * * *$ & $* * * *$ & $* * * *$ & $\star * * *$ & $* * * *$ & $* * * *$ & $* * * *$ & $* * * *$ & $* * * *$ & $* * * *$ & $* * * *$ & & & & & & & & \\
\hline 11 & C- & $48 \mathrm{H}$ & $\mathrm{FGH}$ & 0,345600 & & $* * * *$ & $* * * *$ & $* * * *$ & $* * * *$ & $* * * *$ & $* * * *$ & $* * * *$ & $* * * *$ & $* * * *$ & $* * * *$ & $* * * *$ & $* * * *$ & & & & & & & \\
\hline 10 & C- & $24 \mathrm{H}$ & FSD & 0,366800 & & & $* * * *$ & $* * * *$ & $* * * *$ & $* * * *$ & $* * * *$ & $* * * *$ & $* * * *$ & $* * * *$ & $* * * *$ & $* * * *$ & $* * * *$ & $* * * *$ & & & & & & \\
\hline 3 & $\mathrm{C}+$ & $48 \mathrm{H}$ & $\mathrm{FGH}$ & 0,372800 & & & $* * * *$ & $* * * *$ & $* * * *$ & $* * * *$ & $* * * *$ & $* * * *$ & $* * * *$ & $* * * *$ & $* * * *$ & $* * * *$ & $* * * *$ & $* * * *$ & & & & & & \\
\hline 15 & C- & $96 \mathrm{H}$ & $\mathrm{FGH}$ & 0,400000 & & & $* * * *$ & $* * * *$ & $* * * *$ & $* * * *$ & $* * * *$ & $* * * *$ & $* * * *$ & $* * * *$ & $* * * *$ & $* * * *$ & $* * * *$ & $* * * *$ & $* * * *$ & & & & & \\
\hline 2 & $\mathrm{C}+$ & $24 \mathrm{H}$ & FSD & 0,428200 & & & & $* * * *$ & $* * * *$ & $* * * *$ & $* * * *$ & $* * * *$ & $* * * *$ & $* * \star *$ & $* * * *$ & $* * * *$ & $* * * *$ & $* * * *$ & $* * * *$ & $* * * *$ & & & & \\
\hline 57 & LED5 & $24 \mathrm{H}$ & $\mathrm{FGH}$ & 0,450600 & & & & & $* * * *$ & $* * * *$ & $* * * *$ & $\star * * *$ & $* * * *$ & $\star * * *$ & $* * * *$ & $* * * *$ & $* * * *$ & $* * * *$ & $* * * *$ & $* * * *$ & $* * * *$ & & & \\
\hline 21 & LIV5 & $72 \mathrm{H}$ & $\mathrm{FGH}$ & 0,451800 & & & & & $* * * *$ & $* * * *$ & $* * * *$ & $* * * *$ & $* * * *$ & $* * * *$ & $* * * *$ & $* * * *$ & $* * * *$ & $* * * *$ & $* * * *$ & $* * * *$ & $* * * *$ & & & \\
\hline 44 & LV8 & $48 \mathrm{H}$ & FSD & 0,454200 & & & & & $* * * *$ & $* * * *$ & $* * * *$ & $* * * *$ & $* * * *$ & $* * * *$ & $* * * *$ & $* * * *$ & $* * * *$ & $* * * *$ & $* * * *$ & $* * * *$ & $* * * *$ & & & \\
\hline 61 & LED5 & $72 \mathrm{H}$ & $\mathrm{FGH}$ & 0,471000 & & & & & & $* * * *$ & $* * * *$ & $* * * *$ & $* * * *$ & $* * * *$ & $* * * *$ & $* * * *$ & $* * * *$ & $* * * *$ & $* * * *$ & $* * * *$ & $* * * *$ & $* * * *$ & & \\
\hline 36 & LV5 & $48 \mathrm{H}$ & FSD & 0,473400 & & & & & & & $* * * *$ & $* * * *$ & $* * * *$ & $* * * *$ & $* * * *$ & $* * * *$ & $* * * *$ & $* * * *$ & $* * * *$ & $* * * *$ & $* * * *$ & $* * * *$ & & \\
\hline 34 & LV5 & $24 \mathrm{H}$ & FSD & 0,478000 & & & & & & & $* * * *$ & $* * * *$ & $* * * *$ & $* * * *$ & $* * * *$ & $* * * *$ & $* * * *$ & $* * * *$ & $* * * *$ & $* * * *$ & $* * * *$ & $* * * *$ & $* * * *$ & \\
\hline 35 & LV5 & $48 \mathrm{H}$ & $\mathrm{FGH}$ & 0,487800 & & & & & & & & $* * * *$ & $* * * *$ & $* * * *$ & $* * * *$ & $* * * *$ & $* * * *$ & $* * * *$ & $* * * *$ & $* * * *$ & $* * * *$ & $* * * *$ & $* * * *$ & \\
\hline 54 & LED3 & $72 \mathrm{H}$ & FSD & 0,490400 & & & & & & & & $* * * *$ & $* * * *$ & $* * * *$ & $* * * *$ & $* * * *$ & $* * * *$ & $* * * *$ & $* * * *$ & $* * * *$ & $* * * *$ & $* * * *$ & $* * * *$ & \\
\hline 7 & $\mathrm{C}+$ & $96 \mathrm{H}$ & $\mathrm{FGH}$ & 0,499200 & & & & & & & & & $* * * *$ & $* * * *$ & $* * * *$ & $* * * *$ & $* * * *$ & $* * * *$ & $* * * *$ & $* * * *$ & $* * * *$ & $* * * *$ & $* * * *$ & \\
\hline 43 & LV8 & $48 \mathrm{H}$ & $\mathrm{FGH}$ & 0,507200 & & & & & & & & & & $* * * *$ & $* * * *$ & $* * * *$ & $* * * *$ & $* * * *$ & $* * * *$ & $* * * *$ & $* * * *$ & $* * * *$ & $* * * *$ & \\
\hline 18 & LIV5 & $24 \mathrm{H}$ & FSD & 0,520800 & & & & & & & & & & & $* * * *$ & $* * * *$ & $* * * *$ & $* * * *$ & $* * * *$ & $* * * *$ & $* * * *$ & $* * * *$ & $* * \star *$ & $* * * *$ \\
\hline 53 & LED3 & $72 \mathrm{H}$ & $\mathrm{FGH}$ & 0,523200 & & & & & & & & & & & $* * * *$ & $* * * *$ & $* * * *$ & $* * * *$ & $* * * *$ & $* * * *$ & $* * * *$ & $* * * *$ & $* * * *$ & $* * * *$ \\
\hline 42 & LV8 & $24 \mathrm{H}$ & FSD & 0,527400 & & & & & & & & & & & $* * * *$ & $* * * *$ & $* * * *$ & $* * * *$ & $* * * *$ & $* * * *$ & $* * * *$ & $* * * *$ & $* * * *$ & $* * * *$ \\
\hline 62 & LED5 & $72 \mathrm{H}$ & FSD & 0,534400 & & & & & & & & & & & & $* * * *$ & $* * * *$ & $* * * *$ & $* * * *$ & $* * * *$ & $* * * *$ & $* * * *$ & $* * * *$ & $* * * *$ \\
\hline 50 & LED3 & $24 \mathrm{H}$ & FSD & 0,619600 & & & & & & & & & & & & & $* * * *$ & $* * * *$ & $* * * *$ & $* * * *$ & $* * * *$ & $* * * *$ & $* * * *$ & $* * * *$ \\
\hline 22 & LIV5 & $72 \mathrm{H}$ & FSD & 0,623000 & & & & & & & & & & & & & $* * \star *$ & $* * * *$ & $* * * *$ & $* * * *$ & $* * * *$ & $* * * *$ & $* * * *$ & $* * * *$ \\
\hline 23 & LIV5 & $96 \mathrm{H}$ & $\mathrm{FGH}$ & 0,631200 & & & & & & & & & & & & & & $* * * *$ & $* * * *$ & $* * * *$ & $* * * *$ & $* * * *$ & $* * * *$ & $* * * *$ \\
\hline 56 & LED3 & $96 \mathrm{H}$ & FSD & 0,634400 & & & & & & & & & & & & & & $* * * *$ & $* * * *$ & $* * * *$ & $* * * *$ & $* * * *$ & $* * * *$ & $* * * *$ \\
\hline 64 & LED5 & $96 \mathrm{H}$ & FSD & 0,658600 & & & & & & & & & & & & & & & $* * * *$ & $* * * *$ & $* * * *$ & $* * * *$ & $* * * *$ & $* * * *$ \\
\hline 58 & LED5 & $24 \mathrm{H}$ & FSD & 0,671000 & & & & & & & & & & & & & & & $* * * *$ & $* \star * *$ & $* \star * *$ & $* * * *$ & $* * * *$ & $* * * *$ \\
\hline 24 & LIV5 & $96 \mathrm{H}$ & FSD & 0,673200 & & & & & & & & & & & & & & & $* * * *$ & $* * * *$ & $* * * *$ & $* * * *$ & $* * * *$ & $* * * *$ \\
\hline
\end{tabular}




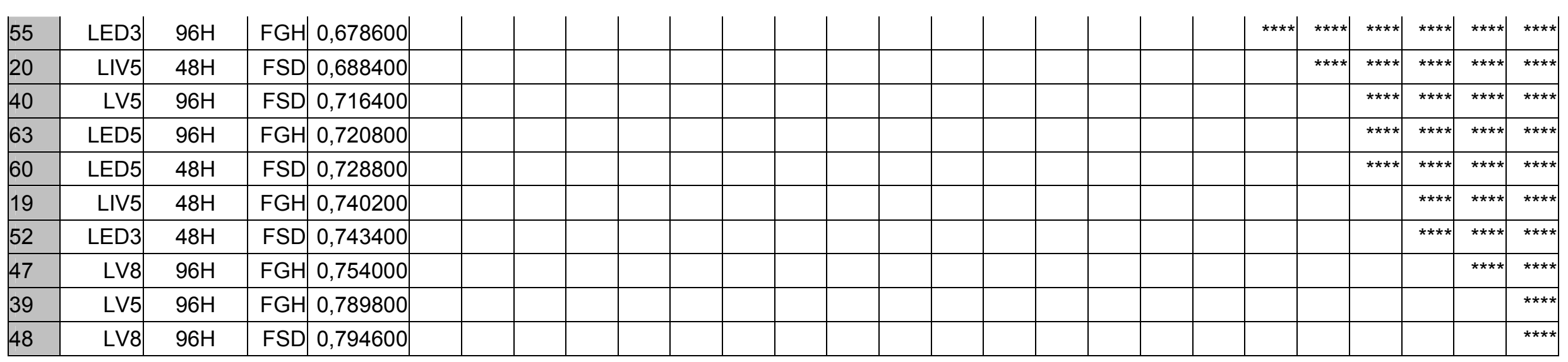



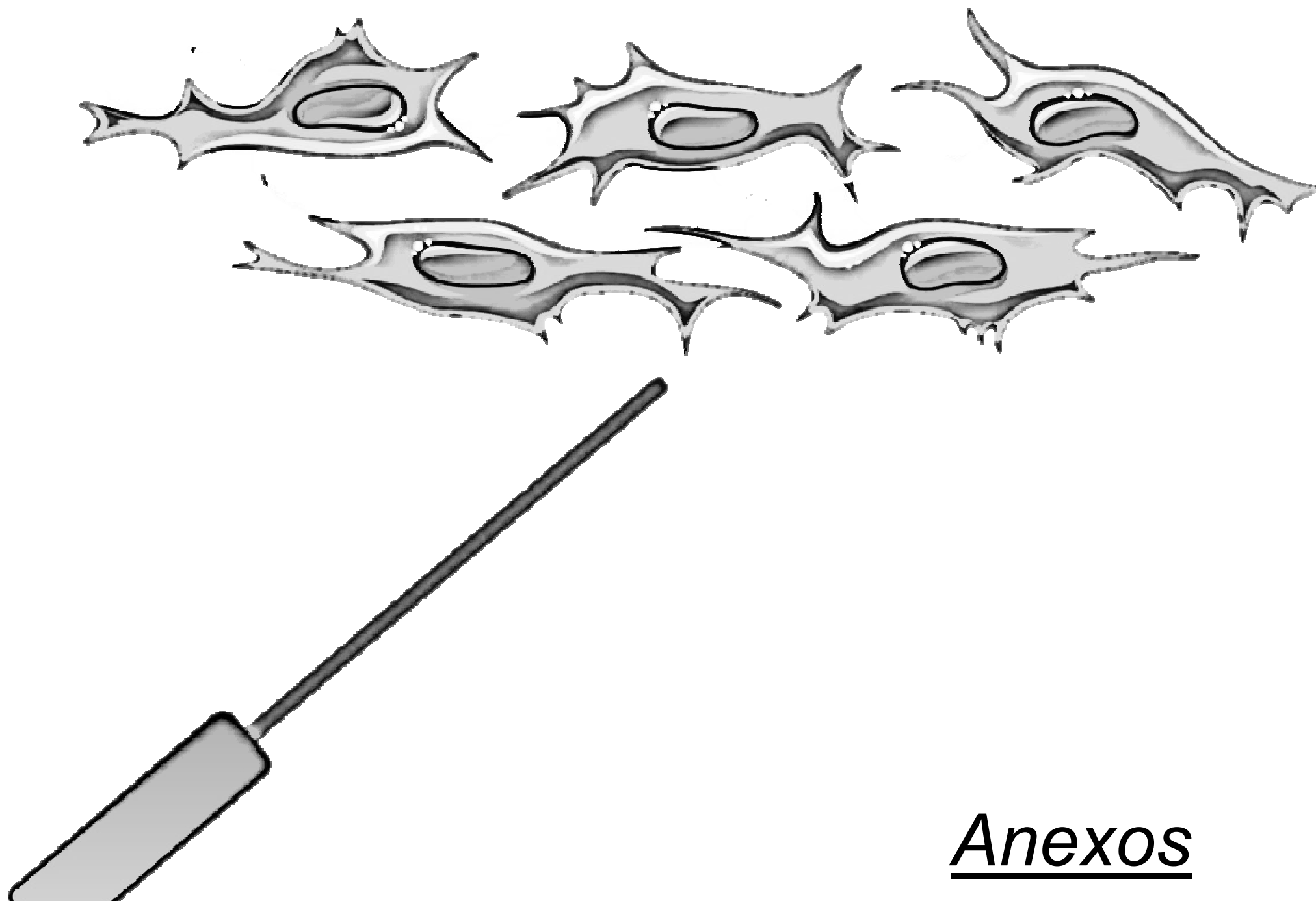



\section{Anexo 1: Parecer aprovado pelo comitê de ética em pesquisa}

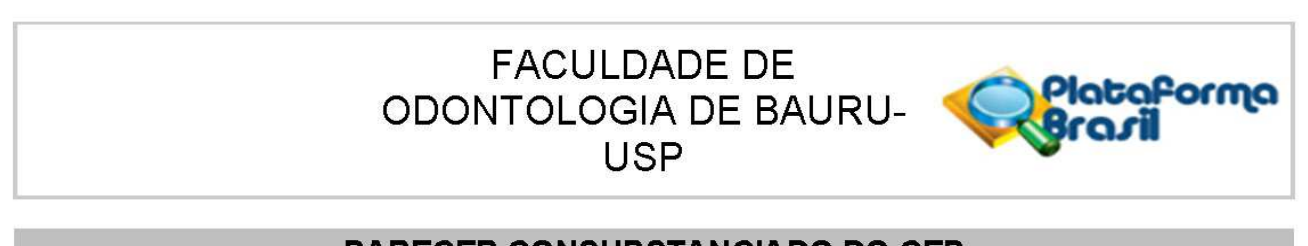

\section{PARECER CONSUBSTANCIADO DO CEP}

\section{DADOS DO PROJETO DE PESQUISA}

Título da Pesquisa: Avaliação comparativa dos efeitos da fototerapia com laser e LED no crescimento de fibroblastos gengivais de pacientes com Síndrome de Down.

Pesquisador: Raphaella Coelho Michel

Área Temática:

Versão: 2

CAAE: 49844715.0 .0000 .5417

Instituição Proponente: Universidade de São Paulo - Faculdade de Odontologia de Bauru

Patrocinador Principal: Financiamento Próprio

\section{DADOS DO PARECER}

Número do Parecer: 1.352 .282

Apresentação do Projeto:

Idem ao parecer 1.298.456.

Objetivo da Pesquisa:

Idem ao parecer 1.298.456.

Avaliação dos Riscos e Benefícios:

Riscos:

Por se tratarem de células doadas, os riscos inerentes à coleta da amostra tecidual são os mesmos descritos no projeto de pesquisa de número CAAE: 26051214.0.0000.5417, no qual salientou que a amostra seria coletada de uma cirurgia de remoção de gengiva em excesso. Portanto, os riscos não são maiores que os previstos para esse tipo de procedimento, podendo ocorrer, sangramento, desconforto, dor, inchaço. Pode ser necessário usar remédio para dor e inchaço. Após a cirurgia, devido à anestesia e amortecimento da boca, deve-se tomar cuidado para não morder o lábio e a língua. Os cuidados com a área operada estarão impressos em um papel que será dado após a cirurgia.

Benefícios:

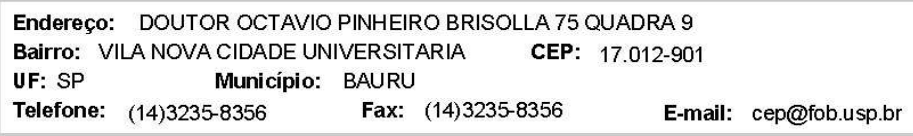




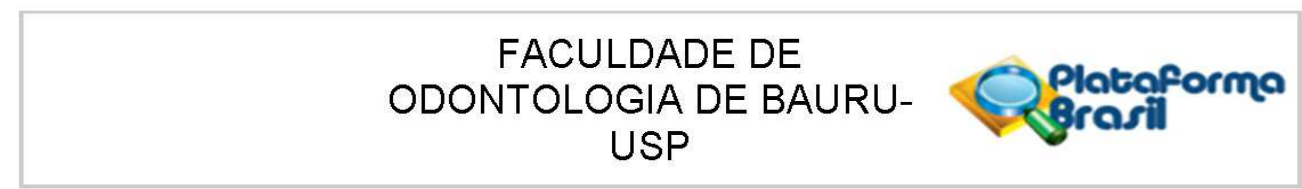

Cantinuaçẳo da Parecer: 1.352 .282

Por se tratar de uma pesquisa in vitro, o presente estudo não apresenta benefícios diretos aos pacientes com e sem sindrome de Down. Todavia, a avaliação do comportamento celular frente a utilização de Laserterapia e LED, em diferentes protocolos de aplicação, é de grande importância na busca de um tratamento adjuvante para a doença periodontal, principalmente em pacientes com Síndrome de Down, os quais apresentam alta prevalência da doença em questão.

\section{Comentários e Considerações sobre a Pesquisa:}

Há inconsistência no Projeto e na Plataforma Brasil quanto a origem das células a serem utilizadas no experimento e também em relação ao número de participantes. Na Plataforma Brasil colocou n=3 e, na divisão de grupos, apenas 2 grupos (laser e LED) com 1 participante cada. E os participantes não portadores da Sindrome? Quantos serão?

\section{PENDÊNCIA ATENDIDA.}

FOI PEDIDO DISPENSA DO TCLE "Em um estudo prévio, de número CAAE: 26051214.0.0000.5417, as células de pacientes com síndrome de Down e de pacientes sem síndrome foram utilizadas e grande parte das mesmas congeladas. Dessa forma, como são exatamente as mesmas células que precisam ser avaliadas nopresente estudo, não há necessidade da aquisição de mais células (intervenção em pacientes), somente de um termo de doação de células, conforme em anexo."

\section{Considerações sobre os Termos de apresentação obrigatória:}

No projeto de pesquisa e na Plataforma Brasil está descrito que os TCLEs serão assinados pelos responsáveis dos participantes, e que serão coletados fragmentos de tecido gengival de 3 participantes portadores de Síndrome de Down e de participantes não portadores da síndrome. No entanto, na Plataforma Brasil coloca dispensa de TCLE e nos documentos anexados, há um termo de autorização, onde a pesquisadora relata que irá trabalhar com células congeladas provenientes do Projeto de responsabilidade da Profa Dra Mariana Zangrando.

\section{PENDÊNCIA ATENDIDA. TERMO DE CESSÃO DE CÉLULAS APRESENTADO}

Recomendações:

1) Adicionar nome de todos os membros da equipe na Plataforma Brasil, assim como consta na capa do Projeto.

PENDÊNCIA ATENDIDA.

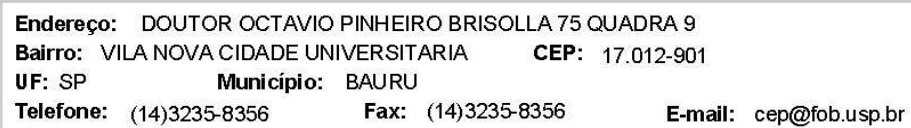




\section{FACULDADE DE ODONTOLOGIA DE BAURU- USP}

Continuação do Parecer: 1.352 .282

2) Adequar riscos e benefícios na Plataforma Brasil PENDÊNCIA ATENDIDA.

3) Adequar no item Material e Métodos, tanto da Plataforma Brasil como do Projeto, qual será a origem das células a serem utilizadas, explicar que será utilizado material congelado, coletado no Projeto da Professora Mariana (adicionar o número do CAAE do projeto).

PENDÊNCIA ATENDIDA.

4) Na autorização para uso de material congelado deve constar o número do CAAE do Projeto da profa Mariana Zangrando, o número que foi colocado é referente ao parecer e não deve ser utilizado. PENDÊNCIA ATENDIDA.

Conclusões ou Pendências e Lista de Inadequações: NENHUMA.

Considerações Finais a critério do CEP:

Esse projeto foi considerado APROVADO na reunião ordinária do CEP de 02.12.2015, com base nas normas éticas da Resolução CNS 466/12. Ao término da pesquisa o CEP-FOB/USP exige a apresentação de relatório final. Os relatórios parciais deverão estar de acordo com o cronograma e/ou parecer emitido pelo CEP. Alterações na metodologia, título, inclusão ou exclusão de autores, cronograma e quaisquer outras mudanças que sejam significativas deverão ser previamente comunicadas a este CEP sob risco de não aprovação do relatório final. Quando da apresentação deste, deverão ser incluídos todos os TCLEs e/ou termos de doação assinados e rubricados, se pertinentes.

Este parecer foi elaborado baseado nos documentos abaixo relacionados:

\begin{tabular}{|c|c|c|c|c|}
\hline Tipo Documento & Arquivo & Postagem & Autor & Situação \\
\hline $\begin{array}{l}\text { Informações Básicas } \\
\text { do Projeto }\end{array}$ & $\begin{array}{l}\text { PB_INFORMAÇŌES_BÁSICAS_DO_P } \\
\text { ROJETO 595293.pdf }\end{array}$ & $\begin{array}{c}26 / 11 / 2015 \\
20: 49: 54 \\
\end{array}$ & & Aceito \\
\hline $\begin{array}{l}\text { Projeto Detalhado/ } \\
\text { Brochura } \\
\text { Investicaador }\end{array}$ & Projeto.docx & $\begin{array}{c}26 / 11 / 2015 \\
20: 46: 19\end{array}$ & $\begin{array}{l}\text { Raphaella Coelho } \\
\text { Michel }\end{array}$ & Aceito \\
\hline $\begin{array}{l}\text { TCLE / Termos de } \\
\text { Assentimento / } \\
\text { Justificativa de }\end{array}$ & Doacao.pdf & $\begin{array}{c}26 / 11 / 2015 \\
20: 31: 43\end{array}$ & $\begin{array}{l}\text { Raphaella Coelho } \\
\text { Michel }\end{array}$ & Aceito \\
\hline
\end{tabular}

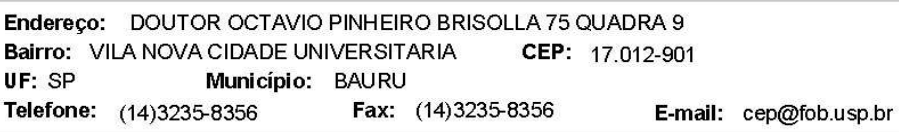




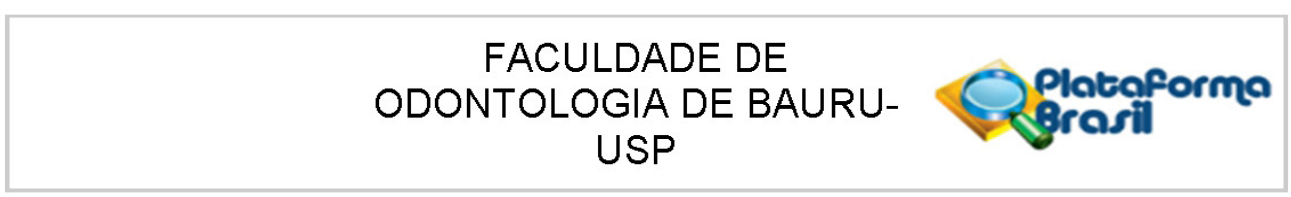

Cantinuaçä̀ da Parecer: 1.352 .282

\begin{tabular}{|l|l|c|l|c|}
\hline Ausência & Doacao.pdf & $\begin{array}{c}26 / 11 / 2015 \\
20: 31: 43\end{array}$ & $\begin{array}{l}\text { Raphaella Coelho } \\
\text { Michel }\end{array}$ & Aceito \\
\hline Outros & encaminhamento.pdf & $\begin{array}{c}05 / 10 / 2015 \\
20: 32: 26\end{array}$ & $\begin{array}{l}\text { Raphaella Coelho } \\
\text { Michel }\end{array}$ & Aceito \\
\hline Declaração de & Compromisso.pdf & $\begin{array}{c}01 / 10 / 2015 \\
14: 12: 07\end{array}$ & $\begin{array}{l}\text { Raphaella Coelho } \\
\text { Michel }\end{array}$ & Aceito \\
\hline Pesquisadores & & $01 / 10 / 2015$ \\
$14: 11: 18$ & $\begin{array}{l}\text { Raphaella Coelho } \\
\text { Michel }\end{array}$ & Aceito \\
\hline Outros & ClP.pdf & $\begin{array}{c}01 / 10 / 2015 \\
14: 09: 47\end{array}$ & $\begin{array}{l}\text { Raphaella Coelho } \\
\text { Michel }\end{array}$ & Aceito \\
\hline Folha de Rosto & Questionario.pdf & $01 / 10 / 2015$ & $\begin{array}{l}\text { Raphaella Coelho } \\
\text { Michel }\end{array}$ & Aceito \\
\hline
\end{tabular}

Situação do Parecer:

Aprovado

Necessita Apreciação da CONEP:

Não

BAURU, 04 de Dezembro de 2015

Assinado por:

Izabel Regina Fischer Rubira Bullen

(Coordenador)

Endereço: DOUTOR OCTAVIO PINHEIRO BRISOLLA 75 QUADRA 9

Bairro: VILA NOVA CIDADE UNIVERSITARIA CEP: $17.012-901$

UF: SP Município: BAURU

Telefone: (14)3235-8356 Fax: (14)3235-8356 E-mail: cep@fob.usp.br 